\title{
Evaluation of exhaust flowrate measurement techniques for a mobile emissions monitoring system
}

\author{
Eric Todd Meyer \\ West Virginia University
}

Follow this and additional works at: https://researchrepository.wvu.edu/etd

\section{Recommended Citation}

Meyer, Eric Todd, "Evaluation of exhaust flowrate measurement techniques for a mobile emissions monitoring system" (2001). Graduate Theses, Dissertations, and Problem Reports. 1122.

https://researchrepository.wvu.edu/etd/1122

This Thesis is protected by copyright and/or related rights. It has been brought to you by the The Research Repository @ WVU with permission from the rights-holder(s). You are free to use this Thesis in any way that is permitted by the copyright and related rights legislation that applies to your use. For other uses you must obtain permission from the rights-holder(s) directly, unless additional rights are indicated by a Creative Commons license in the record and/ or on the work itself. This Thesis has been accepted for inclusion in WVU Graduate Theses, Dissertations, and Problem Reports collection by an authorized administrator of The Research Repository @ WVU. For more information, please contact researchrepository@mail.wvu.edu. 
Evaluation of Exhaust Flowrate Measurement Techniques for a Mobile Emissions Monitoring System

\title{
Eric Todd Meyer
}

\author{
Thesis submitted to the \\ College of Engineering \& Mineral Resources \\ at West Virginia University \\ In partial fulfillment of the requirements \\ for the degree of
}

\author{
Masters of Science \\ in \\ Mechanical Engineering \\ Nigel N. Clark, Ph.D., Chairman \\ Gregory J. Thompson, Ph.D. \\ Mridul Gautam, Ph.D.
}

Department of Mechanical \& Aerospace Engineering

Morgantown, West Virginia

2001

Keywords: Flowrate, Flowmeter, Emissions, In-use 


\section{Abstract \\ Evaluation of Exhaust Flowrate Measurement Techniques for a Mobile Emissions Monitoring System Eric Todd Meyer}

West Virginia University designed and developed a Mobile Emissions Monitoring System (MEMS) for the six settling Heavy-Duty Diesel Engine (S-HDDE) manufacturers. The United States Environment Projection Agency, the United States Department of Justice, and the California Air Resources Board reached agreements called the Consent Decrees that required the S-HDDE manufacturers to implement in-use testing on heavy-duty diesel vehicles. The MEMS measures emissions concentrations while operating in a real world environment; so all components must be robust and compact in size. The best method for measuring the emissions concentrations was found to be through raw exhaust sampling. In order to properly calculate the emissions mass rate the total exhaust flowrate through the engine must be determined. The devices evaluated were an Annubar, an Accutube, a hot film anemometer, a Pitot static tube, a venturi, and a vortex shedder.

The evaluation of the devices was broken down into two parts, the first part included cold bench testing and the second part included extensive engine testing at the West Virginia University's Engines and Emissions Research Laboratory. The cold bench testing was design to compare the flow devices to a reference flow device, a Laminar Flow Element (LFE). The devices were ranked based upon four equally weighted variables. The variables were: the average absolute percent difference for the reference, the best-fit equation based on a zero intercept, an $\mathrm{R}^{2}$ value based on the best-fit equation, and the standard deviation. Based upon the cold bench testing the Annubar, Accutube, venturi, and the vortex shedder (the original tube and a new tube design) were found to be viable candidates for engine testing. The procedure used for the engine testing 
consisted of steady state tests. The steady state tests consisted of six modes with each mode lasting 240 seconds of which only the last 90 seconds of each mode were the only portions used for determining the flowrate. This was done so the engine could reach a thermal equilibrium. The devices were again compared to the LFE and used the same variables for ranking. The vortex shedder in its original tube was found to be the most accurate; however, the vortex shedder was limited to placement in the intake of the engine because of a limited flow range (up to $450 \mathrm{acfm}$ ). The venturi was found to be the best flow device for a MEMS because of the increased flow range over the vortex shedder and is well suited for the environment of compression ignition exhaust streams. 


\section{Acknowledgements}

I am now 26 years old. I have spent more than $80 \%$ of my life in school. From elementary school, where I learned to tie my shoes and my ABCs up to grad school where I've finally finished my thesis, I can now begin the next step in life. Many people say you're an adult when you start paying your own bills and start thinking of settling down, and I guess I kind of agree. You see I did not complete this first part of my life on my own. I had many people to help me along the way. This is my chance to say thank you for helping me complete this part of my life.

First, I must thank the one who was there with me through all the times, the good, the bad, the happy and the sad. I want to thank my lord and savior, Jesus Christ. He watch over me when no one else was around to help, he guided me in my troubled times when I felt I had no one, and most of all he died for me. I hope I become all you want me to be in the future and I hope I will never let you down though I know I have often in the past. Please let me learn from my mistakes and take every opportunity to serve you.

Now I'd like to thank those who provided me with help that they didn't have to give, but did anyway, Tom Spencer, Richard Atkinson, and Dan Carder, thank you for your help. If ever I had a problem with things I couldn't figure out, you guys were the first to hear about. Thank you for guiding through the past few years and now you may never have to here me complain about things again.

To everyone who has become a friend over the past two and a half years, thank you. I have made many new friends so please forgive me if I forget to mention you. I'd like to thank Ryan Barnett, Brad Bane, Eric Corrigan, Sorin Petreanu, Wes Riddle, and Jason 
Snyder. Without you guys' grad school would have been very boring and nowhere near as fun, again thank you for your help and being my friends.

In my grad school experience I have made some friends who I will never forget for the rest of my life. Jason Evans, Andy Fuller, and Jim Rhodes have become my closest and best friends. I've done everything with these guys, from stealing pumpkins to working long hours at the EERL. Jim and Jason have probably seen more of me than ever wanted to and Andy, try to stay away from those bad web sites. I'm glad we have become friends and hope all of us stay in contact for the years to come.

To Dr. Nigel Clark, I'd like to thank you for the opportunity to work for you and have the chance to learn from one of the greats. To Dr. Greg Thompson, you and I haven't always seen eye to eye, but I believe that's because we're a lot alike. I have learned more from you than I have any other teacher. You've showed me its ok to admit you don't know something or if you make a mistake. This is something few men can do, but if I can take one thing with me from grad school I hope it to be this because it will make me a better person in the along run. You pushed me to do more and I fought you every step of the way and I thank you for not giving up on me. Thank you for your help and guidance, for without it I would not have made it this far.

To my brother and sister, Brain and Teresa, thank you for the support you've offered me in my journey here. I've seen all the mistakes you guys made and learned not to make the same ones or at least not let mom and dad catch me. To my brother-in-law, Brain K., if I can make it through an engineering program than I know you can too, and thank you for taking Teresa away from the rest of us. To my sister-in-law, Missy, I don't know 
what you did to bring Brain out of his shell, but you did it. I never dreamed he be married before me.

To my parents, Ronda and John, everything I am today is possible because of the hard work the two of you put into raising three great kids. Mom, thank you for making sure I had enough to eat, for hiding food in my clothesbasket to take back with me, for checking up on me, and for worrying about all the little things that I often over looked. Dad, I first must say the biggest reason I've done all these things to make you proud of me. I hope I've succeeded. You have no idea how much I've learned from you. I've learned more from you than anyone else. Every decision I've made in life is based on something I learned from you. When I was young, I never listened to you, but now I wish I had because I now see all the chances I had to learn even more. I must say God made the perfect parents when he made you two and I'm one the three luckiest kids in the world.

Last, but not least, Lori. You've been the one who always stood beside me. You've heard it all, and never complained. You've encouraged me to do the best I could and consoled me when I failed. You've been my light through the fog and the sunshine above. I often put you in the back seat, when things I thought to be more important came along. You could have left me a million times for a better life, but you didn't and I thank God you didn't. To you I owe a great debt. Before I can ever begin to pay it off I must ask you for one more thing. Something you have waited somewhat patiently to hear for a long time. I would be honored if you would be my wife for now and forever to come. 


\section{Table of Contents}

Abstract.........................................................................................................ii

Acknowledgements ...........................................................................................iv

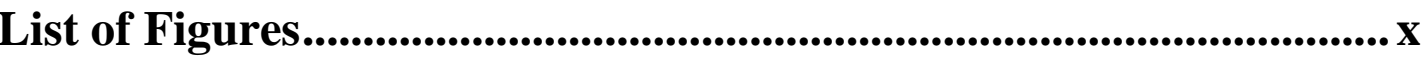

List of Tables .....................................................................................xii

List of Tables ...............................................................................................xii

1. Introduction...........................................................................................................1 1

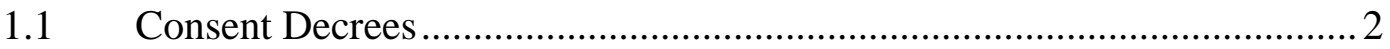

1.2 Development of A Mobile Emissions Monitoring System ......................... 3

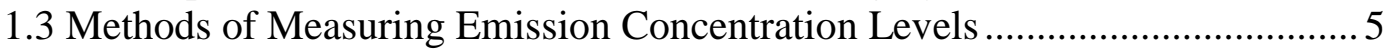

1.4 Necessity for Raw Exhaust Measurements for a MEMS ...............................6

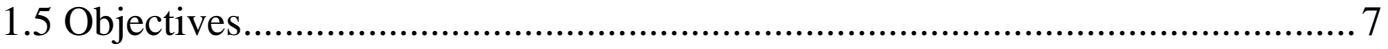

2. Literature Review ....................................................................................8

2.1 Candidate Review ...................................................................................... 9

2.1 .1 Averaging Pitot Tubes .................................................................. 9

2.1.2 Coriolis Mass Flowmeter ...................................................................... 9

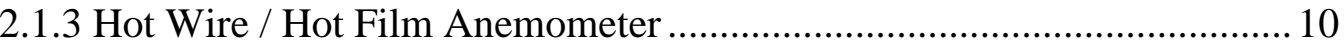

2.1.4 Laser Doppler Anemometer .............................................................. 11

2.1 .5 Pitot Static Tube .............................................................................. 12

2.1 .6 Tracer Gas Method..................................................................... 12

2.1 .7 Turbine Flowmeter.............................................................................. 13

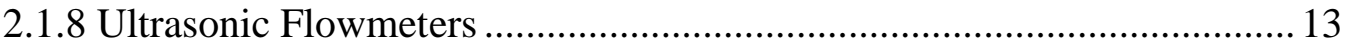

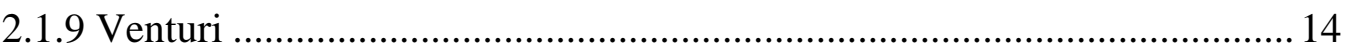

2.1.10 Vortex Shedders ..................................................................... 15

2.2 Detailed View of Candidates .......................................................... 15

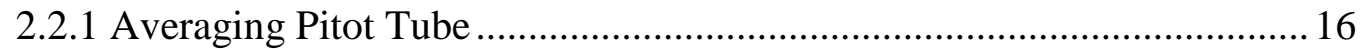

2.2.1.1 Annubar Diamond II, Dieterich Standard ................................... 16

2.2.1.2 Accutube, Meriam Instruments ............................................... 17

2.2 .2 Hot Film ...................................................................................... 18

2.2 .3 Pitot Static Tube ................................................................................ 18

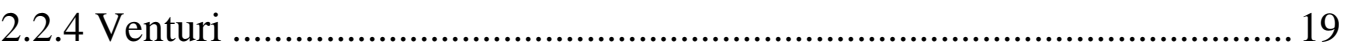

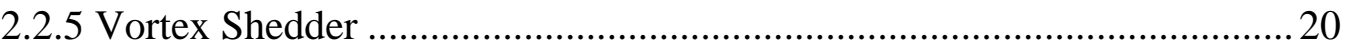

3. Experimental Setup ....................................................................22

3.1 Data Acquisition, Software, \& Pressure Transducers ............................. 22

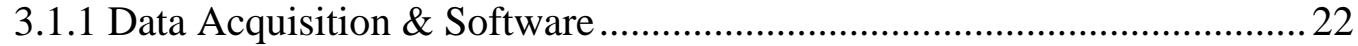




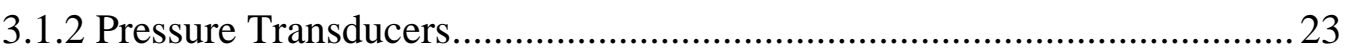

3.2 Cold Bench Setup \& Experiments ...................................................... 25

3.2.1 Cold Bench Layout …………...................................................... 25

3.2.2 Installation Requirements .............................................................26

3.2.2.1 Meriam Instruments Laminar Flow Element ..............................26

3.2.2.2 Accutube \& Annubar .........................................................27

3.2.2.3 Hot Film Anemometer ............................................................ 29

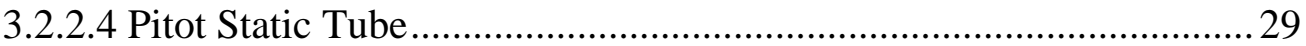

3.2.2.5 Venturi .................................................................... 30

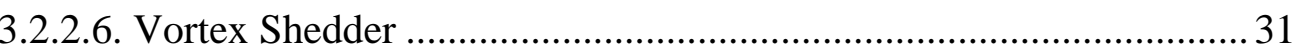

3.3 Cold Bench Testing Procedure .......................................................... 32

3.4 Test Cell .............................................................................................. 33

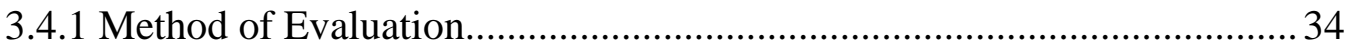

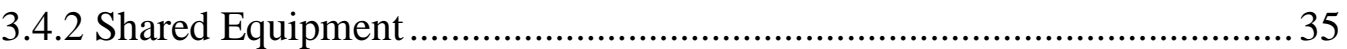

3.4.2.1 Engine Dynamometer ........................................................ 35

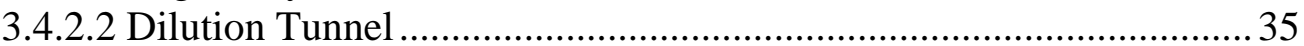

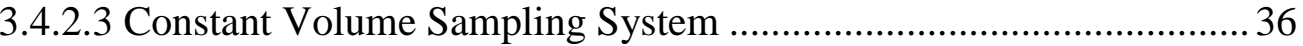

3.4.2.4 Raw Exhaust Sampling System ................................................ 36

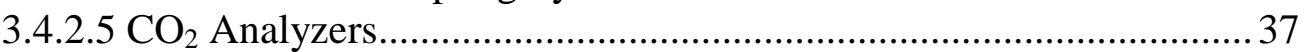

3.5 Engines ................................................................................. 37

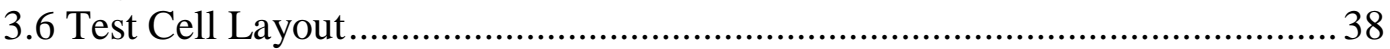

3.7 Test Cell Testing Procedure .......................................................................... 39

4. Experimental Results.......................................................................42

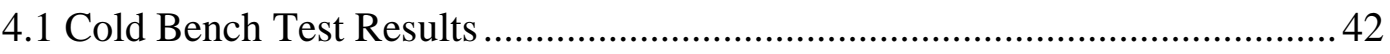

4.1.1 Accutube, Meriam Instruments................................................. 42

4.1.2 Annubar Diamond II, Dieterich Standard ........................................ 45

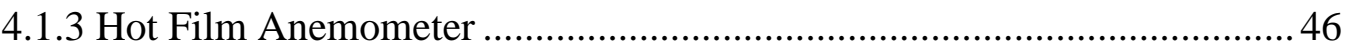

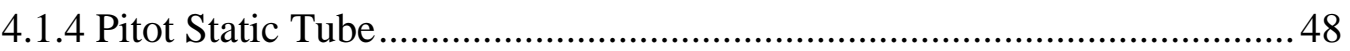

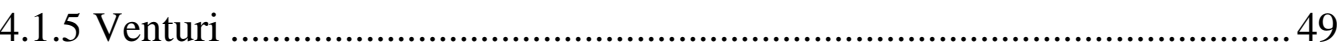

4.1.6 Vortex Shedder ...................................................................... 49

4.1.7 Numerical Comparison ...........................................................51

4.2 Engine Testing Results...............................................................53

4.2.1 Laminar Flow Element vs. Dilute Flow Measurements Methods ............54

4.2.2 Cummins Engine Test Results ............................................................55

4.2.2.1 Accutube, Meriam Instruments Cummins Engine Test Results ........56

4.2.2.2 Annubar Diamond II, Dieterich Standard Cummins Engine Test

Results ..................................................................................... 57

4.2.2.3 Venturi Cummins Engine Test Results ...........................................58

4.2.3 Navistar Engine Tests ....................................................................59

4.2.3.1 Original Vortex Shedder Tube Design........................................60

4.2.3.2 New Vortex Shedder Tube Navistar Test Results ...........................61 61

4.3 Numerical Comparison ......................................................................62

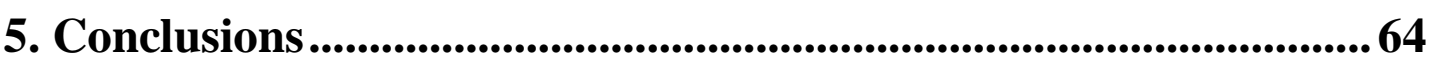


6. Recommendations....................................................................................66

7. References.................................................................................................67

Appendices.......................................................................................................69

Appendix I LFE ................................................................................ 70

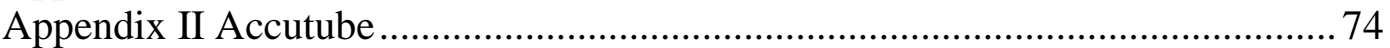

Appendix III Annubar .................................................................................. 77

Appendix IV Hot Film Anemometer ............................................................ 79

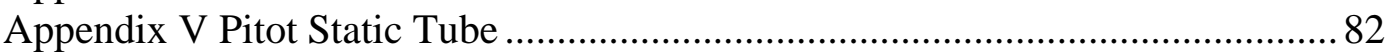

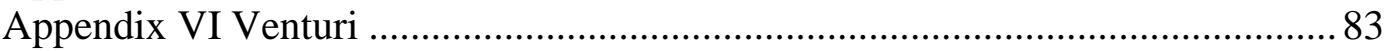

Appendix VII Original Vortex Shedder............................................................. 85

Appendix VIII New Vortex Shedder Design ..................................................8 87

Appendix IX Differential Pressure Transducer Viatran 274 ..............................88

Appendix X Absolute Pressure Transducer Omega PX176 ................................89 


\section{List of Figures}

F GURE 1 VIATRAN MODEL 274 DifFERENTIAL PRESSURE TRANSDUCER ........................24 FigURE 2 OMEGA PX 176 ABSOLUTE PRESSURE TRANSDUCER.......................................24

FIGURE 3 COLD BENCH LAYOUT............................................................................26

FIGURE 4 MERIAM INSTRUMENTS LAMINAR FLOW ELEMENT.........................................2.

FIGURE 5 ANNUBAR DIAMOND II, DIETERICH STANDARD .............................................28

FIGURE 6 MERIAM INSTRUMENTS ACCUTUBE...................................................... 28

FIGURE 7 SIERRA SERIES 620S FAST-FLO INSERTION MASS FLOW METER .........................29

FigURE 8 DWYER PITOT STATIC TUBE....................................................................... 30

FIGURE 9 FLO-DYNE VENTURI............................................................................. 31

FIGURE 10 J-TEC VE503 EXHAUST VORTEX SHEDDER ON ORIGINAL TUBE ...................... 32

FIGURE 11 J-TEC VE503 EXHAUST VORTEX SHEDDER ON NEW FLOW TUBE..................... 32

FIGURE 12 TEST CELL LAYOUT ………..................................................................... 39

FIGURE 13 ENGINE MAP FOR THE NAVISTAR WITH TEST SET POINTS .............................. 41

FIGURE 14 ENGINE MAP FOR THE CUMMINS WITH TEST SET POINTS ............................... 41

FIGURE 15 SINGLE ACCUTUBE COLD BENCH-TESTING RESULTS ......................................43

FIGURE 16 DOUBLE ACCUTUBE COLD BENCH-TESTING RESULTS ................................... 44

Figure 17 Results of Single Accutube Cold Bench Tests using A Non-Zero

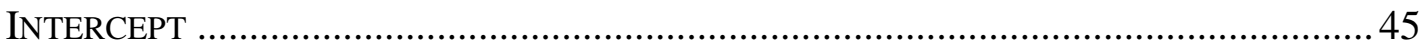

FIGURE 18 ANNUBAR COLD BENCH-TESTING RESULTS................................................ 46

FigURE 19 HOT FILM ANEMOMETER COLD BENCH-TESTING RESULTS ..............................4

FIGURE 20 PITOT STATIC TUBE COLD BENCH-TESTING RESULTS....................................... 48

FIGURE 21 VENTURI COLD BENCH-TESTING RESULTS .................................................. 49

FIGURE 22 ORIGINAL TUBE VORTEX SHEDDER COLD BENCH-TESTING RESULTS.................50

FIGURE 23 NEW TUBE VORTEX SHEDDER COLD BENCH-TESTING RESULTS.......................51

FIGURE 24 COMPARISON OF THE LFE AND DILUTE METHOD USING $\mathrm{CO}_{2}$ MASS RATE.......55

FiGURE 25 SiNGLE ACCUTUBE RESULTS FROM CUMMINS ENGINE TEST............................56

FiguRE 26 Double ACCUTUBE CUMMINS TEST RESULTS...............................................57

FIGURE 27 ANNUBAR CUMMINS TEST RESULTS ........................................................58

FIGURE 28 VENTURI CUMMINS TEST RESULTS ..........................................................59

FIGURE 29 ORIGINAL VORTEX SHEDDER NAVISTAR TESTS RESULTS ................................60 
FigURE 30 NEW VORTEX SHEDDER TUBE NAVISTAR TEST RESULTS .............................61

FIGURE 31 LETTER OF CERTIFICATION FOR THE LFE …….......................................... 72

FIGURE 32 CALIBRATION SHEET FOR THE LFE …….................................................... 73

FiguRE 33 PRODUCT SPECIFICATION SHEET FOR THE HOT FILM ANOMETER..................... 80

FigURE 34 CALIBRATION SHEET FOR THE HOT FILM ANEMOMETER................................ 81

FIGURE 35 CALIBRATION SHEET FOR THE VE 503 VORTEX SHEDDER.............................. 86

Figure 36 Product SPeCiFication SheET For the Viatran 274 Pressure

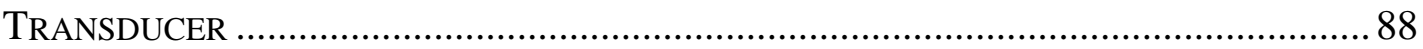

FIGURE 37 OMEGA PX 176 ABSOLUTE PRESSURE TRANSDUCER....................................... 89 


\section{List of Tables}

TABLE 1 EMISSION STANDARDS............................................................................

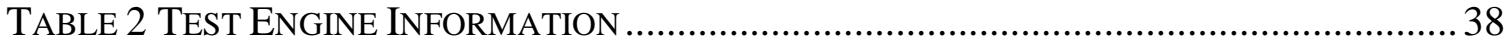

TABLE 3 TEST PROCEDURES FOR TEST CELL EXPERIMENTS ............................................4 40

TABLE 4 RESUlTS OF COLD BENCH-TESTING .......................................................... 52

TABLE 5 FinAl RANKING AFTER COLD BENCH TESTING OF Flow DEVICES ......................53

TABLE 6 RESULTS OF ENGINE TESTS ...................................................................... 62

TABLE 7 FinAl RANKING AFTER ENGINE TESTING OF Flow DEVICES .......................... 63 


\section{Introduction}

Based upon the amendment to the Clean Air Act in 1990, the Environmental Protection Agency (EPA) now requires standards on ambient air known as the National Ambient Air Quality Standards. The amendment identifies two standards. Primary standards are for the protection of the general public and secondary standards are for the protection of the public welfare and the environment [epa.gov, 2000]. The Office of Air Quality Planning and Standards (OAQPS) has set limits for six principal pollutants, namely carbon monoxide $(\mathrm{CO})$, nitrogen dioxide $\left(\mathrm{NO}_{2}\right)$, ozone $\left(\mathrm{O}_{3}\right)$, sulfur dioxide $\left(\mathrm{SO}_{2}\right)$, lead $(\mathrm{Pb})$, and particulate matter (PM). Motor vehicles contributed significantly to the production of all six pollutants until the introduction of unleaded gasoline, which substantially reduced lead emissions. However, motor vehicles are one of the largest sources for $\mathrm{CO}$ and $\mathrm{NO}_{x}$. Even though motor vehicles do not produce $\mathrm{O}_{3}$ as a direct byproduct, they do produce $\mathrm{PM}$ along with $\mathrm{NO}_{2}$, which can combine in the atmosphere to produce $\mathrm{O}_{3}$ [epa.gov, 2000].

With the ever-growing number of motor vehicles in service and the likelihood of global warming as well as increasing effects of acid rain, the EPA continues to tighten the regulation on exhaust emissions. Table 1 shows how the emission standards (in grams per brake horsepower hour) for heavy-duty diesel truck engines are changing [dieselnet.com, 2001]. 


\begin{tabular}{|c|c|c|c|c|}
\hline Year & HC/MNHC & CO & NO $_{\mathbf{x}}$ & PM \\
\hline $\mathbf{1 9 9 0}$ & $1.3 /--$ & 15.5 & 6.0 & 0.60 \\
\hline $\mathbf{1 9 9 1}$ & $1.3 /--$ & 15.5 & 5.0 & 0.25 \\
\hline $\mathbf{1 9 9 4}$ & $1.3 /--$ & 15.5 & 5.0 & 0.10 \\
\hline $\mathbf{1 9 9 8}$ & $1.3 /--$ & 15.5 & 4.0 & 0.10 \\
\hline $\mathbf{2 0 0 7 ~ \& ~ B e y o n d ~}$ & $--/ .14$ & -- & 0.20 & 0.01 \\
\hline
\end{tabular}

Table 1 Emission Standards for Heavy-Duty Truck \& Bus Engines

As the emissions levels continue to decrease, the current technology for monitoring these concentrations is becoming less effective due the limited resolution of the equipment used. New tools must be developed to monitor in-use emissions, acquire data for modeling, and to meet the requirements of the consent decrees.

\subsection{Consent Decrees}

In 1998, the six settling heavy-duty diesel engine manufacturers settled with the EPA over concerns about "defeat" devices. This is an excerpt from Dieselnet.com, which summarizes the Consent Decrees [dieselnet.com].

"In October, 1998, a court settlement was reached between the EPA, Department of Justice, California Air Resources Board, and engine manufacturers (Caterpillar, Cummins, Detroit Diesel, Volvo, Mack Trucks/Renault, and Navistar) over the issue of high $\mathrm{NO}_{\mathrm{x}}$ emissions from heavy-duty diesel engine during driving modes. Since the early 1990s, the manufacturers used engine control software that caused engines to switch to a more fuel-efficient (but higher $\mathrm{NO}_{\mathrm{x}}$ ) driving mode during steady highway cruising. The EPA considered this engine control strategy an illegal 'emission defeat device.' Provisions of the Consent Decree include the following: 
> Civil penalties for engine manufacturers and requirements to allocate funds for pollution research

> Upgrading existing engines to lower $\mathrm{NO}_{\mathrm{x}}$ emissions

> Supplemental Emission Test (steady-state) with a limit equal to the FTP standard and NTE limits of $1.25^{*} \mathrm{FTP}$ (with the exception of Navistar)

> Meeting the 2004 emission standards by October 2002, 15 months ahead of time"

As part of the ruling the manufacturers were ordered to fund projects in the area of pollution research. West Virginia University was chosen to develop a system for testing heavy-duty diesel engine on-road testing.

\subsection{Development of A Mobile Emissions Monitoring System}

When the Environmental Protection Agency developed the Federal Test Procedure the existing technology would not support a mobile emissions testing program, so the procedures were developed in order to test the engines under varying parameters using an engine dynamometer. Today, the technology is readily available to produce such mobile testing equipment. The advantage offered by testing a vehicle on the road is the emissions can be measured from real life applications, unlike the FTP cycle used by the EPA, which can be argued as being unrepresentative to today's electronically controlled heavy-duty diesel engines. The on-road monitoring of emissions can also lead to more realistic regulations and possibly new control technology. The system currently under development is known as a MEMS or Mobile Emissions Monitoring System.

The first requirement for a MEMS is the components must be rugged. These requirements are due to the nature of the environment of operation. The test conditions 
include wide ambient temperature variations, changes in inclination and altitude, the presence of varying vibration frequency and amplitude, and the presence of precipitation and condensation. Standard laboratory grade equipment would be preferred; however, the requirements placed on the necessary equipment limit the usefulness of these devices. The second limitation placed on the components of a MEMS is a finite power supply. The third limitation is the cost the MEMS itself. The final limitation is the size of the equipment, which make up the MEMS.

A MEMS is located in a real-world environment that does not have the luxury of temperature and/or humidity control surroundings found in many engine test cells. The presence of elevated humidity levels or even precipitation eliminates many devices from being considered for a MEMS. Vibrations may affect the accuracy of many devices used in conventional emissions testing, so other techniques may be desired. The vibration caused by road conditions or driver effects may result in failure of many devices, so care must be taken in selecting components.

The test vehicle should provide the power for the MEMS and accessory components. However, power from the vehicle's electrical system is limited. The use of a portable generator may be a possibility for providing additional power.

Since a MEMS is designed to be portable it must be compact in size and lightweight. The system should have the capability of testing different types of heavy-duty dieselpowered vehicles. Once a useful product is completed, researchers will be able to test vehicles in real-world environments and working conditions. This may be accomplished by using techniques not found in laboratory test cells. Since the EPA has no regulations 
on mobile emissions testing many approaches previously found unusable may now be acceptable for on road testing.

\subsection{Methods of Measuring Emission Concentration Levels}

The Code of Federal Regulations Title 40 lists two accepted methods for measuring emissions from a heavy-duty diesel engine depending upon engine usage. The methods are dilute [Title 40 Code of Federal Regulations, Part 86] and raw exhaust measurements [Title 40 Code of Federal Regulations, Part 89]. The CFR allows for alternative methods of testing, but equivalent results must first be presented. The method of sampling is determined by what type of test is being run on the engine. Each method has advantages and disadvantages for testing.

First, dilute measurements require the use of a constant volume sampling system (CVS). The CVS can use a positive displacement pump or a critical flow venturi to maintain a constant amount of ambient air mixed with the exhaust stream. The mixing takes place in a dilution tunnel, where the two streams mix thoroughly. The extracted sample contains a mixture of ambient air and exhaust gases. This mixed sample has a lower dew point then that of raw exhaust, reducing the chance of condensation forming in the sample lines.

Dilute measurements have the advantage of being used for either transient or steady state tests. This is accomplished by integrating the flowrate and work over the entire test cycle. This eliminates any problem of time aligning instantaneous emission concentrations and engine performance. The major disadvantage to dilute systems is the overall size. The components that makeup a dilute system are very large, mainly the dilution tunnel and CVS system. 
Raw exhaust samples are extracted directly from the exhaust stream without any mixing with ambient air. The sample can be taken after the engine and/or aftertreatment devices. Raw measurements do not need a CVS system, but the total flowrate is needed for emission concentration results.

The advantage of using raw measurements is the freedom to choose a location for sample extraction. Another advantage is the relatively small size of the system required to take raw measurements.

\subsection{Necessity for Raw Exhaust Measurements for a MEMS}

Since a MEMS is an mobile test tool, size constraints as well as available power are important issues. The system must be compact in size and robust in order to operate in harsh environments. The available power to operate a MEMS is limited to power from the vehicle and/or the possibility of a small portable generator. The flexibility of transient testing from the dilute measurement system is attractive, but the large size of the components and the power required to operate the system eliminate any possibility of using it [Gautam et al., 1999].

Raw exhaust measurement systems are generally compact in size and only require power for the analyzer units and accessories. Raw exhaust measurement systems can easily be installed on most vehicles with little effort. The only information raw exhaust measurement systems need to calculate useful emissions data is the total mass flowrate thorough the engine and each constituents concentration. Based upon this information a MEMS will incorporate raw exhaust measurements as the method of emissions testing. 


\subsection{Objectives}

Since the raw sampling method was chosen, the total flowrate through the engine must be determined in order to calculate the emission concentrations. The point of this thesis is to determine the best method of determining the total flowrate through an in-use heavy-duty diesel engine. To do this, the evaluation of several chosen flowmeters was broken down into two parts. These two parts are: (1) cold bench testing, and (2) engine testing.

The cold bench testing was designed to compare each instrument against a reference for measuring flowrate. This test is designed to determine which devices should receive further testing on a diesel engine in the test cell. The engine testing is designed to show the instruments performance in the exhaust. Not all devices will be tested in the test cell. This is due to the fact that not all devices can tolerate the extreme conditions found there. Based upon the performance on the cold bench and in the test cell, a ranking system was used to determine which device would be the chosen for a MEMS flow device. 


\section{Literature Review}

There are many different methods of measuring gaseous flowrate. To reduce the number of possible candidates a literature review was performed. Much of the following work parallels that preformed by Gautam et al. (1999) since a similar goal was at hand. The factors that were considered when evaluating the candidates were the following [Gautam et al, 1999]:

$>$ Repeatability and Range

$>$ Size (includes secondary devices as well)

Medium Capable

Environment Tolerant

$>$ Pressure Loss

$>$ Robust

The possible candidates include time-proven devices as well as new techniques. The review included methods for measuring the flowrate in the exhaust as well as the intake. The following is a list of possible candidates.

$>$ Averaging Pitot Tubes

$>$ Coriolis Mass Flowmeter

Hot Wire / Hot Film Anemometer

$>$ Laser Doppler Anemometer

Pitot Static Tube

$>$ Turbine Flowmeter

Tracer Gas Method

Ultrasonic Flowmeter 
Venturi

Vortex Shedder

\subsection{Candidate Review}

The following sections describe the basic operating principals for each device as well as the advantages and disadvantages for each. Each device is judged primarily on the requirements stated in previous sections.

\subsubsection{Averaging Pitot Tubes}

The goal of an averaging Pitot tube is to sample several points in the flow and use the average value to calculate the flowrate. This approach eliminates problems caused by vortices and eddies which cause disturbances that may result in incorrect flowrate values reported by a single Pitot tube. Some averaging Pitots are designed so a buffer zone is formed in front of the probe at higher flowrate. This buffer zone eliminates the chance of ports becoming clogged, which would require shut down and cleaning of the system resulting in increased operating cost [Anon, 1982].

The advantages of an averaging Pitot tube are capable of measuring unsteady flows, offers low head loss, and designed to remain clog-free. The disadvantage of an averaging Pitot tube is that they are not well suited for pulsing flow, based upon the advantages and disadvantages it was decided that an averaging Pitot tube should be further tested to determine if it is suitable to be a MEMS flowmeter.

\subsubsection{Coriolis Mass Flowmeter}

When a fluid is moving in a rotating system a force is exerted perpendicular to the direction of the flow. This force is proportional to the mass and velocity of the fluid and 
the angular velocity of the system [Rusnak, 1989]. The fluid enters the device and is sent into two small tubes. The geometry of these tubes is determined by the physical characteristics of the fluid being measured. The tubes are vibrated at their resonant frequency causing a fluctuating angular velocity. The Coriolis force causes a small deflection in the tubes. The corresponding rate of tube deflection is calibrated with a known flowrate [Miller, 1996].

The advantages of a Coriolis Mass flowmeter are that it offers no obstruction to the flow, is very accurate, and measures a wide range of flows. The disadvantages of a Coriolis Mass flowmeter are that it has a high-pressure drop, is rather expensive, and is sensitive to vibrations. Due to the nature of the operating environment, a Coriolis Mass flowmeter was not evaluated as a candidate for a MEMS.

\subsubsection{Hot Wire / Hot Film Anemometer}

Hot wires and hot film anemometers have been used since the late 1800's. These were crude when compared to what is available today. Hot wires and hot film operate on the same principles. Both measure the velocity through maintaining a constant temperature of the probe (corresponding to resistance) or the flow of current through the probe. This is most commonly done with the aid of a Wheatstone bridge. The probe is cooled by convection as the fluid passes over it this causes the current flow or resistance of the wire to change. This is monitored and calibrated against a known flow. Hot wires are usually about $1 \mathrm{~mm}$ long and $5 \mu \mathrm{m}$ in diameter and hot films are generally a hot wire coated in a quartz film [Lomas, 1986].

The advantages that hot wire and hot film anemometers offer are good spatial resolution, excellent response frequency, and high sensitivity to low flowrates. The 
disadvantages of hot wire and hot film anemometers are they requires clean flow, are sensitive to ambient temperature variations, and is susceptible to turbulence (resulting in false velocity readings).

Even though hot wires and hot films have serious limitations, there is a possibility that one may find a favorable location in a MEMS. It was determine a hot wire or hot film anemometer should be tested.

\subsubsection{Laser Doppler Anemometer}

When a beam of light strikes a particle it scatters the light and the resulting light has a frequency shift proportional to the velocity of the particle [Beckwith et al., 1995]. A LDA (Laser Doppler Anemometer) splits a laser beam into 2 separate beams of the same frequency then directs the beams to cross at a known angle. As a particle passes through the intersection of the two beams the scattered light has a shift in frequency, which is detected by a photomultiplier. The frequency of light is different for each beam because of the direct angles from which they were directed. The photomultiplier detects these different frequencies and converts them into a voltage. This signal is then amplified and calibrated against a know flowrate.

The advantages an LDA enjoys are a fast response time, and good spatial resolution. The disadvantages of an LDA are a need for a constant flow of seeding particles, it is vibration sensitive, and is very expensive. Due to the nature of the operating environment a Laser Doppler Anemometer was found to be not suitable for a MEMS. 


\subsubsection{Pitot Static Tube}

Pitot static tubes are one of the oldest and most versatile methods for measuring flowrate. Pitot static tubes are design to measure the static pressure as well as the total pressure of a fluid. The difference between these two readings is the magnitude of the flowing pressure alone [Klopfenstein, 1998]. By using this pressure along with other fluid properties the velocity can be calculated from which the volumetric or mass flowrate can be found.

The advantages of a Pitot static tube are it is very simple, can be extremely accurate (requires testing across channel), and is inexpensive. The disadvantages of a Pitot static tube are is offers point velocity measurements, has difficulty dealing with pulsing flow, and its ports may become clogged due to presents of dirt or soot. Even with these limitations Pitot static tubes have been found a worthy candidate for a MEMS.

\subsubsection{Tracer Gas Method}

This is a relatively new technique for determining exhaust flowrate so less research has been preformed using this method than others discussed. The system first injects a tracer gas into the exhaust stream. A mass flow controller regulates the amount of tracer gas injected. The tracer gas must be stable and comparably different to the components in the exhaust. A sample is taken downstream after sufficient mixing has occurred. The sample is passed through a sector field mass spectrometer or any other suitable sensor. The flowrate can be determined by the recovery rate of the tracer gas sense the injection occurs at a constant rate [Masayuki et al., 1997].

The tracer gas method offers the advantages of not being disturbed by pulsating flow, has an easy time alignment with gas analyzers, and measurement of dry-based flow 
rate that can be directly multiplied by dry-based gas concentration to obtain mass emission rate. The disadvantages of a tracer gas method are the requirement of a tracer gas, the time delay of injection to sample point, can be affected by presence of tracer gas in ambient air, and the analyzing capability of the mass spectrometer. Since little is known of the reliability and accuracy of the tracer gas method, it was not chosen for further evaluation.

\subsubsection{Turbine Flowmeter}

As the fluid flows through a pipe it has kinetic energy. Turbine flowmeters use the energy of the fluid to turn a turbine. As the turbine turns a magnetic pick up determines how fast it is rotating. The fluid velocity is proportional to the speed of the turbine [Upp, 1993]. There are two different types of turbine flowmeters. One places the entire turbine in the flow where the other places only part of the turbine is in the flow.

The advantages to a turbine flowmeter are its wide rangeability, is inexpensive, and is less sensitive to upstream disturbances then other flowmeters [Hayward, 1979]. The disadvantages to a turbine flowmeter are its temperature limits, its difficulty-measuring transients due to turbine momentum, and a difficulty dealing with low-pressure flows. Due to the nature of the environment and flow characteristics, turbine flowmeters were found to be unsuitable to be a MEMS flowmeter.

\subsubsection{Ultrasonic Flowmeters}

Ultrasonic flowmeters come in two classifications. First is the time of flight type and second is the Doppler effect type. The time of flight type uses two signals, one facing up stream and the second facing down stream. Each unit has a transmitter and receiver. The 
difference in the signals is due the velocity of the flow. The Doppler effect type uses the same principle as the LDA. An acoustic signal is sent out of a transmitter, when it encounters a particle the reflected signal has a different frequency than the original. This signal is picked up by a receiver which processes it and turns it into a voltage [Rusnak, 1989].

The advantages of an ultrasonic flowmeter are it has a high temperature range (up to $800^{\circ} \mathrm{C}$ ), is small and compact, and has a very low pressure drop. The disadvantages of an ultrasonic flowmeter are many systems require purge air (which requires addition equipment), are expensive, and little research has been done on or using these devices [Beck \& Hinterhofer, 1998].

Since little is known about these device one will not be chosen for further testing; however, if no other device are found suitable this may be an alternative for future research.

\subsubsection{Venturi}

Venturis are ideal flowmeters where minimal permanent head loss is an issue. A venturi is designed to incorporate a converging section that accelerates the flow and a diverging section that recovers the dynamic energy of the flow as pressure. There is a pressure tap on the upstream side of the venturi and another at the throat or smallest restriction. This pressure difference is proportional to the flowrate [Miller, 1996].

The advantages of a venturi flowmeter are its simple design and operation, has a low operating cost, is very accurate, and can be used with dirty fluids. The disadvantage of a venturi flowmeter is it is excessively heavy (due to manufacturing process, but can be reduced with some modifications). 
Venturi flowmeters have been chosen for further testing for a MEMS.

\subsubsection{Vortex Shedders}

When a bluff body is placed in a flow stream an unsteady boundary layer forms on the surface of the body. As the boundary layer becomes unstable separation occurs causing vortices to form downstream stream. The vortices form in an alternation pattern, which is repeated. The frequency of the forming vortices is directly proportional to the flowrate [ASME MFC-6M-1998]. A transmitter and receiver detect the frequency of the vortices. The transmitter sends out a signal at a specific frequency, as the vortices travel downstream they modify the signal from the transmitter. The receiver detects the frequency shift from the original signal. An electronics package then processes the data in terms of flowrate.

The advantages of a vortex shedder are its linear relationship with flowrate, its capable of dealing with high temperatures, its very accurate, and its rugged and reliable. The disadvantages of a vortex shedder are it has a limitation on pipe size, it may require purge air (requires additional equipment), and the influence of pulsations on the accuracy

of the device is unknown. Based upon these factors it was found that a vortex shedder should undergo further testing to determine if it can be a MEMS flowmeter.

\subsection{Detailed View of Candidates}

The following sections describe the principles of operation and the fundamental equations for each device. Additional information on each device can be found in Section 3 or Appendix I. 


\subsubsection{Averaging Pitot Tube}

Two types of averaging Pitots were tested. One was a Accutube from Meriam Instruments (Meriam Instrument a Scott Fetzer Company, 10920 Madison Avenue, Cleveland, OH 44102) and the other was a Annubar Diamond II from Dieterich Standard (Dieterich Standard, Inc., P.O. Box 9000, Boulder, CO 80301). Both instruments are designed on the same principal, but differ in their geometries. Detailed descriptions of each instrument along with basic equations for computing flowrate are presented below.

\subsubsection{Annubar Diamond II, Dieterich Standard}

As a fluid flows around an object in a flow field a zone of high pressure is formed in front of the object. The point of high pressure is known as the stagnation point. It is called this because the flow stops or becomes "stagnate." As the rest of the flow flows the streamlines around the object they meet at a point downstream away from the object. This is due to the wake left in the flow by the object. The pressure in this wake is less than that of the surrounding flow. This zone is known as the suction point and is typically measured in the downstream surface of the object [Annubar Diamond II+ Flow Handbook, 1998].

The Annubar has pressure ports aligned along the upstream portion and the downstream portion of the probe to measure these two pressure points. The ports are positioned across the flow so an average of each pressure can be processed. This offers the advantage of sampling a larger portion of the flow than a point device like a Pitot static tube or a hot wire. This is important because the velocity profile is not constant across the channel or pipe. The Annubar is in the shape of a diamond with a point into the flow a point downstream. The sampling ports are on the tip of the point. 
As with any flowmeter the proper installation is an important issue with the Annubar. The required straight run of piping for the fully developed flow for an Annubar is 8 diameters upstream and 4 diameters downstream. When the Annubar is installed the proper alignment must be checked. This includes aligning the front of the probe with the flow streamlines as well as setting the probe perpendicular to the piping. The maximum allowable outset is 3 degrees for each alignment [Annubar Averaging Pitot Tube Installation and Operation Manual, 1998]. The basic equation used to compute the flowrate in standard cubic feet per minute from the Annubar is:

$$
Q_{S}=F_{N A} * K * D^{2} * F_{R A} * Y_{A} * F_{P B} * F_{T B} * F_{T F} * F_{A A} * \sqrt{h_{w}^{*} \rho_{f}} \quad \text { Eq. } 1
$$

The following equation was used to determine the mass flowrate in pounds per minute.

$$
\begin{array}{ll}
W=Q_{S} * \rho & \text { Eq. } 2
\end{array}
$$

Appendix III includes the relevant calculations, definitions, and units for each coefficient as well as the calculations preformed on the raw data in the form of a spreadsheet.

\subsubsection{Accutube, Meriam Instruments}

An Accutube is designed in the same manner as the Annubar in terms of location of ports (front and back as well as across the flow), but there is one major difference. The Accutube is in the shape of a cylinder. This causes the separation point of the flow to become a function of the Reynolds Number. As the Reynolds number increases the separation point moves around the cylinder in the direction of the flow changing the area of the wake this in turn changes the suction pressure. 
The same installation recommendations were followed for the Accutube. This is because both the Annubar and the Accutube are the same type of device and have the same requirements. The equation used for computing the flowrate in standard cubic feet per minute for an Accutube is [Meriam Accutube Flow Handbook, 1984]:

$$
Q_{S}=C^{\prime} * K * D^{2} * \sqrt{\frac{\Delta P * P f}{T f+459.67}} * Y^{*} F_{A} * F_{P B} * F_{T B} * F_{R A} \quad \text { Eq. } 3
$$

Appendix II includes the relevant calculations, definitions, and units for each coefficient as well as the calculations preformed on the raw data in the form of a spreadsheet. The same equation (Eq. 2) can be used to determine the mass flowrate for the Accutube.

\subsubsection{Hot Film}

A hot film anemometer was chosen for further testing. The hot film anemometer that was chosen was a model 620 Series Accu-Flo from Sierra Instruments (Sierra Instruments, Inc., 5 Harris Court, Bldg. L, Monterey, CA 93940). This model had a zero to five-volt output with a full-scale value of $1500 \mathrm{scfm}$. It had the advantage of being a linear response device [Sierra Instruments Product Catalog, 1998]. Appendix IV includes the relevant calculations for all correction factors as well as the calculations used to reduce the raw data in the form of a spreadsheet. A complete calibration sheet provided by the manufacturer is also included.

\subsubsection{Pitot Static Tube}

The Pitot static tube chosen for testing was manufactured by Dwyer Instruments, Inc. (Dwyer Instruments, Inc., P.O. Box 373, Michigan City, IN 46360). Pitot Static Tubes are designed to measure the difference between a stagnation pressure and a static 
pressure. The static pressure is the pressure exerted by an element of flowing fluid and the stagnation pressure is the pressure of the fluid when its velocity is zero. These two measurements along with correction factors for temperature and pressure are what determine the flowrate of the fluid. Dwyer Instruments produced the Pitot static tube chosen for further testing. The Pitot static tube is an air velocity device, which means it is used to compute the volumetric flowrate. To compute the volumetric flowrate in cubic feet per minute the following equation was used [Dwyer Bulletin No. H-11, 1992].

$$
\text { Air Velocity }=1096.2 * \sqrt{\frac{P_{V}}{\rho}}
$$

To compute the mass flowrate in pounds per minute the following equation should be used.

$$
W=\text { Air Velocity }{ }^{*} \text { Cross Sectional Area } * \rho \quad \text { Eq. } 5
$$

The major problem with Pitot static tubes is present in the air velocity term of Eq. 5 . if the velocity profile is not constant across the flow than an error is introduced. This is typically handled by using a correction factor to obtain an average velocity profile. See Appendix $\mathrm{V}$ for relevant calculations, definitions, and units for all correction factors as well as the calculations used to reduce the raw data in the form of a spreadsheet.

\subsubsection{Venturi}

The venturi chosen for testing was produced by Flo-Dyne Engineering, Inc. (FloDyne Engineering, Inc., P.O. Box 161655, Fort Worth, TX 76161-1655). Venturis are designed to offer a low permanent pressure loss. This is accomplished by gradually converging the flow to a smaller area and then gradually expanding the flow back to the original pipe size. When this is done the velocity increases causing a pressure drop at the 
smaller restriction. A pressure tap is placed upstream of this restriction and one is placed at the restriction as well. The pressure difference between these two pressure taps is proportional to the flowrate. This causes the venturi to present the flowrate as a function of the square root of the differential pressure. This is one disadvantage venturi flowmeters have when compared to linear output devices. However, with proper design and the proper selection of secondary devices a venturi can function quite efficiently.

The equation for determining flowrate in pounds per minute for a venturi is [FlowDyne Engineering, Inc., 1991)]

$$
\dot{m}=0.52502 *\left(\frac{C^{*} Y^{*} d^{2} * F_{a}}{\sqrt{1-\beta^{4}}}\right) * \sqrt{\rho^{*}(P 1-P 2)} \quad \text { Eq. } 6
$$

To compute the volumetric flowrate simply divide the mass flowrate by the density of the fluid. See Appendix VI for complete calculations, definitions, and units used to reduce the Flo-Dyne Venturi data used for MEMS testing.

\subsubsection{Vortex Shedder}

The vortex shedder chosen for testing was manufactured by J-TEC Associates, Inc. (J-TEC Associates, Inc., 5255 Rockwell Drive, N.E., Cedar Rapids, IA 52402-2020). Until recently vortex shedders could not operate in the harsh environment of diesel engine. The excessive heat caused the electronics in the transmitter and receiver to fail. A new design by J-TEC Associates, Inc. has overcome this problem. A VE 503-Exhaust Vortex Shedder was chosen for further testing. The device is designed for a 3-inch pipe diameter. The small size is due to a limitation on the distance the transmitter and receiver can be separated. The current device has a maximum throughput of $450 \mathrm{scfm}$. The device offers both a voltage output as well as a frequency output [Operator's Manual for 
the VE503 Exhaust Flowmeter, 1993]. The device offers the flowrate in terms of volumetric flowrate, which can then be turned into mass flowrate in pounds per minute by using the following equation.

$$
\dot{m}=\text { Cross Sectional Area } * \text { VolumetricFlowrate } * \rho \quad \text { Eq. } 7
$$

According to the manufacturer, the required straight runs of pipe upstream of the vortex shedder are 20 diameters and 10 diameters downstream of the device. If pressure and temperature measurements are to be taken this should be done downstream of the device to ensure no additional flow disturbances.

Since the VE 503 Vortex Shedder has a maximum volumetric flowrate of $450 \mathrm{scfm}$ a newly designed flow tube was also tested. The new flow tube still maintains the maximum distance the transmitter and receiver could be apart, but instead of a round tube it was rectangular. The cross sectional area of the rectangular design is equal to the cross sectional area of round exhaust pipe. New equations need to be developed for this new flow tube sense the geometry was changed from the original. See Appendix VII and VIII for complete calculations, definitions, and units used to reduce the raw data for the J-TEC VE503 Exhaust Vortex Shedder. 


\section{Experimental Setup}

The experiments discussed below were conducted at the West Virginia University's Engine \& Emissions Research Laboratory (EERL). For additional information on the EERL and the equipment used there see Influence Of Fuel Sulfur Content on Emissions From Diesel Engines Equipped With Oxidation Catalysts by Jason Evans and A Performance Evaluation of the MEMS - An On-Road Emissions Measurement System Study by Ben Shade.

The following sections discuss the apparatus used to perform the cold bench and test cell experiments. The first section discusses the data acquisition, software, and pressure transducers. The next section presents the cold bench setup and the experiments performed on it. A section dealing with the Cummins compression ignition engine and the experiments performed in the test cell are next. The last section covers the work completed on a Navistar compression ignition engine and the experiments performed on it.

\subsection{Data Acquisition, Software, \& Pressure Transducers}

This section covers some of the devices used in both the cold bench testing and the engine testing portions of this project. The devices include the data acquisition system, the software used by the data acquisition computer, and the pressure transducers used as the secondary systems of many of the flow devices.

\subsubsection{Data Acquisition \& Software}

One of the most important pieces of equipment is the data acquisition hardware and software. The equipment used in the testing was chosen for its capability of working in harsh environments and its performance. The data acquisition system used for the testing 
was a PXI-1025 from National Instruments. The PXI-1025 has a 6071E data acquisition card and a RS-232 Serial card. The system uses a National Instruments PXI-8156B computer, which offers two additional serial ports, one USB port, one GPIB interface, as well as a hard, floppy, and CD drives (Gautam et al., 2000).

A signal conditioning/power box was used to supply power to the devices (and secondary components) and condition the output signals. The box converted an AC power supply into 12 and 5 Volt DC power. The box used a clock-tunable linear phase $5^{\text {th }}$ order Bessel lowpass filter for $10 \mathrm{kHz}$ filtering. The signal was transferred to the computer via a shielded cable.

The software used for the data acquisition was produced by Robert Craven, a Research Scientist at WVU. The software allows the user the option to zero secondary components (such as transducers) by means of shifting a calibration curve, which is stored in a database. The software also allows the user to change sampling frequencies, $\log$ ECU, GPS, and emissions data.

\subsubsection{Pressure Transducers}

Many of the devices tested require a secondary system that converts a physical measurement into an electrical signal that is acceptable to the computer. Such devices are known as transducers. The requirements for a pressure transducer for the experiments preformed in these tests are as follows.

$>$ Fast Time Response

$>$ Minimally Affected by Environment

$>$ Small Temperature Effect

Limited Orientation Effect 
Two different types of pressure transducers were need for these experiments. One was a differential pressure transducer. Differential pressure transducers measure a pressure difference between two locations. The other type was an absolute pressure transducer. An absolute pressure transducer measures the pressure caused by the fluid medium with reference to a vacuum. The two pressure transducers chosen for these experiments were a Viatran Model 274 differential pressure transducer and an Omega Model PX 176 absolute pressure transducer. The differential pressure transducer (Viatran) can be seen in Figure 1. See Appendix IX and X for manufacturer specification sheets. The absolute pressure transducer (Omega 176) can be seen in Figure 2.

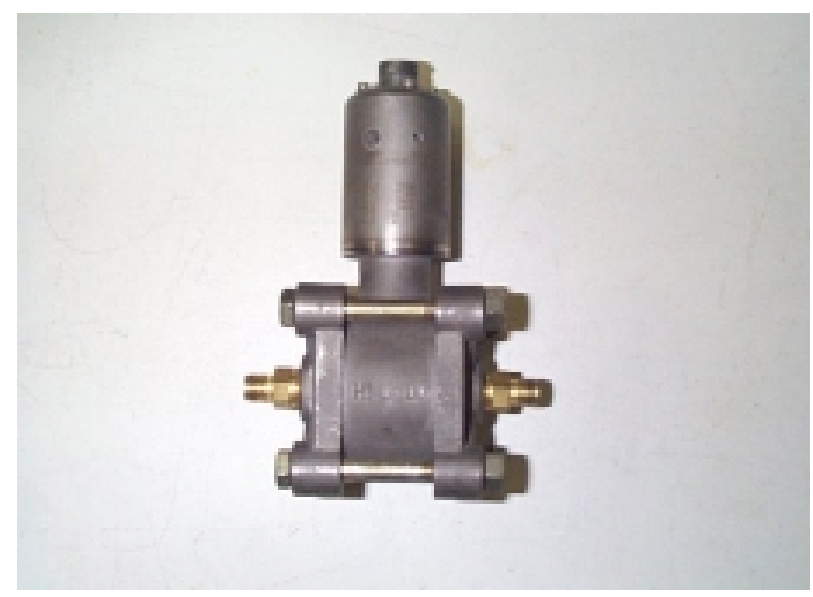

Figure 1 Viatran Model 274 Differential Pressure Transducer

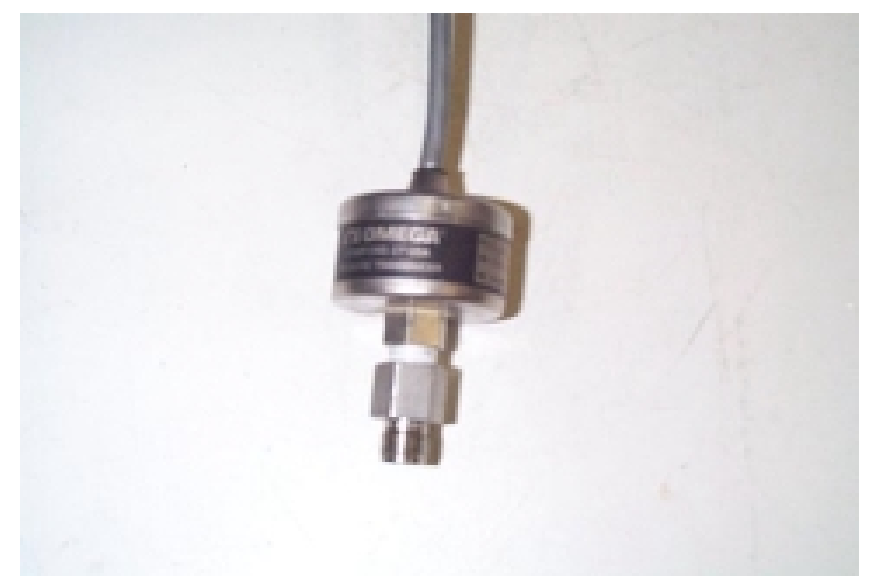

Figure 2 Omega PX 176 Absolute Pressure Transducer 
Both the Omega PX 176 and the Viatran 274 were calibrated using a Heise handheld LCD Digital Calibrator Type PTE-1 Pressure, Temperature, Voltage, and Current Measurement unit. The Heise offers an accuracy of .0076 in of $\mathrm{Hg}$ for the absolute pressure transducer calibration and $+/-.06$ in of $\mathrm{H}_{2} \mathrm{O}$ for the differential pressure transducer calibration.

\subsection{Cold Bench Setup \& Experiments}

This section begins with the layout of the cold bench, and then each device that was tested will be discussed in terms of installation requirements. The components and their purpose will also be discussed as well as procedures used for testing.

\subsubsection{Cold Bench Layout}

The cold bench was set up in one of the testing rooms at the WVU EERL. An air compressor capable of supplying least $1000 \mathrm{scfm}$ supplied the low-pressure air for the cold bench. A gate valve was used to control the flowrate from the line. The air then travels into a water-air heat exchanger after the gate valve and used in house water as the cooling agent. After exiting the heat exchange the air traveled through the air filter. Upon exiting the air filter the air flowed through the LFE then into the devices being tested after which it was released into the atmosphere. The setup was regularly checked for leaks at the pressure ports as well as at the line junctions. A schematic of the cold bench can be seen in Figure 3. 


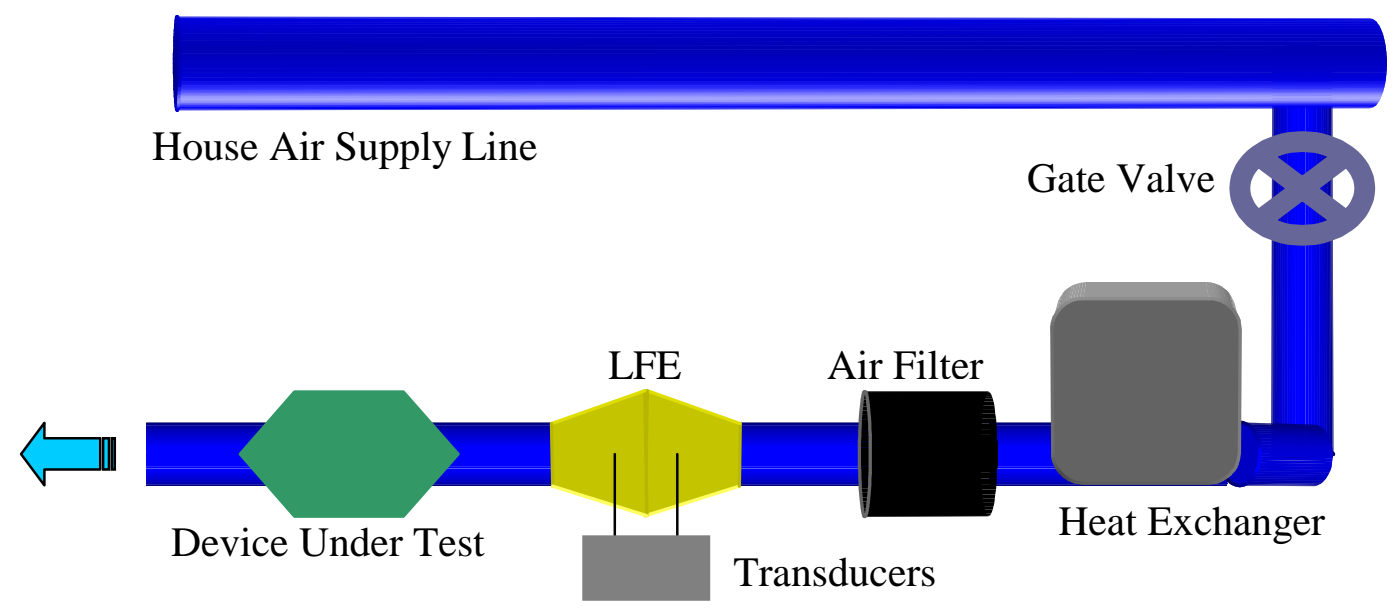

Figure 3 Cold Bench Layout

\subsubsection{Installation Requirements}

This section covers the requirements for the proper installation of each device and the placement of additional equipment used during testing. The minimal required straight run of pipe for fully developed flow were used for testing.

\subsubsection{Meriam Instruments Laminar Flow Element}

The purpose of the cold bench experiments was to determine the best devices for further testing in the exhaust. This was done by comparing each device to a reference flowmeter and checking the results for accuracy. The reference flowmeter used in these experiments was a Laminar Flow Element (LFE) from Meriam Instruments. The LFE was chosen because of is high accuracy and is currently used at the EERL as a primary flow device. The LFE offers a nearly linear relationship with differential pressure where most pressure related devices have a square root relationship.

The chosen LFE can measure a maximum flowrate of 964.95 acfm at a differential pressure of 8 inches of water and $70^{\circ} \mathrm{F}$. This was approximately the upper limit of flowrate from the engines to be tested. A J type thermocouple was placed downstream of the LFE to minimize disturbance of the flow. According to the LFE manual the 
requirements for fully developed flow was 10 diameters upstream (60 inches) and 5 diameters downstream (30 inches). Since an LFE is capable with only clean gas an air filter was placed upstream. The LFE also had an upper temperature limit of $150^{\circ} \mathrm{F}$. To maintain an acceptable air temperature a heat exchanger was placed in line using house water as the cooling agent. The heat exchanger was used to cool the air because excessive heat caused by the compressor unit use to supply the air. See Appendix I for calculations, a calibration sheet, and a letter of certification. The LFE used for the cold bench testing can be seen in Figure 4.

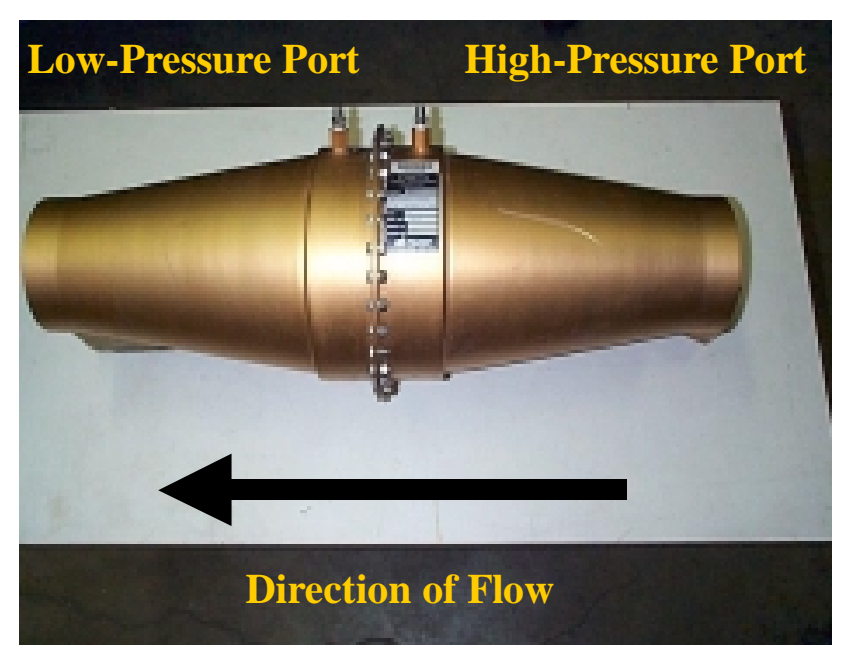

Figure 4 Meriam Instruments Laminar Flow Element

\subsubsection{Accutube \& Annubar}

Both the Accutube and Annubar required the same pipe geometry for fully developed flow. The upstream requirement for fully developed flow following an elbow, which is in plane with the probe, is 12 diameters (60 inches) and 4 diameters (20 inches) downstream. A J type thermocouple was placed approximately $1 \frac{1 / 2}{2}$ diameters downstream. The absolute pressure sensor was place 1 diameter downstream and was rotated approximately $45^{\circ}$ from the probe to reduce flow disturbance. The Accutube was 
tested two different ways. The first test consisted of a single Accutube inserted in the flow stream and the second test crossed two Accutubes at right angles in the flow stream. The high side ports were connected together and the low side ports were connected together. By connecting the ports together an average reading would be presented. The goal here was to increase the spatial resolution of the cross sectional area in case of poor flow symmetry. This decreases the effect of small vortices and disturbances. The probes were inserted perpendicular to each other and separated by 1 diameter. The Annubar tested can be seen in Figure 5 and the Accutubes tested can be seen in Figure 6.

High-Pressure Port

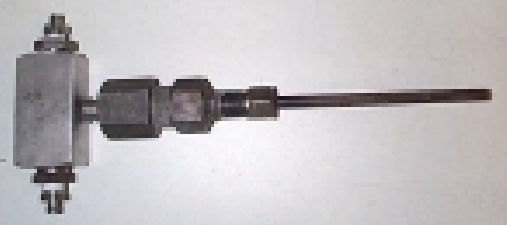

Low-Pressure Port

Figure 5 Annubar Diamond II, Dieterich Standard

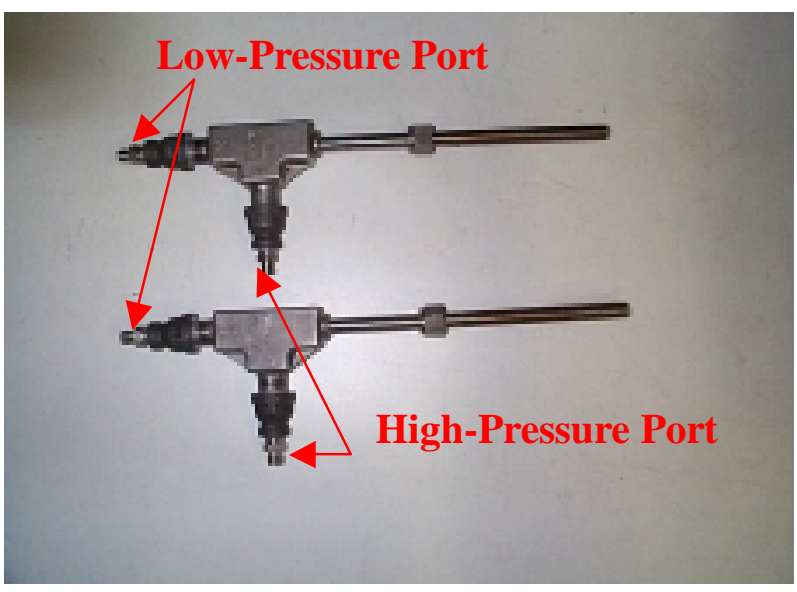

Figure 6 Meriam Instruments Accutube 


\subsubsection{Hot Film Anemometer}

The hot film anemometer chosen to be tested was a Sierra Series 620S Fast Flo Insertion Mass Flow Meter. The recommended upstream straight runs of pipe is 10 diameters (60 inches) and the downstream straight runs of pipe is 5 diameters (30 inches). The hot film anemometer was calibrated for flow at $70^{\circ} \mathrm{F}$ and at 1 atmosphere of pressure so a $\mathbf{J}$ type thermocouple was placed approximately 2 diameters downstream for temperature compensation purposes. The 620S Fast Flo Insertion Mass Flow Meter can be seen in Figure 7.

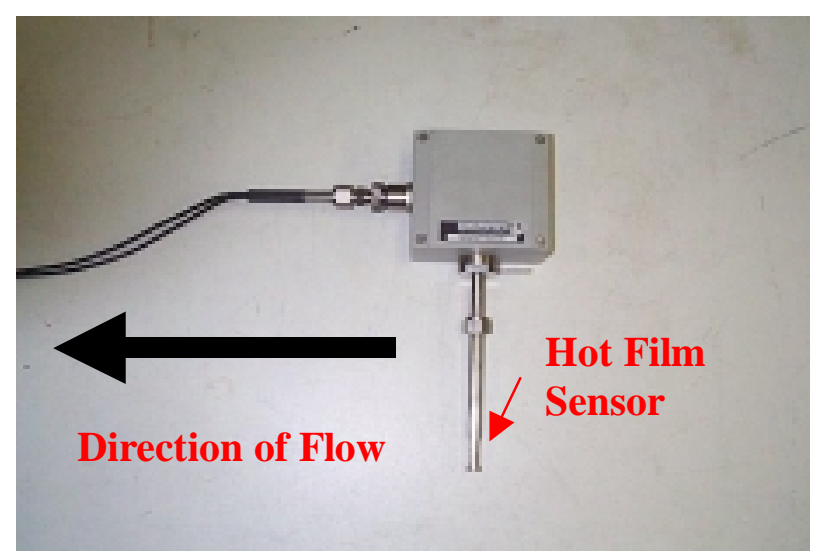

Figure 7 Sierra Series 620S Fast-Flo Insertion Mass Flow Meter

\subsubsection{Pitot Static Tube}

Dwyer, the manufacturer of the Pitot Static Tube that was tested recommends $81 / 2$ diameters upstream (42.5 inches) and 11/2 diameters downstream (7.5 inches) for fully developed flow measurements. The absolute pressure tap was placed 2 diameters downstream of the probe. A $\mathrm{J}$ type thermocouple was placed 3 diameters downstream of the probe. Since traversing the pipe would be difficult in a test cell the manufacturer recommends placing the probe so that the tip is in the center of the duct and proceeding with the normal flow calculations. Once the average flow velocity was determined a 
correction factor of .9 should applied to the velocity to compensate for the probe placement. This correction factor was designed for flows that are turbulent with a symmetric flow profile. If the flow was not turbulent or does not have a symmetric flow profile than the accuracy of the devices greatly reduced. The test Pitot Static Tube can be seen in Figure 8.

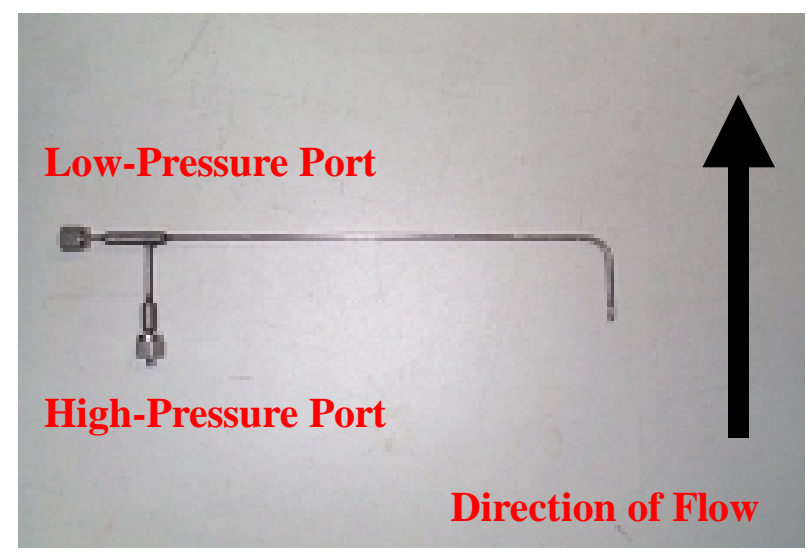

Figure 8 Dwyer Pitot Static Tube

\subsubsection{Venturi}

The venturi chosen to be tested was produced by Flo-Dyne Engineering Inc. The recommended straight runs of pipe for a venturi with a throat to pipe diameter ratio of .75 is 3 diameters upstream and 4 diameters downstream of the venturi [ASME MFC-3M1989]. These values change with the addition of valves and elbows. The reported value includes a single short radius $90^{\circ}$ elbow upstream. The absolute pressure measurement was taken from the high-pressure port on the venturi according to the manufacturer's instructions. A J type thermocouple was place approximately 4 diameters downstream from the high-pressure port. The venturi was spot welded to 5-inch exhaust line then band clamps were placed over the welds to eliminate leaks. The venturi can be seen in Figure 9. 


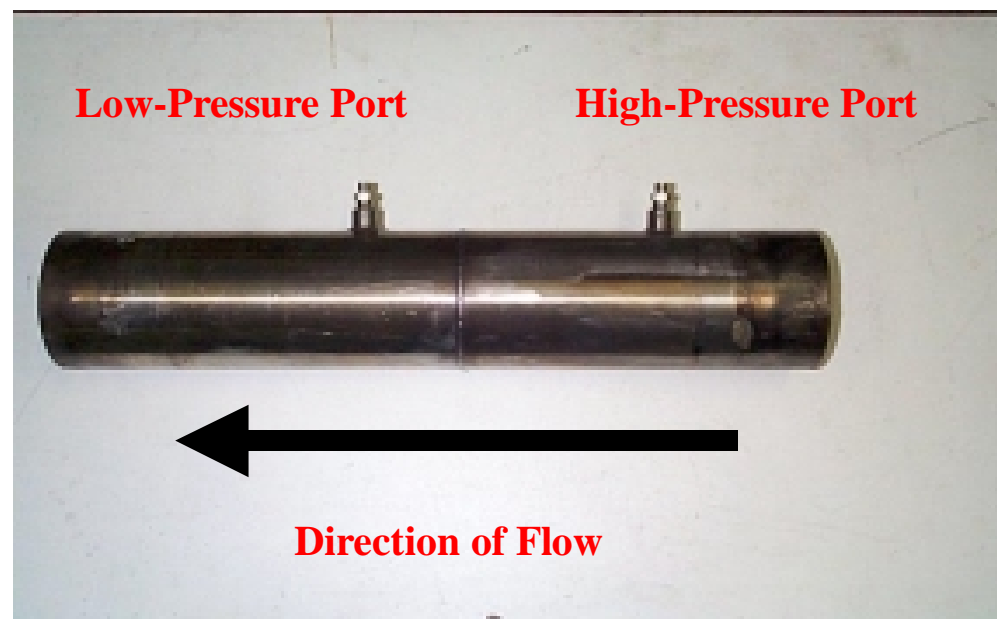

Figure 9 Flo-Dyne Venturi

\subsubsection{Vortex Shedder}

The vortex shedder tested was produced by J-Tec Associates, and is a model VE503.

The vortex shedder was tested in two ways. It was first tested in the original housing it came in, but this configuration only allowed a maximum flowrate of $450 \mathrm{scfm}$. This prompted the design of a new flow tube for the vortex shedder. The new housing allowed for a maximum flowrate of approximately $820 \mathrm{scfm}$. The new housing used a rectangular duct with 40 inches of duct upstream of the sensors and 20 inches downstream. The absolute pressure port was placed approximately 12 inches downstream and a $\mathbf{J}$ type thermocouple was placed approximately 8 inches downstream of the sensors. The original vortex shedder configuration can be seen in Figure 10 and the new design configuration can be seen in Figure 11. 


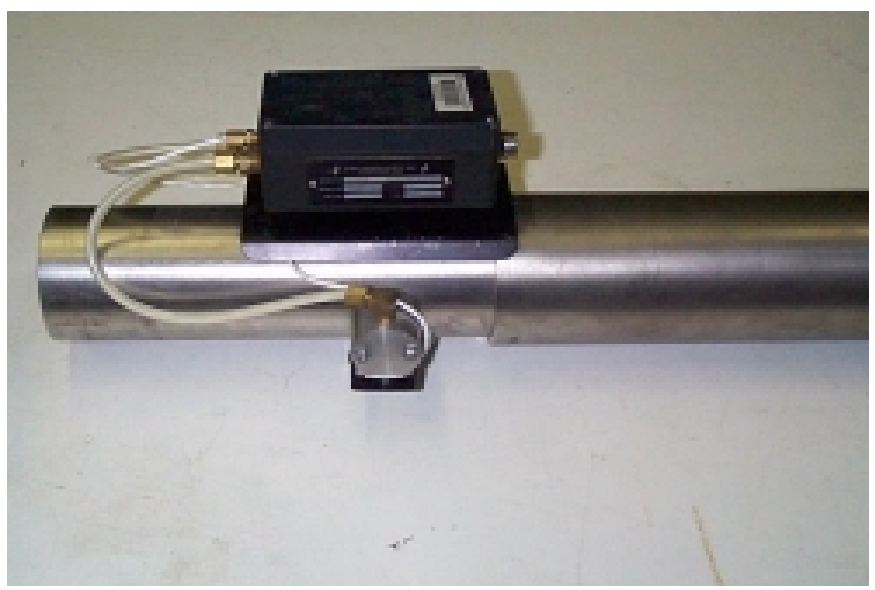

Figure 10 J-TEC VE503 Exhaust Vortex Shedder on original tube
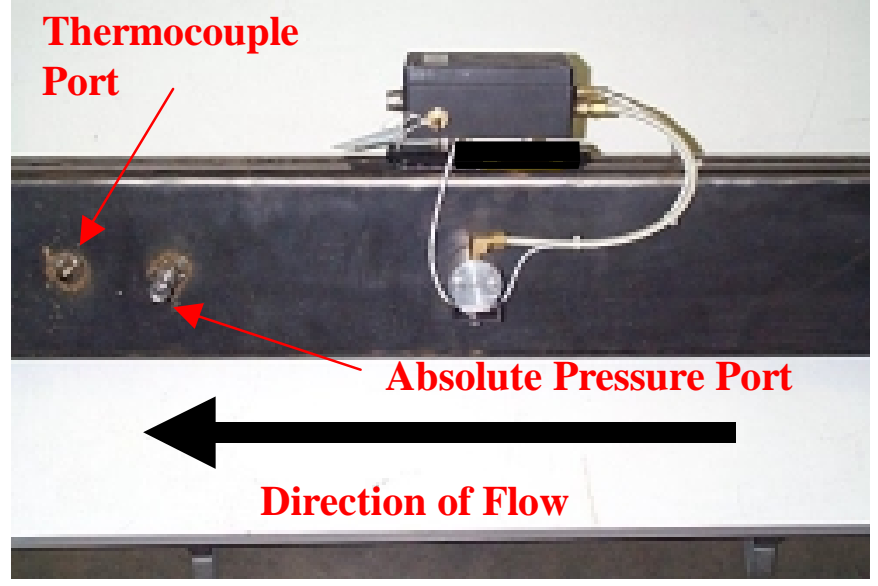

Figure 11 J-TEC VE503 Exhaust Vortex Shedder on new flow tube

\subsection{Cold Bench Testing Procedure}

Since all devices could not be tested at one time, a method that was relatively repeatable had to be used to compare the devices. The software configuration would only show raw voltages from the devices during testing, so to compute the flowrate post processing had to be performed. This prompted the use of voltage of the LFE being used as the set points for the tests.

The goal was to repeat the same point in every test as well as map the entire flow range of the device. The LFE had a maximum flowrate of $964 \mathrm{acfm}$ that corresponded to 8 inches of water drop. A Viatran differential pressure transducer with a range of 0 to 10 
inches of water was used with the LFE. This allowed the user to approximate a voltage to a rough flowrate value. Since 8 inches of water to correspond to 4 Volts, this became the upper limit of the tests. Points were then picked below this point to complete the range of flow. The intervals chosen were every quarter Volt ( 0.25 Volts). The flowrates would only be approximately equal between each test due to variations in absolute pressure, ambient temperature, and relative humidity.

Two tests were performed on each device. Three output value points were taken at zero flowrate and then the flowrate was increased to the next interval where the flow was allowed to stabilized and three data points were taken. Each data point was time averaged for one second at $1000 \mathrm{~Hz}$ each. This continued output of the LFE was 4 at which point the last data points were taken. At this point the relative humidity value was recorded using a sling psychrometer. Then the post processing was used to determine the flowrate for each device.

\subsection{Test Cell}

After the cold bench testing determined the most accurate devices from the group of candidates, further testing was performed in the engine test cell. This section begins with a section that covers the method of evaluating the devices. Since both engines used much of the same equipment, the shared equipment will be discussed next along with the significance of each component. A section discussing the engines used is next. Due to the fact that not all flow devices had the same flow range two different engines were used. The first engine was a Cummins ISM370 ESP and the second was a Navistar T444E. The following sections will cover the layout of components and ending with a section discussing the tests performed on each engine. 


\subsubsection{Method of Evaluation}

The engine testing was used to determine which device was best suited for a MEMS with the flowmeter placed in the exhaust. The cold bench testing cannot determine this because there are phenomena present in the exhaust that are not present in the cold bench testing. The phenomena include pulsations, high temperature, particulate matter, and turbulent flow. These phenomena may have unknown effects on the devices including the standard (LFE) by which cold bench testing was compared. This forces a need for other means of comparing the results of the testing. The new method of comparing the device uses the concentration of $\mathrm{CO}_{2}$ as a new standard. The new method is a dilute $\mathrm{CO}_{2}$ comparison. The goal was to compare the concentration of $\mathrm{CO}_{2}$ from the dilute measurements to the concentrations from raw measurements.

The dilute system uses a constant volume sampling system so a constant known amount of air is drawn into the dilution tunnel. The $\mathrm{CO}_{2}$ analyzer gives an output in the form of a percentage from a $\mathrm{CO}_{2}$ parts per million (ppm) to total flowrate ppm ratio. Since the flowrate is constant it is fairly simple to calculate a value of $\mathrm{CO}_{2}$ in grams per second.

The raw sampling system is used to determine the concentration of $\mathrm{CO}_{2}$ based upon the flowrate reported by the LFE. The $\mathrm{CO}_{2}$ analyzer used for the raw sampling system is the same as the one used for the dilute system except the raw exhaust $\mathrm{CO}_{2}$ analyzer was calibrated for a higher ppm value. The concentration of $\mathrm{CO}_{2}$ is determined by the same calculation except the total flowrate is not constant. Where the dilute system has a constant volume, the raw system uses values directly from the exhaust pipe, leaving out the dilution tunnel and the CVS system. This causes the total flowrate to change in the 
calculation for $\mathrm{CO}_{2}$. The concentrations of $\mathrm{CO}_{2}$ from the raw measurements are then compared to the dilute measurements. This shows the accuracy of the LFE in determining the total flowrate through the engine. If a correction factor is needed one can be determined from this data resulting in an adjusted LFE flowrate. The LFE can then be used as a standard for which all other devices are compared against.

\subsubsection{Shared Equipment}

This section discusses the equipment used by both the Cummins and Navistar engines. The discussion begins with the engine dynamometer, then the dilution tunnel followed by the CVS, after which comes the raw exhaust sampling system, and ending with the $\mathrm{CO}_{2}$ analyzers.

\subsubsection{Engine Dynamometer}

The dynamometer used for engine testing at the WVU EERL is a GE 550-hp direct current engine dynamometer. The dynamometer was used to apply a load to the engine as well as for motoring the engine. The dynamometer is connected to the engine via a drive shaft. The dynamometer was controlled by a computer program developed inhouse.

\subsubsection{Dilution Tunnel}

The purpose of the dilution tunnel in engine testing was to dilute the raw exhaust with larger quantities of conditioned atmospheric air. This mixing lowers the dew point temperature of the mixture. This eliminates condensation from forming in the sample lines and analyzers, which would alter the exhaust concentration values. 


\subsubsection{Constant Volume Sampling System}

The CVS system was designed to provide a known quantity of air for the calculation of the massrate of $\mathrm{CO}_{2}$. This can be done two ways according to the CRF 40 Part 86 Subpart N. The first method is a positive displacement pump and the second is a critical flow venturi. The system in use at the EERL was a critical flow venturi. The critical flow venturi will only allow a constant amount of air to pass through part of which is the exhaust from the engine. This constant amount of total flowrate is used in the calculation of $\mathrm{CO}_{2}$ concentrations. The amount of air was said to be constant, but the amount did change slightly due to temperature fluctuations during the test. The constant volume sampling system used a critical flow venturi, which was dependent on absolute pressure and the density of the fluid. The fluctuating temperature caused changes in the density of the fluid.

\subsubsection{Raw Exhaust Sampling System}

The raw exhaust sampling system is made up of several components whose purpose was to deliver the sample stream to the analyzers in a manner in which the analyzers can process the sample with no interference from water. The components that make up the raw exhaust sample system are a sampling probe, heated lines, a heated head pump, and a thermoelectric chiller. The sampling probe had a 0.25 -inch outside diameter made of stainless steel tube with nine sampling holes as stated in the CFR 40 Part 89 Subpart E. A temperature control was used to maintain a desired temperature in the heated lines. The temperature of the line was above the dew point temperature so water will not form and absorb some of the exhaust constituents. The purpose of the heated head pump was to transport the sample from the probe to the analyzers. The thermoelectric chiller was used 
to remove water and reduce the sample stream temperature to levels acceptable to the analyzers.

\subsubsection{5 $\mathrm{CO}_{2}$ Analyzers}

Since $\mathrm{CO}_{2}$ concentration was the standard by which the devices were being compared much attention should be paid to the analyzers and their accuracy. Two different analyzers were used for engine testing, but both operate under the same principal. The dilute system used a Rosemount Analytical Model 880A Non-Dispersive Infrared Analyzer, and the raw measurement system used a Rosemount Analytical Model 868 Non-Dispersive Infrared Analyzer. These analyzers used an infrared beam that was split into two identical beams. One beam passed through a cell containing a reference gas and the other beam passed through a cell with flowing sample gas. As the beam flowed through the sample gas some of the infrared energy was absorbed by the component being measured. The amount of energy absorbed was proportional to the concentration of the component of interest. The analyzers were designed to sample different concentration values of the components in the sample stream. This was achieved by calibrating the analyzers against samples of known concentration.

\subsection{Engines}

Some of the devices tested had different flow ranges, so to ensure that each device was tested at its greatest resolution more than one engine had to be used. The two engines used were a Cummins ISM370 ESP (10.8L, 99MY) and the second was a Navistar T444E (7.3L, 94MY). In Table 2 relevant information about each engine is listed. The Cummins engine was used to test the venturi, the Accutube, and the Annubar while the Navistar was used to test the vortex shedder in the original and new tubes. 


\begin{tabular}{|l|c|c|}
\hline & Cummins ISM370 ESP & Navistar T444E \\
\hline Ignition Type & Compression & Compression \\
\hline Injection & Direct & Direct \\
\hline Cylinder Configuration & In-Line 6 & V-8 \\
\hline Bore (inches) & 5.92 & 4.11 \\
\hline Stroke (inches) & 5.79 & 4.18 \\
\hline Displacement (liters) & 10.8 & 7.3 \\
\hline Compression Ratio & $16.3: 1$ & $17.5: 1$ \\
\hline Peak Torque & $1350 \mathrm{ft}-\mathrm{lbs}$ & $480 \mathrm{ft}-\mathrm{lbs}$ \\
\hline Rated Power & $370 \mathrm{hp}$ & $185 \mathrm{hp}$ \\
\hline $\begin{array}{l}\text { Approximate Maximum } \\
\text { Flowrate }\end{array}$ & $750 \mathrm{scfm}$ & $430 \mathrm{scfm}$ \\
\hline
\end{tabular}

Table 2 Test Engine Information

\subsection{Test Cell Layout}

This section discusses the layout used in the test cell. The basic layout with components in place can be seen in Figure 12.

The air used for the intake on the test engines was conditioned before it entered the test cell. After the air was conditioned it traveled through the LFE then into the turbocharger, and than through an intercooler. The air then passed through the manifold into the engine, through the turbocharger, and on through the flow measurement device. At this point the raw exhaust sample was taken. The sample traveled through the heated line into the heated head pump and through the thermoelectric chiller into the raw exhaust analyzer. The rest of the exhaust travels into the dilution tunnel where the exhaust was mixed with additional conditioned air. The mixture traveled down the dilution tunnel a minimum of ten diameters (to ensure proper mixing) at which point the dilute sample was taken and sent to the analyzers through another pump. The remainder of the exhaust goes through the CVS, which consists of a critical flow venturi, and a blower system then the mixture was expelled into the atmosphere. 


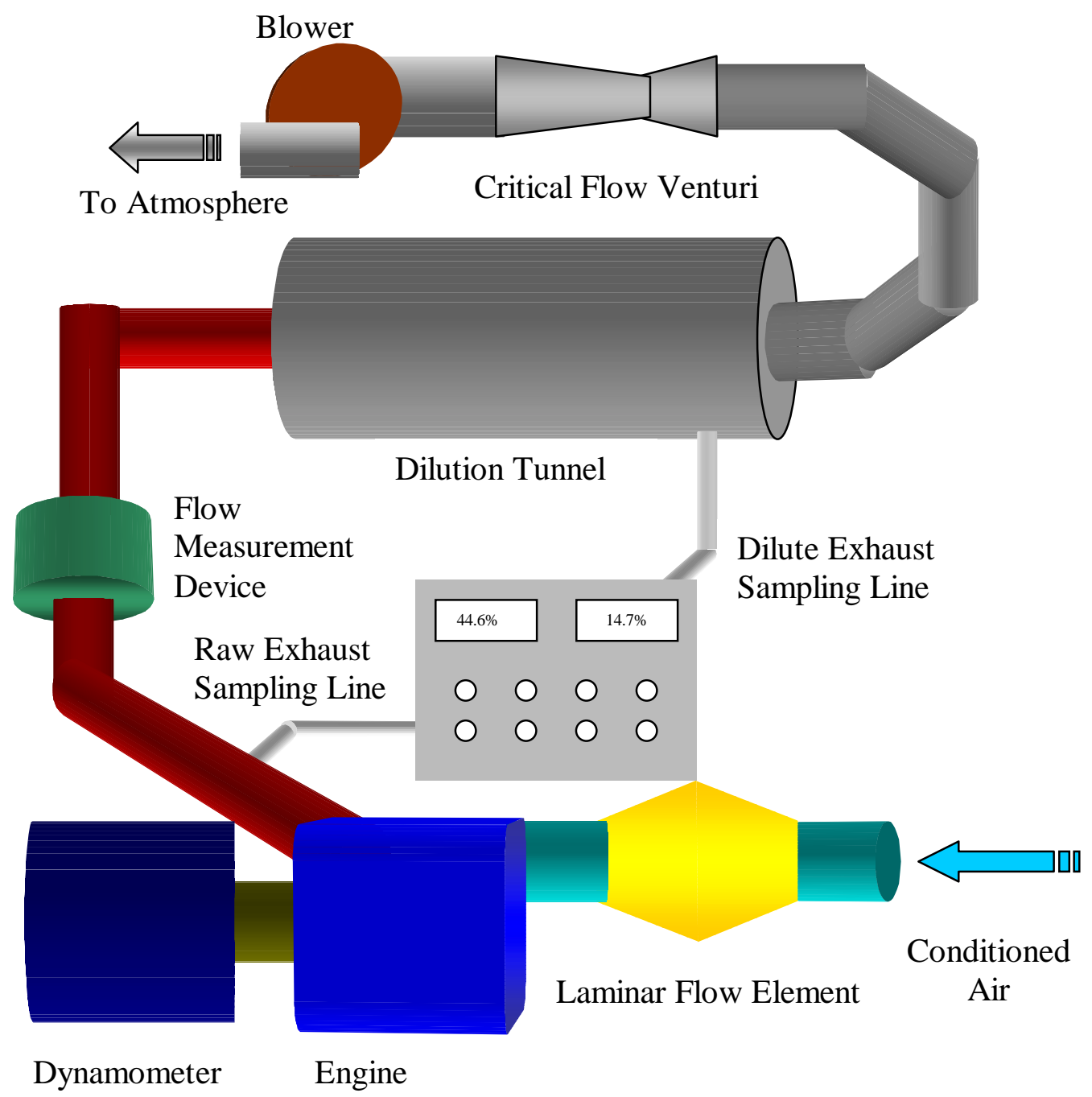

Figure 12 Test Cell Layout

\subsection{Test Cell Testing Procedure}

To ensure the devices operated properly in a harsh environment, the engines were run at several different speeds and torque settings within their envelop of operation. The purpose of was to ensure the devices could handle the varying flowrates, temperature fluctuations, and pulsations present in the exhaust line, and other undesirable conditions 
that may cause failure to the device. The tests consisted of six steady state modes each with different engine speed and load. The steady state tests used can be seen in Table 3 .

\begin{tabular}{|c|c|c|c|c|c|}
\hline & & \multicolumn{2}{|c|}{ Cummins ISM370 ESP } & \multicolumn{2}{c|}{ Navistar T444E } \\
\hline Mode & $\begin{array}{c}\text { Duration of } \\
\text { Mode seconds }\end{array}$ & $\begin{array}{c}\text { Engine Speed } \\
\text { rpm }\end{array}$ & $\begin{array}{c}\text { Load } \\
\text { ft-lbs }\end{array}$ & $\begin{array}{c}\text { Engine Speed } \\
\text { rpm }\end{array}$ & $\begin{array}{c}\text { Load } \\
\text { ft-lbs }\end{array}$ \\
\hline $\mathbf{1}$ & 240 & 710 & 0 & 710 & 0 \\
\hline $\mathbf{2}$ & 240 & 1200 & 638 & 1500 & 238 \\
\hline $\mathbf{3}$ & 240 & 1800 & 1100 & 2300 & 420 \\
\hline $\mathbf{4}$ & 240 & 1200 & 1275 & 1500 & 475 \\
\hline $\mathbf{5}$ & 240 & 1800 & 539 & 2300 & 210 \\
\hline $\mathbf{6}$ & 240 & 710 & 0 & 710 & 0 \\
\hline
\end{tabular}

Table 3 Test Procedures for Test Cell Experiments

During the test continuous data was taken from the output of each flow device.

However, the dilute $\mathrm{CO}_{2}$ data was only taken for the last 90 seconds of each mode even though the modes were 240 seconds long. The purpose of this was to ensure that the engine has reached an approximate steady condition. The 240 seconds is a trade-off between reaching thermal equilibrium in the engine and the length of each mode. In Figures 13 and 14 the engine maps for the Navistar and Cummins engines can be seen along with the set points used for each test. 


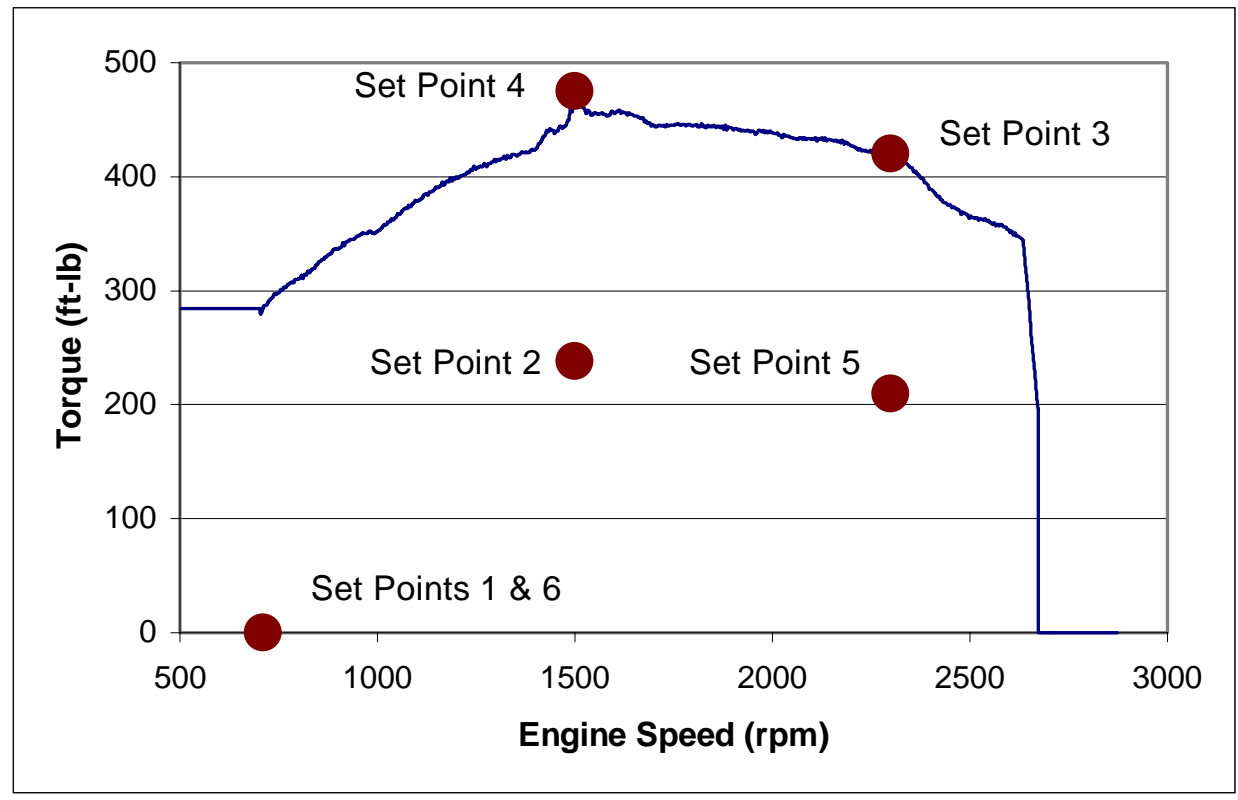

Figure 13 Engine Map for the Navistar with Test Set Points

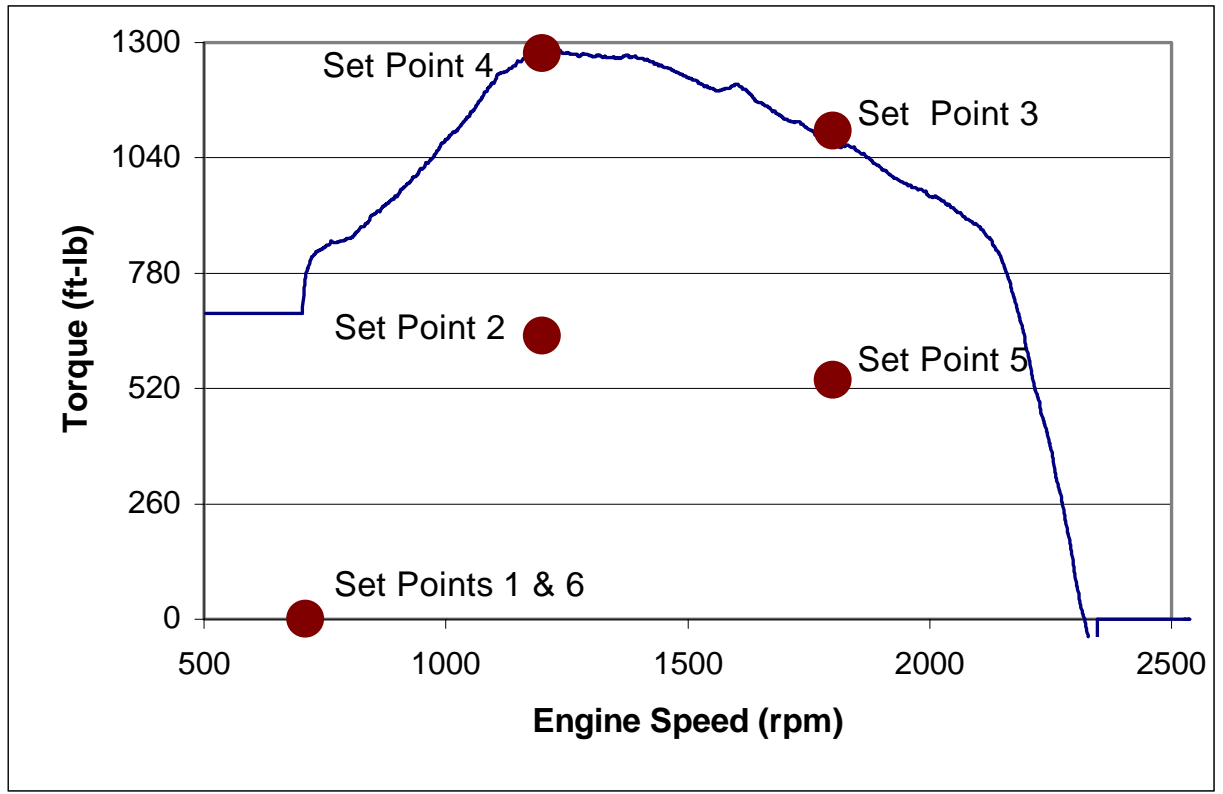

Figure 14 Engine Map for the Cummins with Test Set Points 


\section{Experimental Results}

This section discusses the results of the experiments performed on the cold bench as well as in the test cell. The first section discusses the work completed on the cold bench and ranks the devices based on a comparison with the LFE. The second section discusses work done in the test cell and evaluates the devices based on flowrate reported by the LFE.

\subsection{Cold Bench Test Results}

This portion of the testing compares various devices to a reference. The reference, a LFE, was chosen because it has a high degree of accuracy and was used as the means of varying the flowrate through the engines at the EERL. The results are reported in two different ways. The first way is based upon the percent difference from the accepted standard at varying flowrates. The second graphically compares the flowrates of the LFE and the device being tested. The results can be seen in graphical form as well as in the form of a table, which gives details on the average absolute percent difference as well as a standard deviation value for each device. The graphs for each device are a composite of all tests performed. For a complete set of equations used for comparing the device see Appendix I.

\subsubsection{Accutube, Meriam Instruments}

Two different configurations were run using the Accutube flow device. The first test consisted of a single Accutube inserted into the flow. The second test consisted of two Accutubes crossed in the flow stream. The goal in doing this was to increase the resolution of the flow device. The ports from both flow devices were connected together so an average pressure reading would be reported. The results of the cold bench testing 
on the single Accutube and double Accutubes can be seen in Figures 15 and 16 respectively. An alternative method of presenting the results can be seen in Figure 17.

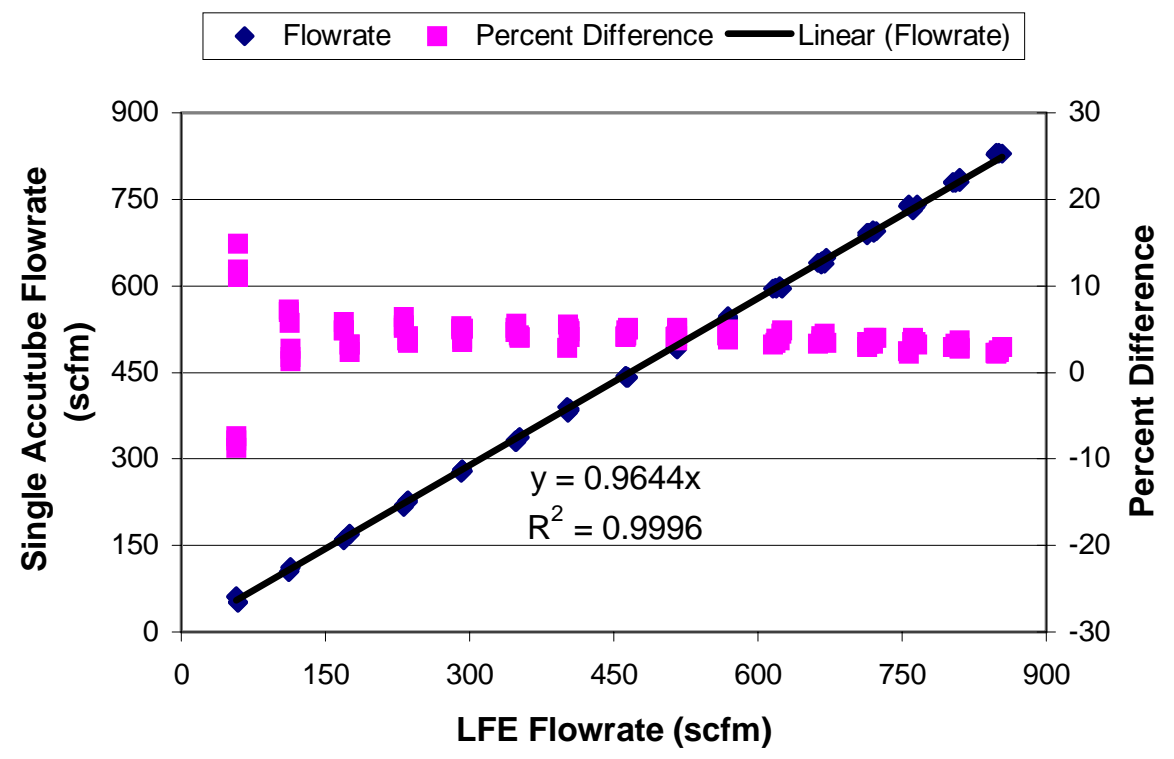

Figure 15 Single Accutube cold bench-testing results

The accuracy of the single Accutube appears to be flow dependent. At approximately $60 \mathrm{scfm}$ the percent difference was about $14.9 \%$, at $400 \mathrm{scfm}$ the percent difference was about $5.5 \%$ and at $850 \mathrm{scfm}$ the percent difference fell to about $2.9 \%$. Notice that the results of the Accutube testing are very repeatable. Notice at the zero flow position the Accutube reported a value of approximately 30-scfm, which could be attributed to transducer drift. The percent difference appears to decrease as the flow rate increases. A possible cause of this is the influence of Reynolds Number on the Accutube or the percent for this device is most noticeable at the lower flowrates. At the higher flowrate the percent difference caused by the percent error of the device decreases due to the increasing denominator (LFE flowrate). 


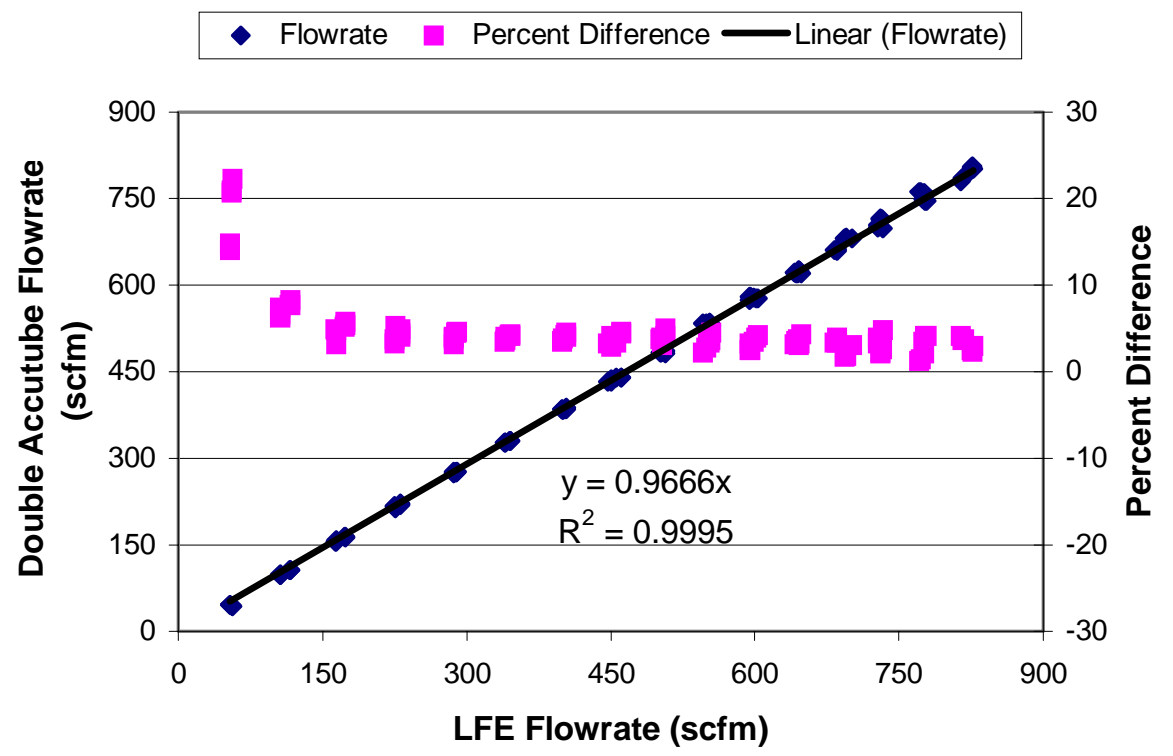

Figure 16 Double Accutube cold bench-testing results

The double Accutube appears to follow the same pattern as the single Accutube. The area of concern is once again low flowrates. At approximately $55 \mathrm{scfm}$ the percent difference was $22.3 \%$, at $400 \mathrm{scfm}$ the percent difference was $4.2 \%$, and at $825 \mathrm{scfm}$ the percent difference fell to $3.0 \%$. The results for the double Accutube are as repeatable as the case involving the single Accutube testing. The 30-scfm offset seen in the single Accutube test is not present in the double Accutube test. This may be due to the zero and spanning of the transducer or the added dead volume in the form of additional line required to connect the ports (see Fuller, 2001 for additional information). 
- Accutube $\square$ Percent Difference - Linear (Accutube)

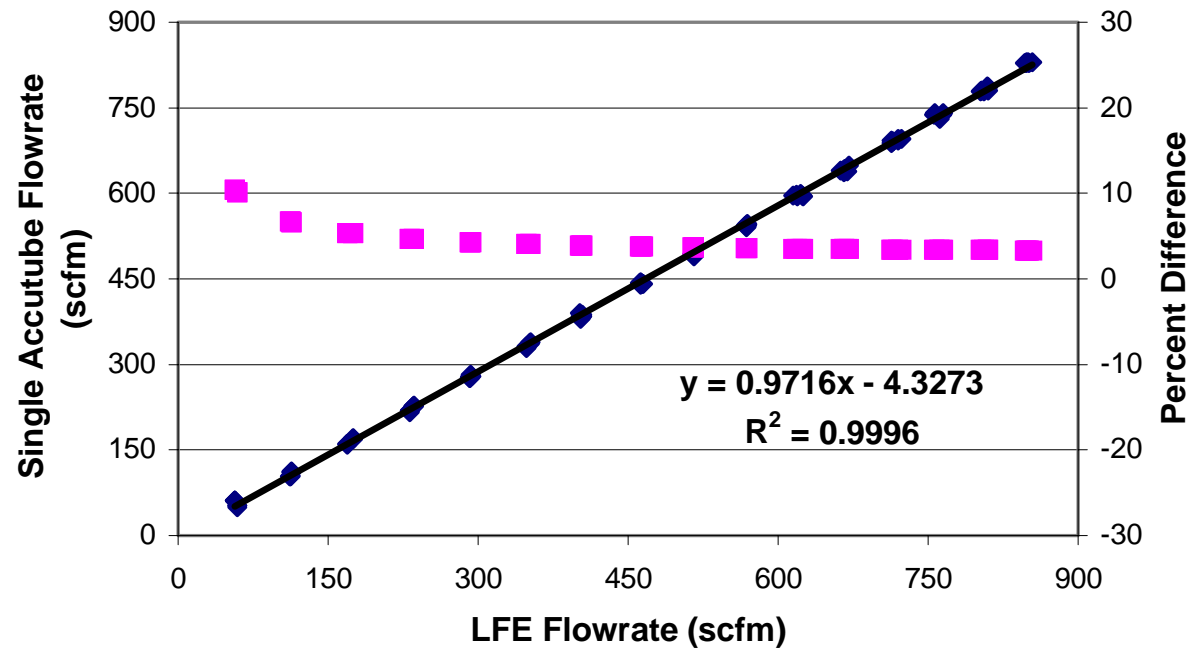

Figure 17 Results of Single Accutube Cold Bench Tests using a Non-Zero Intercept

This graph used a non-zero intercept. This shows the offset error and how is effect of the error is less apparent at larger flowrates. The percent difference curve was determined by using the best-fit equation with the LFE flowrate values to arrive at an expected Accutube flowrate. The expected Accutube results were than subtracted from the LFE results than divided by the LFE results than this quantity was multiplied by 100 to give a percent difference. The same analysis could be performed on each device but instead the a zero intercept was rest of the devices.

\subsubsection{Annubar Diamond II, Dieterich Standard}

One would expect the results from the Annubar testing to be similar to those seen in the Accutube tests since the devices are similar. Both devices operate on the same principle and have the same basic geometry with the exception of the probe design. It can be seen that this small difference in probe design can make a noticeable difference in the results. Even with a correction factor for Reynolds Number effect the Accutube is not 
as accurate as the Annubar and its diamond shape geometry which is unaffected by Reynolds Number. The results of the Annubar testing can be seen in Figure 18.

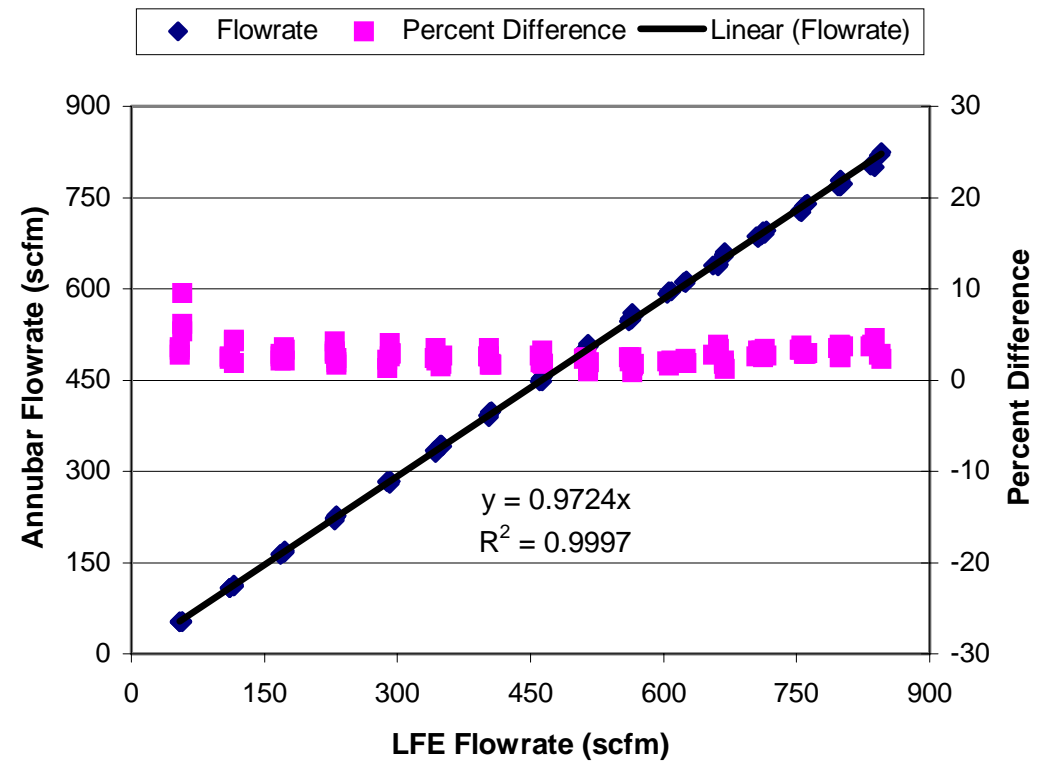

Figure 18 Annubar cold bench-testing results

The accuracy of the Annubar appears to follow the same pattern as the Accutubes. At approximately $60 \mathrm{scfm}$ the percent difference was $6.0 \%$, at $400 \mathrm{scfm}$ the percent difference was $3.5 \%$, and at $830 \mathrm{scfm}$ the percent difference was $3.6 \%$. The major differences between the Annubar and the Accutube are the Annubar starts out with a smaller percent difference and the Accutubes appear to decrease as the flowrate increases. Notice that the results of the Annubar tests are also repeatable as in the case of the Accutube tests.

\subsubsection{Hot Film Anemometer}

The hot film anemometer was chosen for further testing in hopes of a possible application as a flowmeter for the intake. The major concern of using a hot film anemometer is over the large temperature range in which the flow devices must operate. 
Even with the aid of the heat exchanger the effects of varying temperature can be seen on the hot film anemometer. The hot film anemometer has the same problem as the Pitot Static Tube. It too determines the flowrate based upon a measurement taken at one point in the flow, so flow disturbances can have a profound effect on its output. The results from the hot film anemometer testing can be seen in Figure 19.

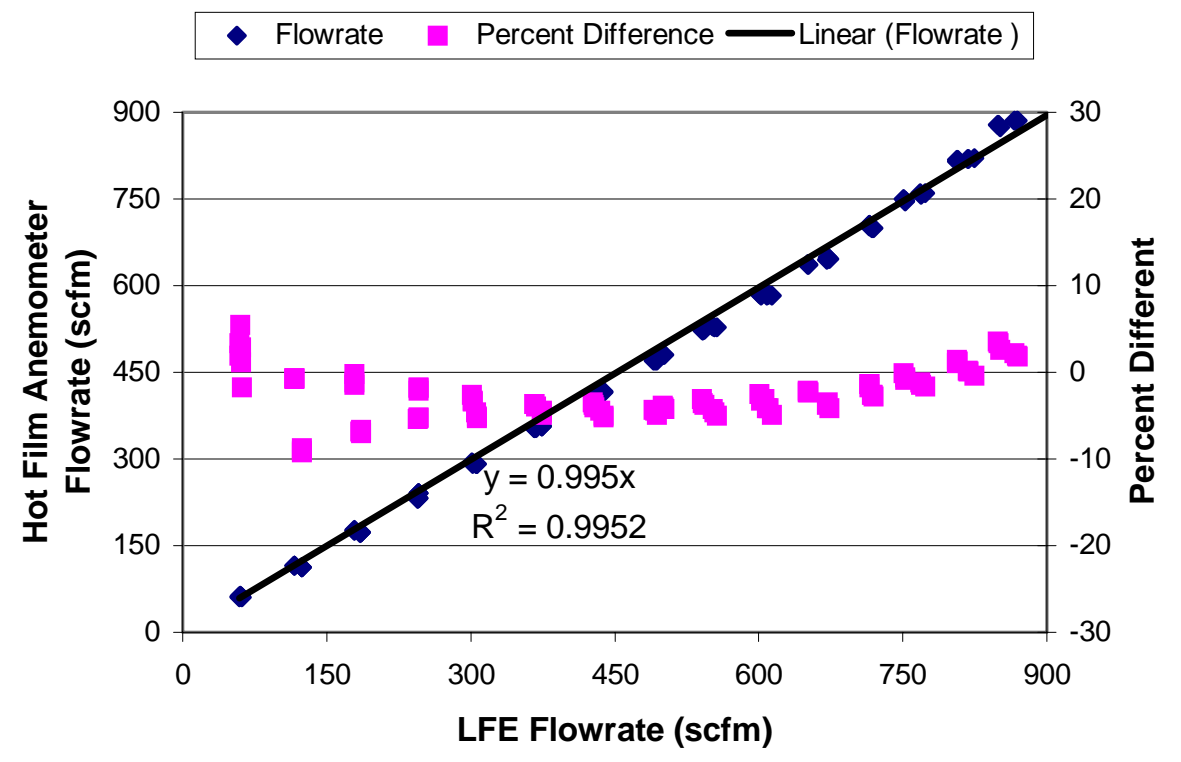

Figure 19 Hot Film Anemometer cold bench-testing results

The hot film anemometer performed better than it was expected to. At approximately $60 \mathrm{scfm}$ the percent difference was $5.5 \%$, at $425 \mathrm{scfm}$ the percent difference was $-4.0 \%$, and at $870 \mathrm{scfm}$ the percent difference was $1.8 \%$. This may be due to the electronics package, which accompanies the hot film anemometer. The package allows the user to zero and span as well as change the user full-scale range of the instrument. This offers better resolution of the flow. The hot film's largest obstacle is the elevated temperature in the exhaust stream. The hot film seemed to drift more than the venturi and averaging Pitots did in terms of repeatability of data. 


\subsubsection{Pitot Static Tube}

Pitot static tubes have been used for many different applications and much research has been performed on them over the years so it must be considered as a possible candidate. The major concern of using a Pitot static tube is they are greater affected by flow disturbances. This is due to the fact that the flow is determined from a single point taken in the flow. The results of the Pitot static tube tests are presented in Figure 20.

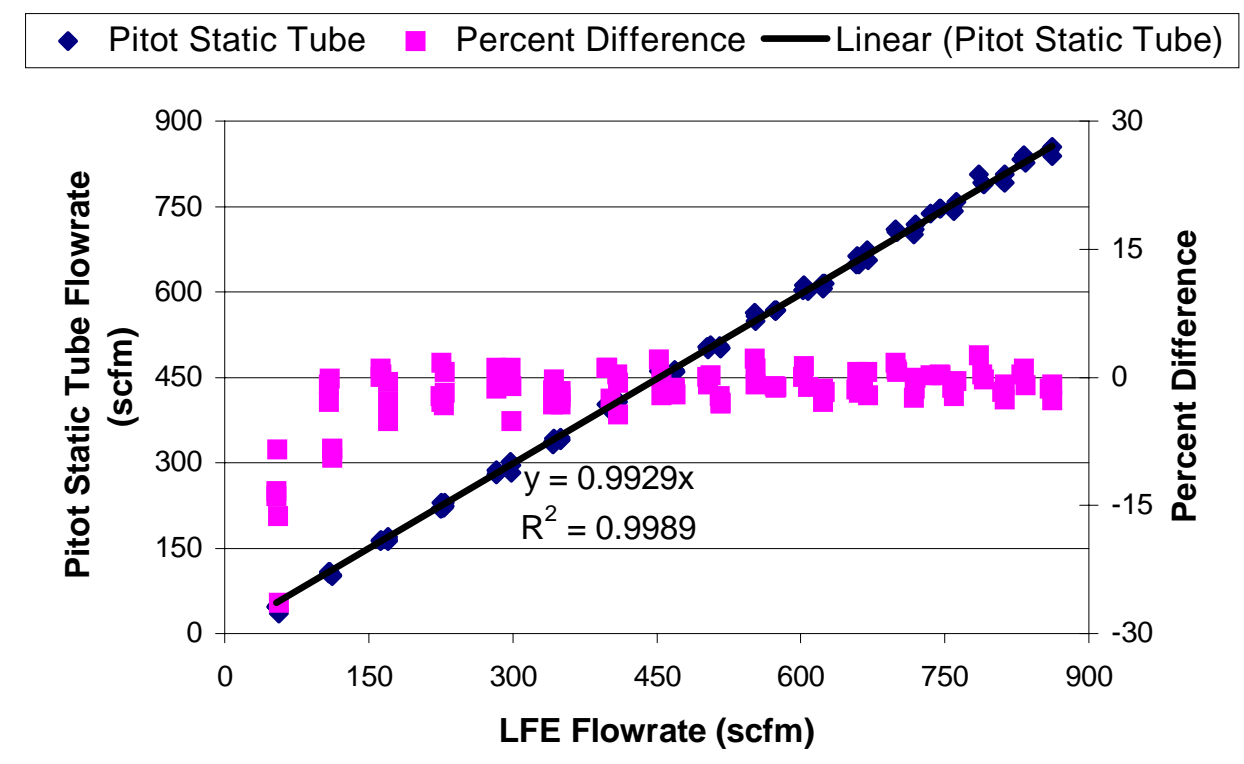

Figure 20 Pitot static tube cold bench-testing results

Upon inspection of the results of the Pitot static tube tests, one can see the data is not as repeatable as the Accutube and Annubar appear to be. This may be due to flow fluctuations, which were an initial concern with this device. Even with this scatter the Pitot Static Tube appears to closely agree with the indicated values from the LFE. At approximately $55 \mathrm{scfm}$ the percent difference was from $-8.5 \%$ to $-37.4 \%$, at $410 \mathrm{scfm}$ the percent was an average of $-0.6 \%$, and the percent difference was $-1.3 \%$ at $860 \mathrm{scfm}$. 


\subsubsection{Venturi}

The results from the venturi testing are presented in Figure 21.

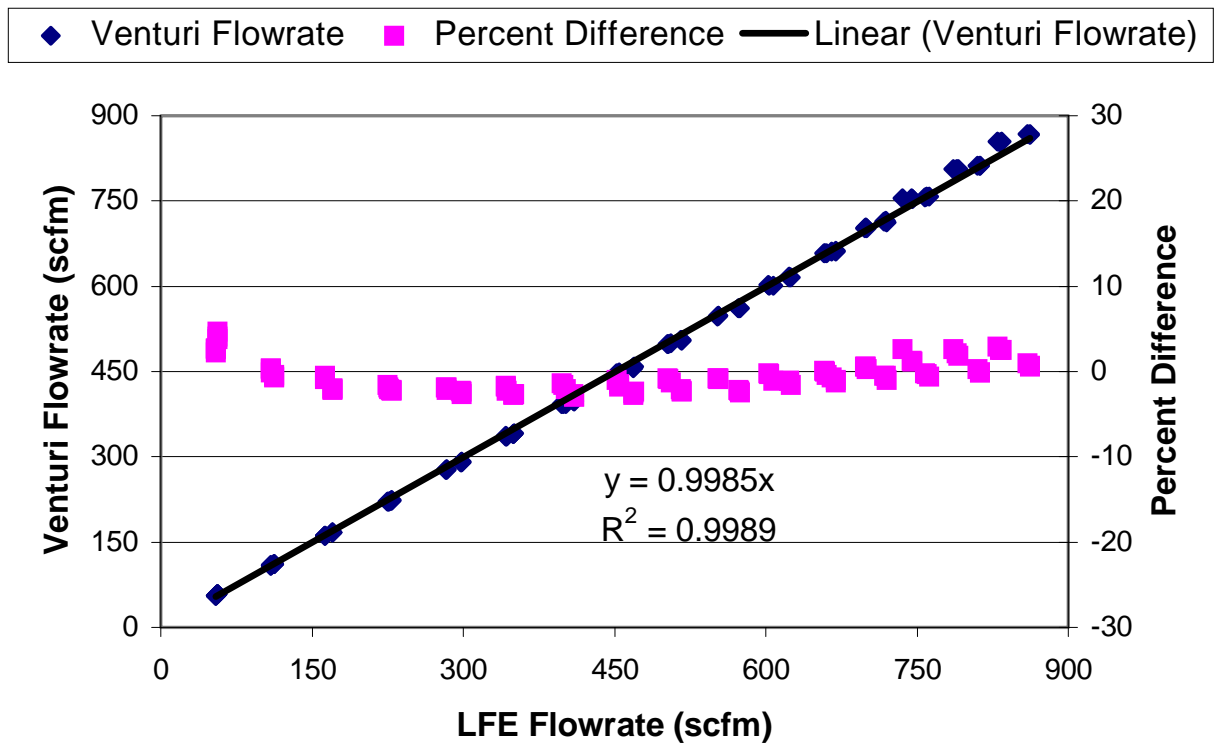

Figure 21 Venturi cold bench-testing results

The results from the venturi testing show that the data was very repeatable and closely agrees with the LFE. At approximately $55 \mathrm{scfm}$ the percent difference was $3.2 \%$, at 400 scfm the percent difference was $-1.7 \%$, and at $800 \mathrm{scfm}$ the percent difference was $1.0 \%$. The percent error is the best of any device thus far. The venturi even offers a better correlation at lower flowrates than does the Accutube or Annubar. The venturi does not have offset that appeared with the Accutubes and it offers the best linear relationship of all the devices.

\subsubsection{Vortex Shedder}

Two sets of tests involving the vortex shedder were performed. The first set of tests used the original flow tube. The second set of tests used a newly designed flow tube, 
which would increase the flow range of the device. The results from the tests can be seen in Figure 22 (original tube) and Figure 23 (new tube design).

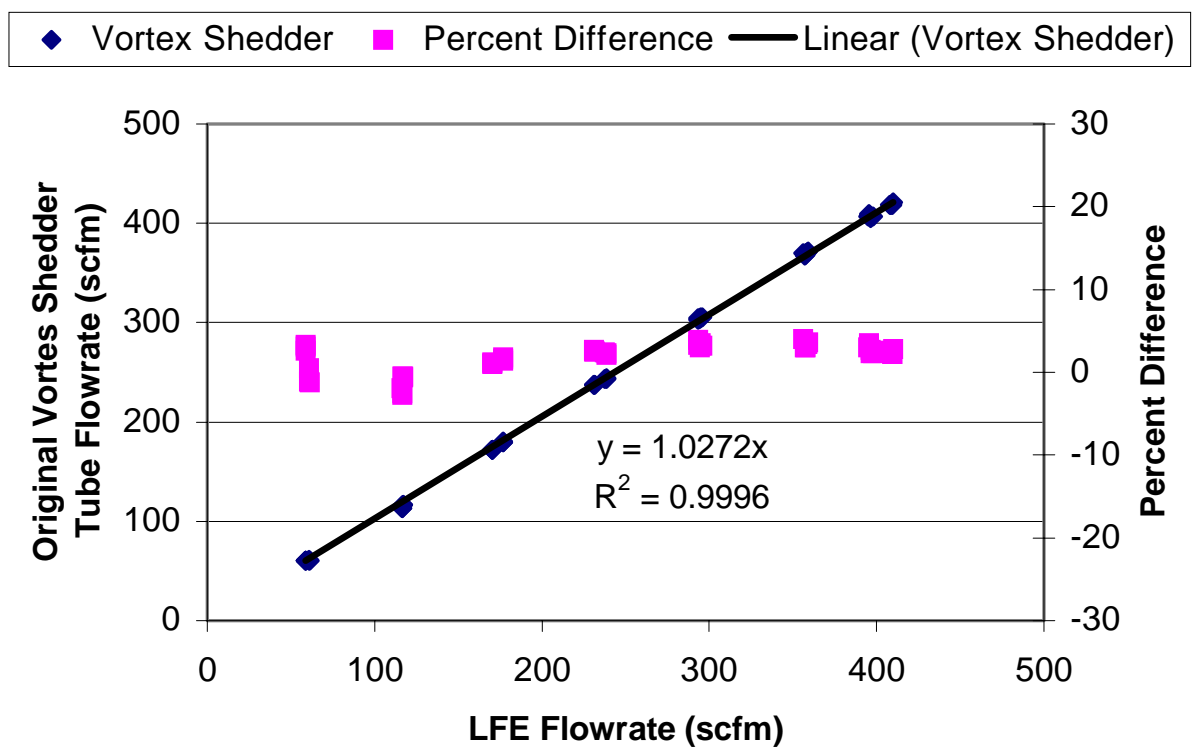

Figure 22 Original Tube Vortex Shedder cold bench-testing results

The original vortex shedder design performed very well in terms of repeatability and in agreement with the LFE. At approximately $60 \mathrm{scfm}$ the percent difference was $1.5 \%$, at $230 \mathrm{scfm}$ the percent difference was $2.5 \%$, and at $410 \mathrm{scfm}$ the percent difference was $2.6 \%$. The original vortex shedder was the only device that had a relatively constant percent difference for all test points. The percent difference for this device was among the best of the devices tested. The only drawback to this device is its limited flow range. For this reason a new tube design was tested. 


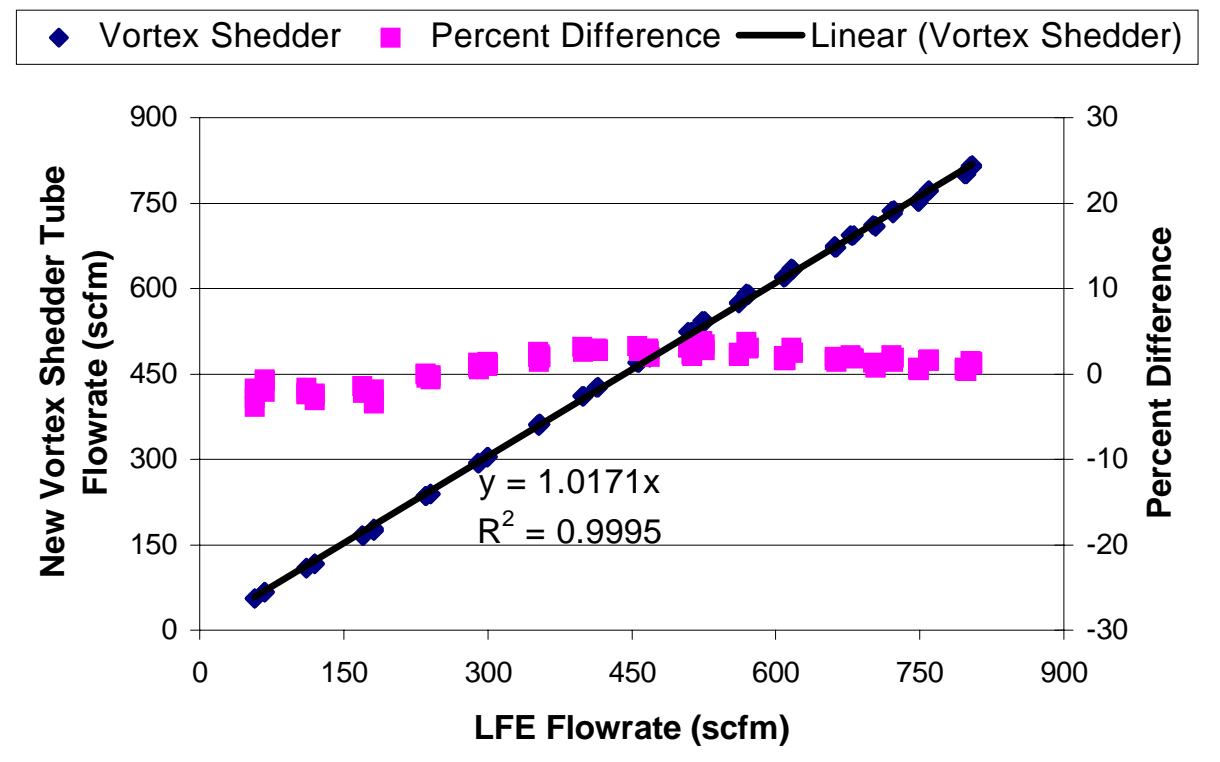

Figure 23 New Tube Vortex Shedder cold bench-testing results

The newly designed flow tube appears to show a close agreement with the LFE and the data points are repeatable. At $60 \mathrm{scfm}$ the percent difference was $-1.8 \%$, at $400 \mathrm{scfm}$ the percent difference was $2.6 \%$, and at $800 \mathrm{scfm}$ the percent difference was $0.7 \%$.

\subsubsection{Numerical Comparison}

The goal of this section is to show how well each device performed when compared to the LFE by a calculation of several comparative metrics. The methods of comparing the devices were an R-squared value, absolute average percent difference, and a standard deviation. Theoretically the result should be a line with a slope of one. If this were the case the device being compared to the LFE would match each point exactly. Since this is not the case a measure of how much the data point vary can be computed. This measure is R-squared value. The R-squared value can be understood as the proportion of the variance in the ordinate variable attributable to the variance in the abscissa variable. The absolute average percent difference shows a true value of differences by eliminating the 
affect of negative values that cancel the positive values, which results in an over all lower average. The standard deviation is a measure of how widely values are dispersed from the average value. The variables are all of equal weight. If the variable is less than one than the reciprocal is used. The four methods of comparison and the results can be seen in Table 4.

\begin{tabular}{|c|c|c|c|c|}
\hline & $\begin{array}{c}\text { Single } \\
\text { Accutube }\end{array}$ & $\begin{array}{c}\text { Double } \\
\text { Accutube }\end{array}$ & Annubar & Hot Film \\
\hline $\begin{array}{c}\text { Absolute Average } \\
\text { Percent Difference }\end{array}$ & 4.39 & 4.82 & 2.77 & 3.35 \\
\hline Standard Deviation & $\mathbf{2 . 6 1}$ & $\mathbf{3 . 6 7}$ & 1.07 & $\mathbf{3 . 1 2}$ \\
\hline R-squared Value & $\mathbf{0 . 9 9 9}$ & $\mathbf{0 . 9 9 9}$ & $\mathbf{0 . 9 9 9}$ & $\mathbf{0 . 9 9 8}$ \\
\hline Best Fit Equation & $\mathbf{0 . 9 6 4 x}$ & $\mathbf{0 . 9 6 6 x}$ & $\mathbf{0 . 9 7 2 x}$ & $\mathbf{0 . 9 7 9 x}$ \\
\hline & $\begin{array}{c}\text { Pitot Static } \\
\text { Tube }\end{array}$ & Venturi & $\begin{array}{c}\text { Original Vortex } \\
\text { Shedder }\end{array}$ & $\begin{array}{c}\text { Newly Designed } \\
\text { Vortex Shedder }\end{array}$ \\
\hline $\begin{array}{c}\text { Absolute Average } \\
\text { Percent Difference }\end{array}$ & 2.79 & 1.55 & 2.41 & 1.92 \\
\hline Standard Deviation & 4.99 & 1.68 & 1.66 & 1.90 \\
\hline R-squared Value & $\mathbf{0 . 9 9 9}$ & $\mathbf{0 . 9 9 8}$ & $\mathbf{0 . 9 9 9}$ & $\mathbf{0 . 9 9 9}$ \\
\hline Best Fit Equation & $\mathbf{0 . 9 9 2 x}$ & $\mathbf{0 . 9 9 8 x}$ & $\mathbf{1 . 0 2 x}$ & $\mathbf{1 . 0 1 x}$ \\
\hline
\end{tabular}

Table 4 Results of Cold Bench-Testing

In order to rank the devices an equation was developed which would penalize the device for being too far away from the appropriate value and reward it for being closer. The closer the result of the equation comes to one the better it performed in the test. The equation that was developed can be seen in Equation 8. Note that his is only one method for comparing the devices. If the outcome of the testing were different the use of another equation may have been needed. Since the standard deviation and the average absolute percent difference were not less than one this equation will suffice.

Device Ranking $=$ A.A.P.D. $* \mathrm{STDEV} * \mathrm{RSV} *$ Slope of Best Fit Equation $\quad$ Eq. 8

Where A.A.P.D. represents the absolute average percent difference, STDEV is the standard deviation, RSV is the R-squared term, and the slope of the best-fit equation can 
be found in Table 4. Table 5 shows the results and the final ranking of each device after the cold bench testing.

\begin{tabular}{|l|c|c|}
\hline \multicolumn{1}{|c|}{ Device } & Result of Equation & Ranking \\
\hline Venturi & 2.617 & 1 \\
\hline Annubar & $\mathbf{3 . 0 6 1}$ & 2 \\
\hline Newly Designed Vortex Shedder & 3.722 & 3 \\
\hline Original Vortex Shedder & 4.131 & 4 \\
\hline Hot Film Anemometer & 10.72 & 5 \\
\hline Single Accutube & $\mathbf{1 1 . 9 4}$ & 6 \\
\hline Pitot Static Tube & $\mathbf{1 4 . 0 6}$ & 7 \\
\hline Double Accutube & 18.35 & 8 \\
\hline
\end{tabular}

Table 5 Final Ranking after Cold bench Testing of Flow Devices

Based upon the results of the cold bench testing several devices were chosen for further testing in the test cell. The devices chosen were the Accutube, Annubar, venturi, and the vortex shedder. The hot film anemometer was not chosen based on its inability to deal with elevated temperatures and the deposition of particulate matter causes fouled results. The Pitot Static Tube was not chosen because it cannot account for the particulate matter present in the exhaust. The Accutube and vortex shedder will be tested with both methods evaluated on the cold bench.

\subsection{Engine Testing Results}

This section compares the devices that were found to be the best candidates based on the cold bench testing. The comparison took place on two different engines. This was done to accommodate the different flow ranges of the devices tested. The engines used and the specifications for each can be found in Section 3.4. The devices tested on the Cummins engine were the Accutubes (double and single), the Annubar, and the Venturi. The vortex shedder (original and new tube design) was tested on the Navistar engine. The first part of this section discusses the comparison of the LFE and the dilute methods 
using the $\mathrm{CO}_{2}$ concentrations followed by Cummins engine test results followed by the Navistar engine test results after which a final comparison of the devices is presented.

\subsubsection{Laminar Flow Element vs. Dilute Flow Measurements Methods}

This section is used to show the validity of using the LFE as a standard for comparing the devices in the test cell. The best method would be to compare all of the devices by means of $\mathrm{CO}_{2}$ comparison, which was the original intention of this thesis. After the test apparatus was dismantled, it was determined that the analyzer was not reporting correct values. To save the time of rerunning the entire set of tests, a series of test were run so the LFE could be evaluated against the dilute methods. This was done because the LFE was used on every test previously run so if a corrected value for the LFE could be determined then it could be used as a new standard for comparison.

The LFE was compared to the dilute methods in much the same way the devices were compared to the LFE in the cold bench testing. The reported data compares the LFE on one axis and the dilute method on another. The ideal results would be a slope of one and an $\mathrm{R}^{2}$ value of one. The percent difference is also reported for each test point. The results of the comparison are reported in Figure 24. 
- LFE CO2 Mass Rate a Percent Difference — Linear (LFE CO2 Mass Rate)

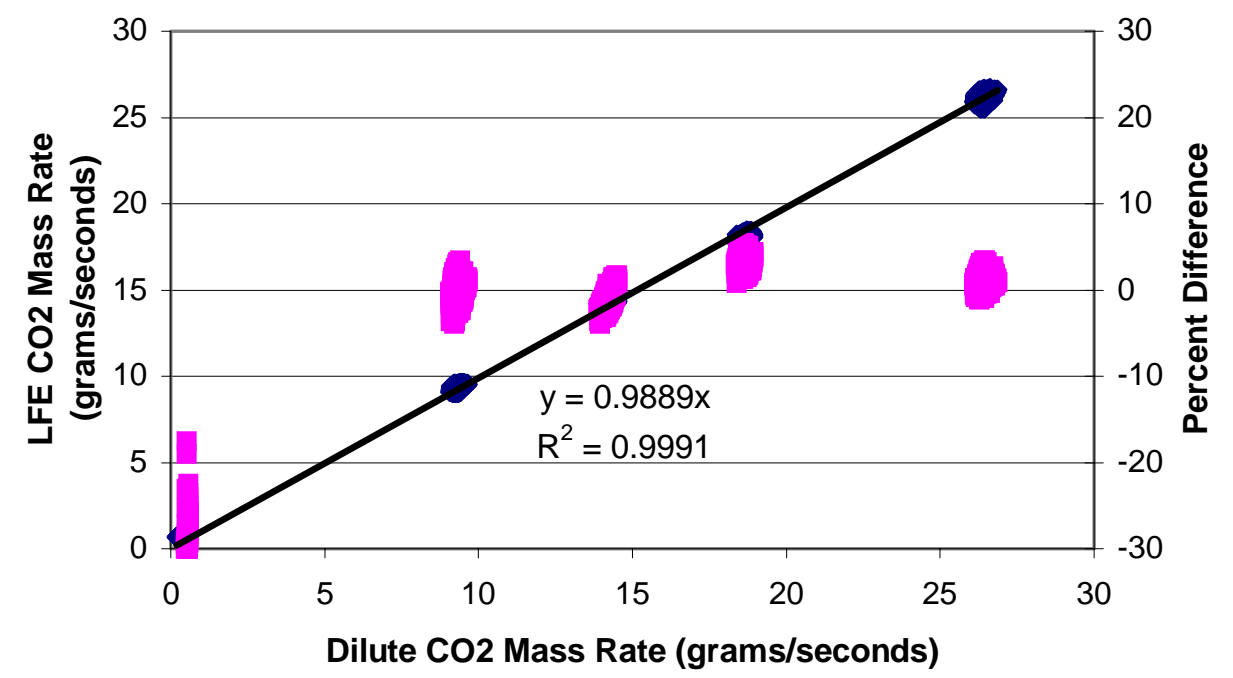

Figure 24 Comparison of the LFE and Dilute Method Using $\mathrm{CO}_{2}$ Mass Rate

The graph shows that the LFE and the dilute method are in good agreement. The difference at the lower flowrate (idle points) may be due the already low $\mathrm{CO}_{2}$ concentration, which may be negated by the background corrections. The fact that the values are already close to zero drives any difference in the flowrates to very large percent differences. The average absolute percent difference including the idle point is $-26.1 \%$ and the average absolute percent difference excluding the idle points is only $0.943 \%$. This shows that the LFE can be used as a standard for comparison without a correction factor being applied.

\subsubsection{Cummins Engine Test Results}

This section discusses the results of the devices tested on the Cummins engine. The section begins with the results of the Accutube tests followed by the Annubar and ending with the Venturi. The results are reported in two ways. The first is a comparison of the 
flowrate of the device under test verses the flowrate of the LFE and the second is the percent difference.

\subsubsection{Accutube, Meriam Instruments Cummins Engine Test Results}

Even though the Accutube did not fare well in the cold bench testing, it was decided to test it in the test cell so it could be compared to the Annubar, which operates on the same principle. The Accutube was again tested using one probe inserted in the flow as well as two probes crossed in the flow. The same line sizes and pressure transducers that were used in the cold bench testing were again used for this phase of testing. The results form the single probe insert test can be seen in Figure 25.

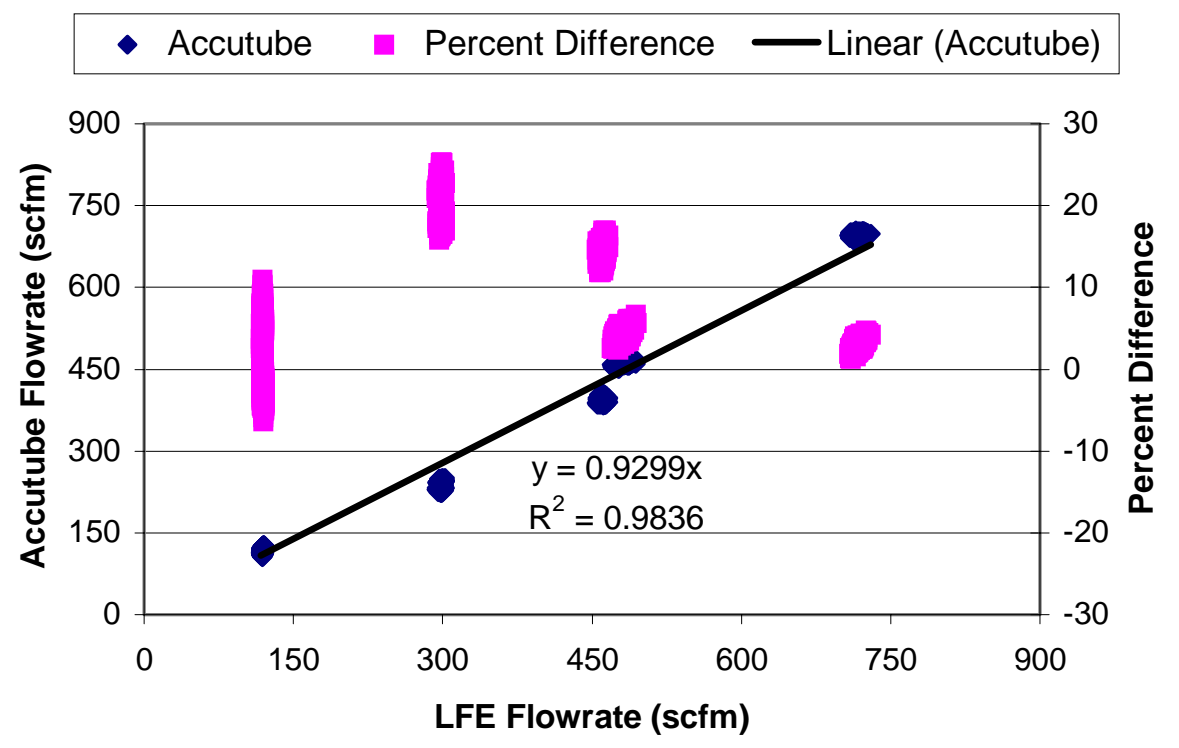

Figure 25 Single Accutube Results from Cummins Engine Test

The relationship between the LFE and the single Accutube is not as close as desired. At approximately $120 \mathrm{scfm}$ the percent difference was $4.2 \%$, at $300 \mathrm{scfm}$ the percent difference was $21.5 \%$, and at $730 \mathrm{scfm}$ the percent difference was $4.2 \%$. There is no true 
linear relationship between the LFE and the single Accutube. The results of the double Accutube tests can be seen in Figure 26.

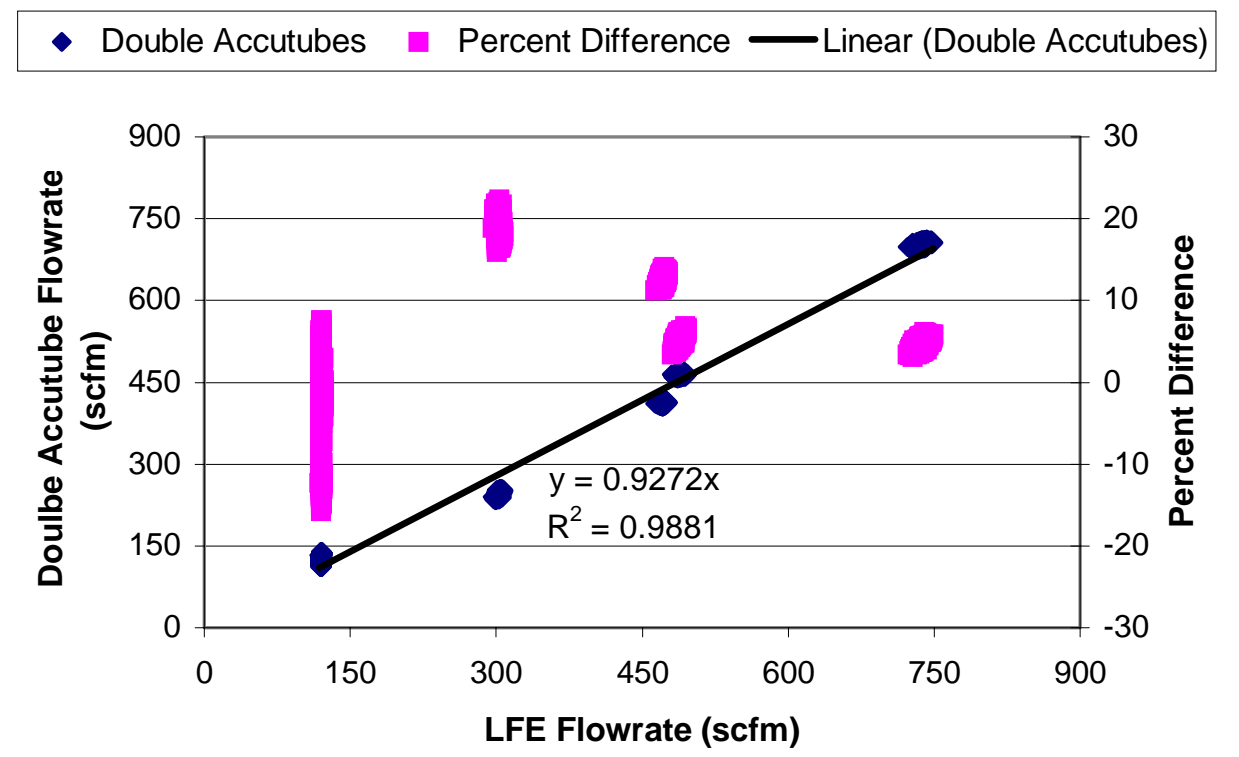

Figure 26 Double Accutube Cummins Test Results

The results of the double Accutube tests are similar to those of the single Accutube tests. At $120 \mathrm{scfm}$ the percent difference varied between $-15.3 \%$ and $7.3 \%$, at $300 \mathrm{scfm}$ the percent difference was $20.5 \%$, and at $745 \mathrm{scfm}$ the percent difference was $5.9 \%$. The linear relationship between the LFE and the double Accutube is still very poorly defined.

\subsubsection{Annubar Diamond II, Dieterich Standard Cummins Engine Test Results}

Only one Annubar was tested in the test cell unlike the test involving Accutube, which an experiment was conducted with crossing two probes to increase the resolution. Only one Annubar was used because of the increased cost of this device compared to the Accutube. If the results of the double Accutube test proved to be more accurate than the single Accutube test than the purchase of a second Annubar would have been justifiable. The Annubar test results can be seen in Figure 27. 


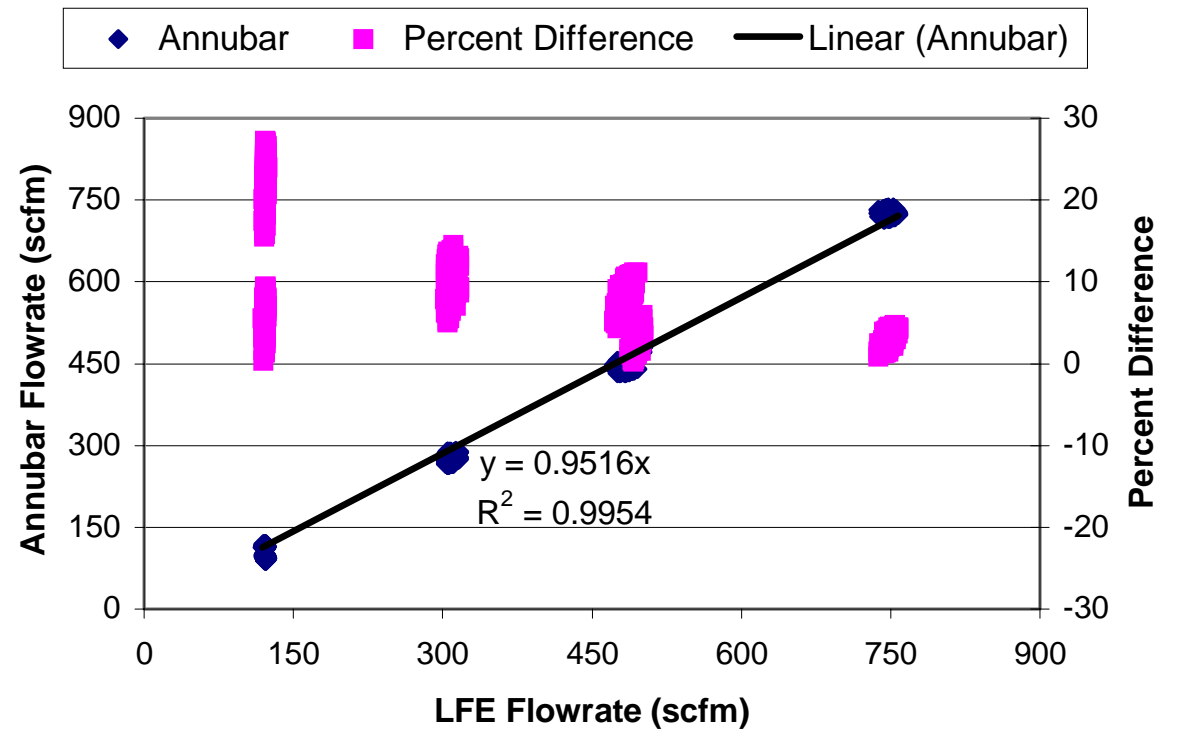

Figure 27 Annubar Cummins Test Results

The Annubar followed the same pattern as the double and single Accutubes. The higher flowrates appear to agree with the LFE more than in the case of the lower flowrates. At $120 \mathrm{scfm}$ the percent difference was from $0.4 \%$ to $27.1 \%$, at $310 \mathrm{scfm}$ the percent difference was $9.9 \%$, and at $750 \mathrm{scfm}$ the percent difference was $3.3 \%$. The relationship between the LFE and the Annubar is more linear then it was for both Accutube cases. The error in the lower flowrates may be similar to the error seen in comparing the LFE and the dilute method. In the case of the LFE and the dilute method there was no way to determine which method was correct because of the low flowrate and lower level of $\mathrm{CO}_{2}$ production. This may show that the LFE was indeed incorrect in the reported flowrate values, but no research was done to determine if this statement is true.

\subsubsection{Venturi Cummins Engine Test Results}

The venturi Cummins engine test results can be seen in Figure 28. 


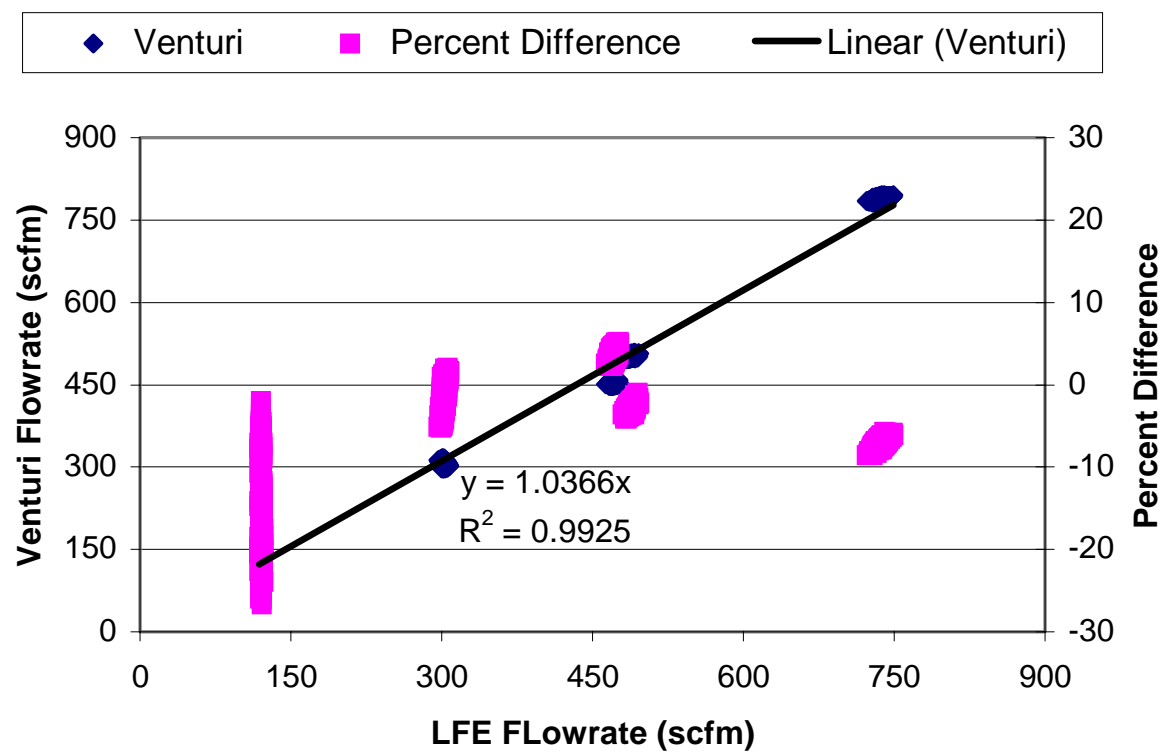

Figure 28 Venturi Cummins Test Results

The results from the venturi Cummins test show a better linear relationship with the LFE then the relationships the Accutubes and Annubar had with the standard. The accuracy of the venturi is also much better then that of the averaging Pitots. At $120 \mathrm{scfm}$ the percent difference was from $-2.7 \%$ to $-26.7 \%$, at $305 \mathrm{scfm}$ the percent difference was $-0.7 \%$, and at $745 \mathrm{scfm}$ the percent difference was $-6.3 \%$.

\subsubsection{Navistar Engine Tests}

This section discusses the tests performed on the Navistar engine. These tests were performed to evaluate the vortex shedder. The vortex shedder was tested in two different ways. The first had the vortex shedder in its original tube placed in the intake stream of the engine. This was done because of the limited range of the device. The device could handle the environment of the exhaust, but the original design was for much smaller engines. Since the device reports actual flowrates the elevated temperatures would have 
made it impossible for the device to measure the flowrate accurately. The second test involved the new tube design for the vortex shedder, which allows for a high flowrate to be measured. The results of the original vortex shedder is presented first and then the new tube design is presented second.

\subsubsection{Original Vortex Shedder Tube Design}

The results of the original vortex shedder can be seen in Figure 29.

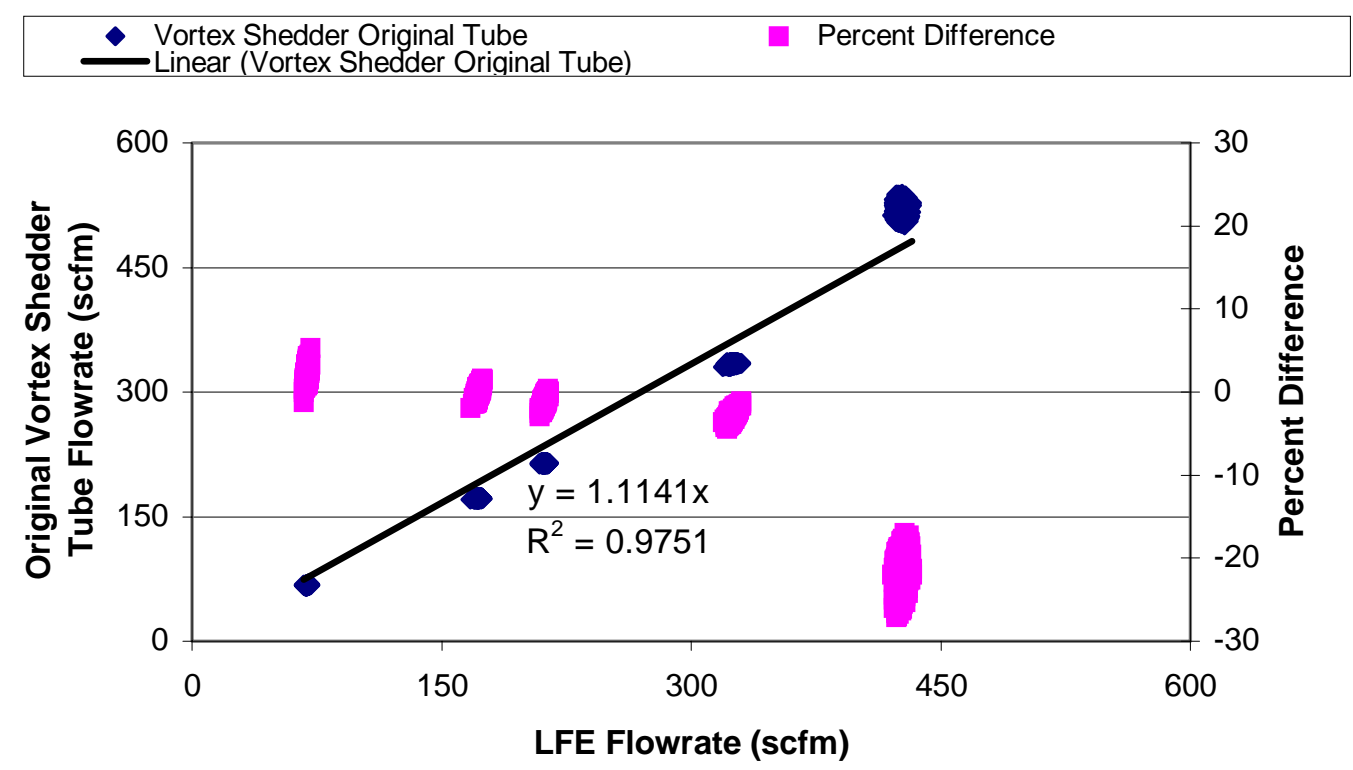

Figure 29 Original Vortex Shedder Navistar Tests Results

The results for the original vortex shedder design show a very good agreement with the LFE for the lower and medium flowrates, much better then the previous devices. The area of concern is the higher flowrates. At $70 \mathrm{scfm}$ the percent difference was $3.2 \%$, at $215 \mathrm{scfm}$ the percent difference was $-0.6 \%$, and at $430 \mathrm{scfm}$ the percent difference was $-19.2 \%$. This large percent difference could possibly be caused by the limit of the device itself. The reported flowrate is approximately $430 \mathrm{scfm}$, which is on the upper limit of 
the devices range since it reports acfm. Even a slight change in temperature can cause a large difference between acfm and scfm.

\subsubsection{New Vortex Shedder Tube Navistar Test Results}

The test results from the new tube design for the vortex shedder on the Navistar engine can be seen in Figure 30.

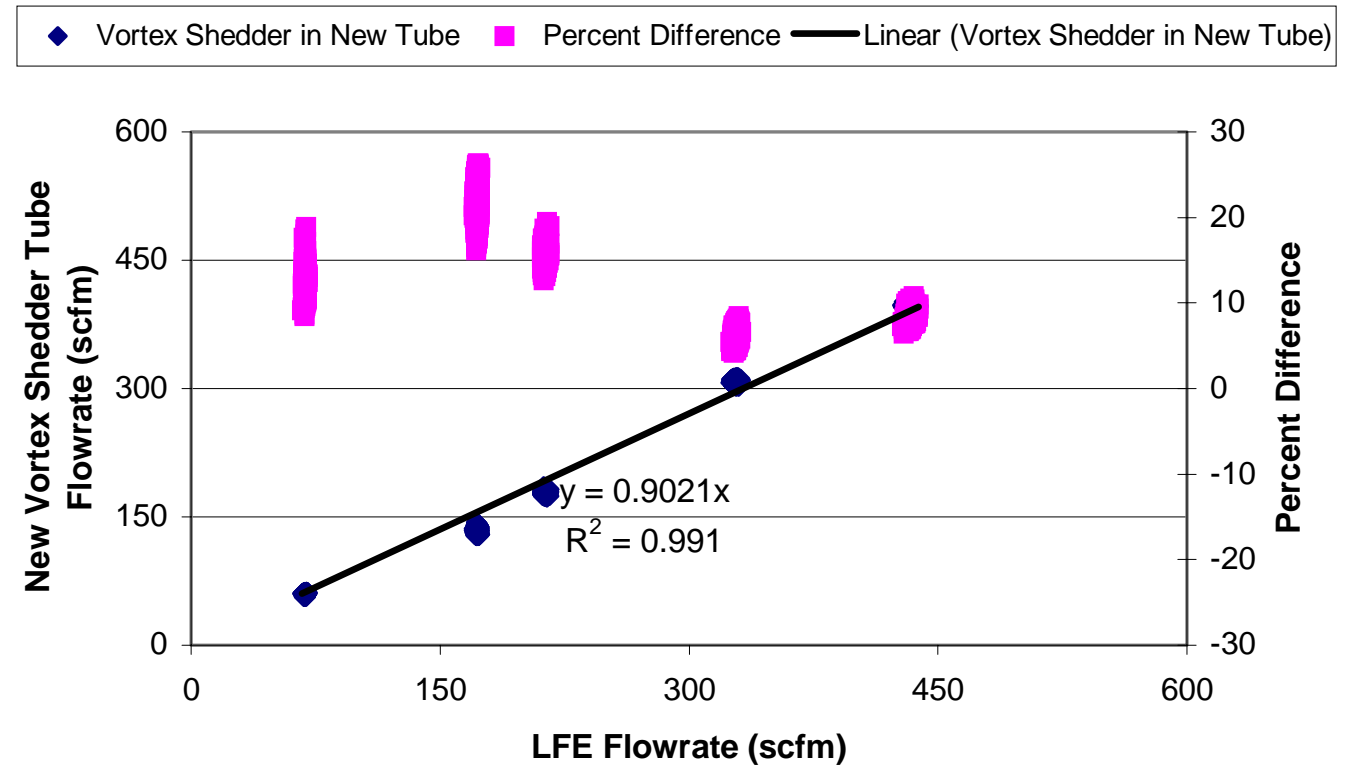

Figure 30 New Vortex Shedder Tube Navistar Test Results

The linear relationship of the new design vortex shedder and the LFE is very poorly defined by the best-fit equation and the overall accuracy of the device is poor when compared to the other devices that were tested. At $70 \mathrm{scfm}$ the percent difference was $13.8 \%$, at $215 \mathrm{scfm}$ the percent difference was $16.1 \%$, and at $435 \mathrm{scfm} 8.8 \%$. Some of the error in the reported values maybe due to a design flaw in the tube itself. The tube has a rapid change from a round duct into the rectangular shape, which may cause flow separation from the duct walls causing the formation of vortices in the flow. The presence of vortices in the flow would cause incorrect readings since the vortex shedder 
operates by measuring the frequency of vortices. This supposition would need further testing to prove or disprove this hypothesis. If true, a more gradual change from the round duct into the rectangular duct could result in more accurate measurements.

\subsection{Numerical Comparison}

The same numerical analysis was performed for the engine data that was performed on the cold bench data. Four variables of equal weight were considered in evaluating the devices. The four variables were, absolute average percent difference, standard deviation, R-squared value, and the best fit equation (slope with zero intercept). Ideally the values of the $\mathrm{R}^{2}$, Best Fit Equation (slope), and the standard deviation would be unity should be one and the multiple of all four numbers would be zero if the percent difference were zero. When evaluating the devices care must be taken because if the R-squared value and/or slope from the best fit equation are less than one it can convey the wrong meaning. For this reason, all four variables can be seen in Table 6 .

\begin{tabular}{|c|c|c|c|}
\hline & $\begin{array}{c}\text { Single } \\
\text { Accutube }\end{array}$ & Double Accutube & Annubar \\
\hline $\begin{array}{c}\text { Average Absolute } \\
\text { Percent Difference }\end{array}$ & 8.21 & 9.10 & 8.66 \\
\hline Standard Deviation & 7.87 & 9.48 & 6.68 \\
\hline R-Squared Value & 0.983 & 0.988 & 0.995 \\
\hline Best Fit Equation & $0.929 \mathrm{x}$ & $0.927 \mathrm{x}$ & $0.951 \mathrm{x}$ \\
\hline & Venturi & $\begin{array}{c}\text { Original Vortex } \\
\text { Shedder Design }\end{array}$ & $\begin{array}{c}\text { New Vortex Shedder } \\
\text { Tube Design }\end{array}$ \\
\hline $\begin{array}{c}\text { Average Absolute } \\
\text { Percent Difference }\end{array}$ & 6.94 & 5.13 & 12.8 \\
\hline Standard Deviation & 7.02 & 8.34 & 5.31 \\
\hline R-Squared Value & 0.992 & 0.975 & 0.991 \\
\hline Best Fit Equation & $1.03 \mathrm{x}$ & $1.11 \mathrm{x}$ & $0.902 \mathrm{x}$ \\
\hline
\end{tabular}

Table 6 Results of Engine Tests 
After the variables were multiplied together (using Equation 8) the final numbers were ranked starting with the device with the least value and increased to the least desirable device. The final ranking of the devices can be seen in Table 7 .

\begin{tabular}{|c|c|c|}
\hline Device & Result of Equation & Ranking \\
\hline Original Vortex Shedder & 48.91 & 1 \\
\hline Venturi & 50.91 & 2 \\
\hline Annubar & 61.11 & 3 \\
\hline Single Accutube & 70.77 & 4 \\
\hline New Vortex Shedder Design & 76.67 & 5 \\
\hline Double Accutube & 94.32 & 6 \\
\hline
\end{tabular}

Table 7 Final Ranking after Engine Testing of Flow Devices

Based upon the results of the table the original vortex shedder had the best ranking followed closely by the venturi and then the Annubar. The remaining devices returned higher measures of error. 


\section{Conclusions}

The main objective of this work was to determine the best flow device for a MEMS based upon the cold bench testing and the engine testing. The venturi, both averaging Pitots, and the vortex shedder showed potential and thus were tested in the test cell on an engine. There is difficultly in choosing the best device for a MEMS based on engine data. The device must be accurate and capable of measuring a large flow range. The original vortex shedder has proven itself to be the most accurate, but it has a very limited flow range. The venturi and even the Annubar have shown they can produce flow measurements with a slightly lower accuracy, but can account for a much greater flow ranges.

In order to answer the second objective, the device must be based on the application. If the application calls for a large range as in the case of a typical 300 or 400 horsepower engine then the answer would be the venturi. If the application were for light-duty diesel engines like the ones found in pickup trucks and possibly small buses then the original vortex shedder would be appropriate.

The venturi would offer the greatest versatility for a MEMS, since the MEMS is going to be used on many different vehicles with many different engines. Due to the flowrate limitations of the vortex shedder, it was placed in the intake of the Navistar test engine. This was easily accomplished in the test cell but would prove to be different for engines in a vehicle for on-road testing since many different intake configurations are used. If technology offers a vortex shedder with an increased flow range in the near future then it would definitely be worth considering since it had an average absolute percent difference of $3.77 \%$ for both cold bench and engine testing. This value may be 
even less if the last data set in the engine tests were dropped due to the fact that the flowrate is slightly outside of the flow range of the device. The current vortex shedder technology does not meet the requirements needed for fully versatile MEMS.

The flow device that was chosen for a MEMS was an Annubar. This selection was based on work not included in this paper (transient test and on-road test). The decision to use an Annubar was also based on the cost of the device. The cost to purchase an Annubar made to the costumer's specification was approximately $\$ 1200$ and for a venturi capable of performing the same task would be approximately $\$ 3000$. These estimates are for a 5 inch flow tube with a range of $100 \mathrm{scfm}$ to $900 \mathrm{scfm}$. 


\section{Recommendations}

This section is designed for individuals who wish to study flow devices further. The goal of this section is to direct individuals towards areas that this thesis did not address or showed areas of possible improvement. This is not to say the results of this thesis are incorrect, but rather to encourage other to add to the results mentioned here.

First, new flowmeters are being developed all the time. If a possible candidate becomes available that may be better suited for a MEMS application then similar test should be performed on it. Second, a new tube design for the vortex shedder could be designed to ensure flow separation had not occurred. Should it be found separation did occur then addition testing on the new tube should be performed. Third information on line sizing and dead volumes should be considered to increase the accuracy of the devices (see Fuller, 2001 for additional information). Finally, all the testing performed on the devices was based on a steady state test. In a MEMS application rarely will the case be steady state testing. To further evaluate the devices transient testing should be considered. The results of the transient testing may be very different from the ones formed in the thesis. The case of transient testing may strongly correlate with the results of line sizing and dead volume test due to the varying flowrates and other exhaust conditions. 


\section{References}

1. http://www.epa.gov/oar/aqtrnd97/brochure/sixprin.html, 2000.

2. http://www.dieselnet.com/standards/us/hd.html, 2000.

3. Code of Federal Regulations, Title 40, Part 86, Subpart N, 1994, United States Government Printing Office, Washington D.C.

4. Code of Federal Regulations, Title 40, Part 89, Subpart E, 1994, United States Government Printing Office, Washington D.C.

5. Gautam, M., Clark, N., Thompson, G., Lyons, D., 1999, "Assessment of Mobile Technologies for Heavy-Duty Vehicle Emissions," Report to Settling Heavy-Duty Diesel Engine Manufacturers, 1999,

6. Anon, 1982, "New Flow Sensor Offers Accurate Measurement, Low Pressure Loss," ENMJA Vol. 183 No. 11, Nov. 1982, pp. 139.

7. Rusnak, J., 1989, "Flowmetering in the 1990's," SAE 890981.

8. Miller, R. W., 1996, Flow Measurement Engineering Handbook, McGraw Hill, New York, New York.

9. Lomas, C. G., 1986, Fundamentals of Hot Wire Anemometry, Cambridge University Press, New York, New York.

10. Beckwith, T. G., Marangoni, R. D., Lienhard V, J. H., 1993, Mechanical Measurements, Addison-Wesley Publishing Company, Reading, Massachusetts.

11. Klopfenstein, R., 1998, "Air Velocity and Flow Measurement Using a Pitot Tube," ISA Transactions Vol. 37 No.4, pages 257 - 263.

12. Adachi, M., Hirano, T., Ishida, K., Cepeda, C., Nagata, Y., Kubo, A., Nakamura, S., 1997, "Measurement of Exhaust Flow Rate: Helium Trace Method with a Mass Spectrometer," SAE 971020.

13. Upp, E. L, 1993, Fluid Flow Measurement, Gulf Publishing Company, Houston, Texas.

14. Hayward, A. T. J., 1981, Flowmeters, The Macmilllan Press LTD., London, England. 15. Beck, M., and Hinterhofer, K., 1998, "Direct High Dynamic Flow Measurement in the Exhaust of Combustion Engines," SAE 980880. 
16. Miller, R. W., Jones, E. H., Padilla, K. M., 1998, "Measurement of Fluid Flow in Pipes Using Vortex Flowmeters," ASME MFC-6M-1998.

17. Annubar Diamond II+ Flow Handbook, 1998, Dieterich Standard a subsidiary of Rosemount Inc., P.O. Box 9000, Boulder, CO 80301.

18. Annubar Averaging Pitot Tube Installation and Operation Manual, 1998, Dieterich Standard, a subsidiary of Rosemount Inc., P.O. Box 9000, Boulder, CO 80301.

19. Meriam Accutube Flow Handbook, 1984, Meriam Instrument., 10920 Madison Avenue, Cleveland, Oh 44102.

20. Sierra Instruments Product Catalog, 1998, Sierra Instruments., 5 Harris Court, Building L, Monterey, CA 93940.

21. Dwyer Bulletin No. H-11, 1992, Dwyer Instruments Inc., P.O. Box 373, Michigan City, Indiana 46360.

22. Primary Flowmeters, 1991, Flow-Dyne Engineering Inc., P.O. Box 161655, Fort Worth, TX 76161-1655.

23. Miller, R. W., Lee, W. F. Z., Gomez, C. J., 1989, "Measurement of Fluid in Pipes Using Orifice, Nozzle, and Venturi," ASME MFC-3M-1989.

24. Operator's Manual for the VE503 Exhaust Flowmeter, 1993,J-TEC Associates, Inc.,5255 Rockwell Drive, N.E., Cedar Rapids, IA 52402-2020.

25. Evans, J., 2000, "Influence of Fuel Sulfur Content on Emissions from Diesel Engines Equipped with Oxidation Catalysts," M.S. Thesis, Department of Mechanical \& Aerospace Engineering, West Virginia University, Morgantown, WV.

26 Shade, B., 2000, "A Performance Evaluation of the MEMS - An On-Road Emissions Measurement System Study," M.S. Thesis, Department of Mechanical \& Aerospace Engineering, West Virginia University, Morgantown, WV.

27. Gautum, M., Clark, N., Thompson, G., Lyons, D., 2000, "Development of In-Use Testing Procedures for Heavy-Duty Diesel-Powered Vehicle Emissions." Report to the Settling Heavy- Duty Diesel Engine Manufacturers, 2000.

28. Fuller, A., 2001 "A Flow Rate Measurement System for a Mobile Emissions Monitoring System," M.S. Thesis, Department of Mechanical \& Aerospace Engineering, West Virginia University, Morgantown, WV. 


\section{Appendices}

This section covers the relevant equations used in reducing data from each flow device. The section begins with the LFE, followed by the Accutube, the Annubar, then the hot film anemometer, the Pitot static tube, venturi, the vortex shedder, the differential pressure transducer, and ending with the absolute pressure transducer. Each section also contains specific information provided by the manufacturer. 


\section{Appendix I LFE}

The LFE reported flowrates in terms of actual flowrate. The basic equation used to determine the actual flowrate is:

$\mathrm{B} * \mathrm{DP}+\mathrm{C} * \mathrm{DP}^{2}=$ Actual Flowrate.

where $\mathrm{B}$ and $\mathrm{C}$ are unique constants to each device. For the device used in this work $\mathrm{B}$ was 127.585 and $\mathrm{C}$ was -.870655 .

In order to standardize the flow, correction factor had to be applied to the actual flowrate. These correction factors included temperature, pressure and viscosity. Meriam Instruments provided a chart of temperatures and pressure and the corresponding correction factor, in order to apply these an equation was developed so the corrections could be made in a spreadsheet. The temperature, pressure, and viscosity correction factors were:

Temperature Correction Factor $=2.9627 * 10^{-6} * \mathrm{x}^{2}-2.2866 * 10^{-3} * \mathrm{x}+1.11419$

and the $\mathrm{R}^{2}$ value for this equation was 0.99999 , and the $\mathrm{x}$ variable was in degrees Fahrenheit.

Pressure Correction Factor $=$ Absolute Pressure of the Flow $/ 29.92$ in Hg.

Viscosity Correction Factor $=2.2907 * 10^{-6} * \mathrm{x}^{2}-1.7697 * 10^{-3} * \mathrm{x}+1.1127$

and the $\mathrm{R}^{2}$ value for this equation was 0.99687 , and the $\mathrm{x}$ variable was in degrees

Fahrenheit. There was also a humidity correction factor that was applied. The humidity correction factor was dependent upon two variables, temperature and relative humidity. Two equations were developed for the correction factor, one for $40 \%$ relative humidity and one for $60 \%$ relative humidity. The equations used were: 
Humidity Correction Factor for 40\% R.H. $=-1.9762 \mathrm{E}-6 * \mathrm{x}^{2}+1.3880 \mathrm{E}-4 * \mathrm{x}+.9962$ which had an R2 value of 0.99852 and the x variable was in degrees Fahrenheit and Humidity Correction Factor for $60 \%$ R.H. $=-2.9405 E-6 * x^{2}+2.0417 E-4 * x+.9945$ which had an R2 value of 0.99911 and the $\mathrm{x}$ variable was in degrees Fahrenheit. These were the values relative humidity that were used in all testing. The following is a letter of certification for the LFE followed by its calibration sheet. Notice that the total rss uncertainty of the completed laminar flow unit is $+/-0.72 \%$ of the reading. 


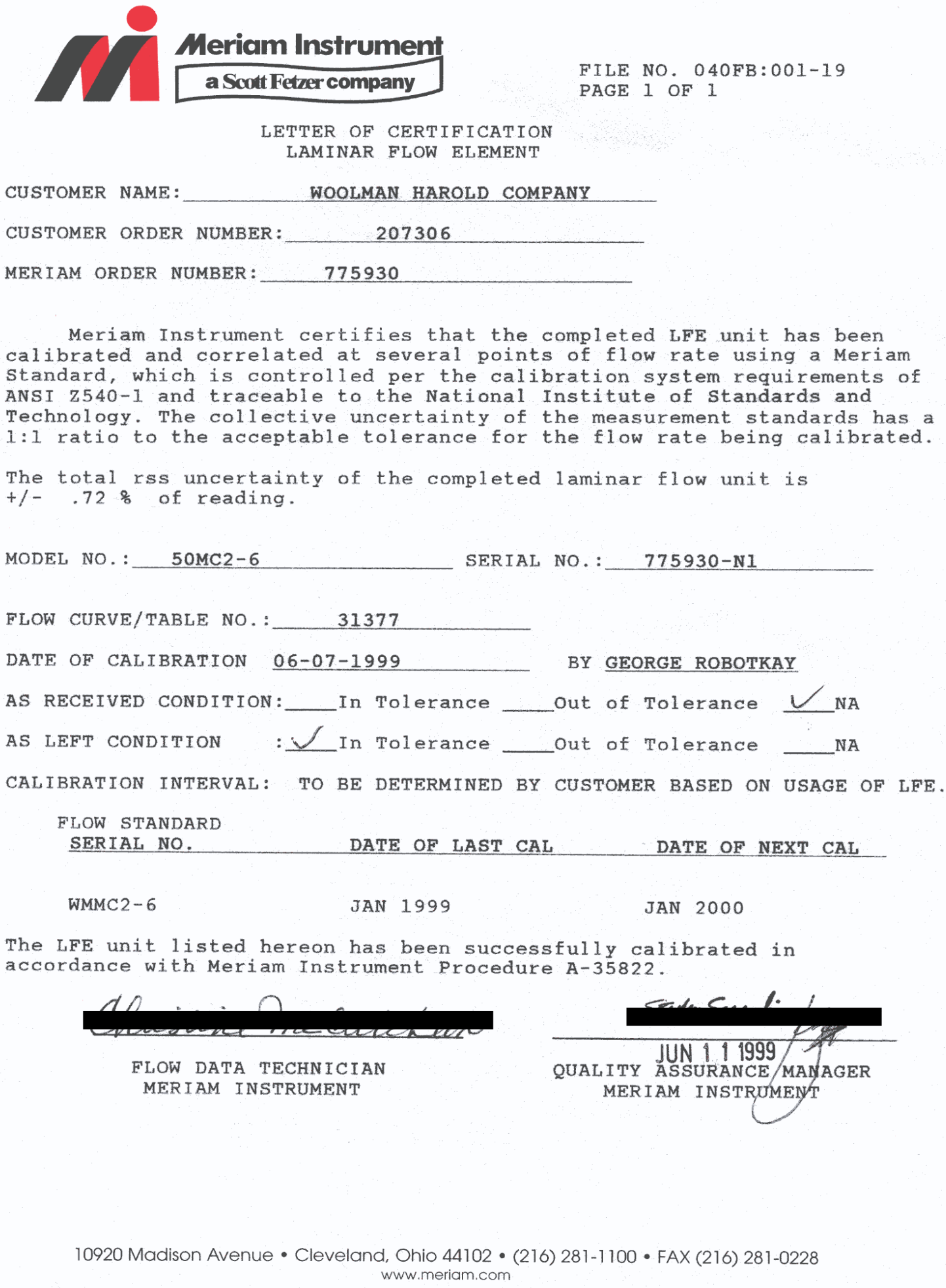

10920 Madison Avenue • Cleveland, Ohio 44102 • (216) 281-1100 • FAX (216) 281-0228 www.meriam.com

Figure 31 Letter of Certification for the LFE 
LAMINAR. BAS SER 1.38 MARCH 1999

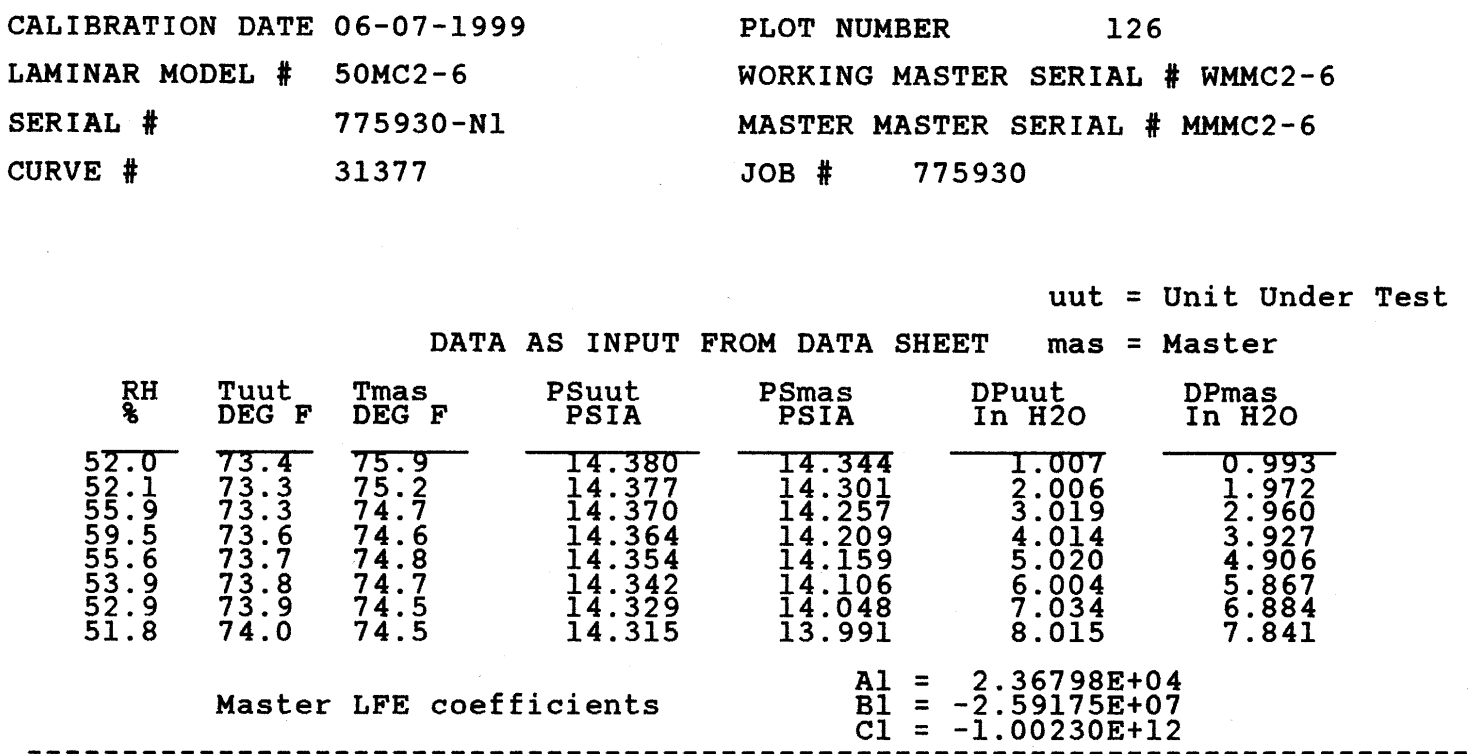

REDUCED DATA, BASED ON MASTER LFE COEFFICIENTS:

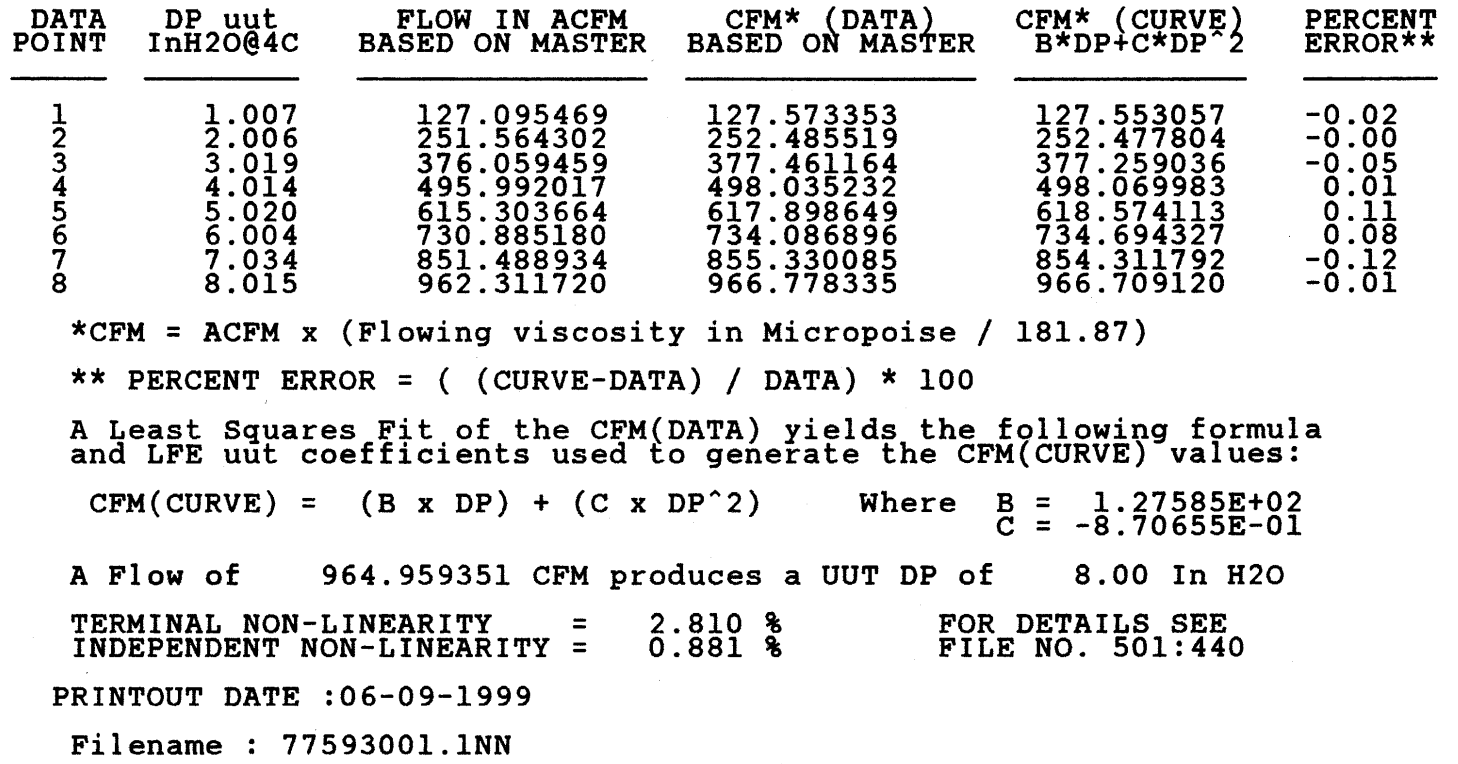

Figure 32 Calibration Sheet for the LFE 


\section{Appendix II Accutube}

The Accutube operates on the fundamental principles of Bernoulli's equation. The derived equation used for data reduction was:

$$
Q_{s}=128.789 K D_{i}{ }^{2} \sqrt{\frac{\Delta P P_{f}}{\left(t_{f}+459.67\right) S_{s}}} \quad Y F_{m} F_{a} F_{L} F_{p b} F_{t b} F_{p v} F_{R A}
$$

The following is the definition of all terms in the flow equation and how they were derived.

$\mathrm{K}$ was the flow coefficient and $\mathrm{F}_{\mathrm{ra}}$ was the Reynolds number correction factor. The flow coefficient was determined by,

$\mathrm{K}=\mathrm{A}+\mathrm{B} * \mathrm{RD}+\mathrm{C} * \mathrm{RD}^{2}+\mathrm{D} * \mathrm{RD}^{3}$

and the Reynolds number correction factor was determined by

$F_{r a}=\left(A+B * R D+C * R D^{2}+D * R D^{3}\right) / K$.

Where A, B, C, and D, were constants. A was 6.4136E-01, B was -1.7091E-8, C was

1.9586E-13, and D was -1.6283E-19. RD was the Reynolds number and the following equation was used to determine it.

$\mathrm{RD}=($ Flow Stream Velocity $*$ Cross Sectional Area of Pipe $) /$ Kinematic Viscosity

The velocity was a function of the flowrate so a circular loop had to be incorporated. The kinematic viscosity was found by using the following equation.

Kinemaic Viscosity $=6.2299 \mathrm{E}-07 \mathrm{x}+1.2029 \mathrm{E}-4$

Where $\mathrm{x}$ was in degrees Fahrenheit. This equation was developed by plotting values of kinematic viscosity against temperature. The resulting equation has an $\mathrm{R}^{2}$ value of 0.99687. 
The $D_{i}$ term in the flow equation was the inside diameter of the pipe in inches.

The $\Delta \mathrm{P}$ term was the differential pressure generated by the device psia.

The $\mathrm{P}_{\mathrm{f}}$ term was the absolute pressure of the flow in pounds per square foot.

The $t_{f}$ term was the temperature of the flow in degrees Fahrenheit.

The $S_{\mathrm{s}}$ term was the specific gravity of the flowing fluid and was 1 in all work performed.

The Y term was the Gas Expansion Factor. This factor compensates for changes in density at the sensing ports caused by changes in pressure. The formula used to determine the Gas Expansion Factor was:

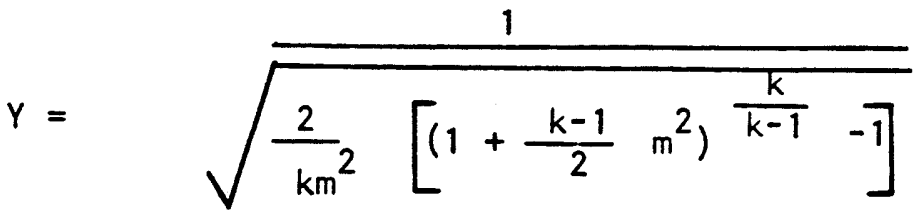

Where $\mathrm{m}$ was the Mach number of the flow. The Mach number was found by using the following equation.

$$
m^{2}=\frac{2}{k-1}\left[\left(1+0.0361\left(\frac{\Delta P K^{2}}{P_{f}}\right)^{\frac{k-1}{k}}-1\right]\right.
$$

Where $\mathrm{k}$ was the gas isentropic exponent. The following equation was developed by plotting known value for the gas isentropic exponent against temperature.

$\mathrm{k}=1.2420 \mathrm{E}-11 * \mathrm{x}^{3}-3.3138 \mathrm{E}-8 * \mathrm{x}^{2}-2.8834 \mathrm{E}-5 * \mathrm{x}+1.4036$

Where $\mathrm{x}$ was in degrees Fahrenheit and the $\mathrm{R}^{2}$ value was 0.99797.

The $F_{m}$ term in the flow equation is the manometer correction factor. Since no manometer was used the value was 1. 
The Fa term was the Thermal Expansion correction factor. The following equation was used to determine the Thermal Expansion correction factor.

$\mathrm{F}_{\mathrm{a}}=\left[\left(\mathrm{T}_{\mathrm{f}}-\mathrm{T}_{\mathrm{s}}\right) * \text { coefficient of thermal expansion for pipe material }+1\right]^{2}$

Where $T_{f}$ was the temperature of the flowing fluid and $T_{s}$ was the temperature at which the inside diameter measurement was taken.

The $\mathrm{F}_{\mathrm{L}}$ term in the flow equation is the location correction factor, which was used for manometers. Since no manometer was used the value was 1 .

The $\mathrm{F}_{\mathrm{pb}}$ term was for a correction of pressure base, but since the same pressure base was used the value was 1 .

The $\mathrm{F}_{\mathrm{tb}}$ term was for a temperature base correction factor. The factor that was used was 0.98484. This was done because the manufacturer references all measurements to $60{ }^{\circ} \mathrm{F}$ where all work done in the paper uses $68^{\circ} \mathrm{F}$.

The last term, $\mathrm{F}_{\mathrm{pv}}$, was a super compressibility correction factor and was set to be 1 in all work done in this thesis. 


\section{Appendix III Annubar}

The Annubar operates on the same principles as the Accutube so many of the correction factors are the same. The flow equation for the Annubar was

$\mathrm{Qs}=\mathrm{F}_{\mathrm{NA}} * \mathrm{~K} * \mathrm{D}^{2} * \mathrm{~F}_{\mathrm{RA}} * \mathrm{Y}_{\mathrm{A}} * \mathrm{~F}_{\mathrm{pb}} * \mathrm{~F}_{\mathrm{tb}} * \mathrm{~F}_{\mathrm{tf}} * \mathrm{~F}_{\mathrm{g}} * \mathrm{~F}_{\mathrm{pv}} * \mathrm{~F}_{\mathrm{M}} * \mathrm{~F}_{\mathrm{AA}} * \mathrm{~F}_{\mathrm{L}} *\left(\mathrm{~h}_{\mathrm{w}}\right)^{.5} *\left(\rho_{\mathrm{f}}\right)^{.5}$

The FNA term was the Unit Conversion factor. The value used for all testing in this thesis was 5.6362 .

The $\mathrm{K}$ term was the flow coefficient, which is constant for an Annubar unlike the Accutubes. The flow coefficient was 0.6264 .

The $\mathrm{D}$ term was again the inside diameter in inches.

The $\mathrm{F}_{\mathrm{RA}}$ term was the Reynolds number correction factor, which was 1 for an Annubar unlike the Accutubes.

The $\mathrm{Y}_{\mathrm{A}}$ term was the Gas Expansion factor, which was similar to that of the Accutube. The equation used to determine the Gas Expansion factor was $\mathrm{Y}_{\mathrm{A}}=1-.00585 *\left[\Delta \mathrm{P} /\left(\mathrm{P}_{\mathrm{f}} * \mathrm{k}\right)\right]$

where $\Delta \mathrm{P}$ was again the differential pressure, $\mathrm{P}_{\mathrm{f}}$ was the absolute pressure, and $\mathrm{k}$ was the gas isentropic exponent.

The $\mathrm{F}_{\mathrm{pb}}$ term in the flow equation was the pressure base correction factor. The value used for the Annubar was 1.0023 .

The $\mathrm{F}_{\mathrm{tb}}$ term was the temperature base correction factor and the value used was 1.0154. The $\mathrm{F}_{\mathrm{tf}}$ term was a flowing temperature factor. It converts the flowrate to a standard flowrate at $60{ }^{\circ} \mathrm{F}$. The equation used was:

$\mathrm{F}_{\mathrm{tf}}=\left[520 /\left(\right.\right.$ Temperature Base $\left.\left.\left({ }^{\circ} \mathrm{F}\right)+460\right)\right]$

The $F_{\mathrm{g}}$ term was the specific gravity factor. The value used for data reduction was 1 . 
The $\mathrm{F}_{\mathrm{pv}}$ was the Super compressibility factor and it was also 1.

The $\mathrm{F}_{\mathrm{M}}$ term was the manometer correction factor and it too was 1 .

The $\mathrm{F}_{\mathrm{AA}}$ term was the Thermal Expansion correction factor. An equation was developed by plotting the Thermal Expansion correction factor against various temperatures. The resulting equation had an $\mathrm{R}^{2}$ value of 0.99999 . The equation used was:

$\mathrm{F}_{\mathrm{AA}}=2.9786 \mathrm{E}-9 * \mathrm{x} 2+1.2620 \mathrm{E}-5 * \mathrm{x}+0.99912$

where $\mathrm{x}$ was in degrees Fahrenheit.

The $\mathrm{F}_{\mathrm{L}}$ term was a location correction factor, which corrects for changes in gravity, since the testing was performed in only one location the gravity never changed. The value used was 1 .

The $\left(\mathrm{h}_{\mathrm{w}}\right)^{5}$ term was the square root of differential pressure measured by the Annubar. The $\left(\rho_{\mathrm{f}}\right)^{.5}$ term was the square root of the fluid density. The density was interpreted by various equations, which include a circular loop in a spreadsheet. 


\section{Appendix IV Hot Film Anemometer}

The hot film anemometer that was used had a user full-scale range of $1500 \mathrm{scfm}$. To increase the resolution of the device the range was changed to $965 \mathrm{scfm}$. The hot film anemometer was than calibrated against the LFE. The resulting calibration curve was

Hot Film Anemometer Flowrate $=(192.46 *$ Voltage Output +3.23$) *$ P.C. $*$ T.C. $*$ T.E. The equation had an $\mathrm{R}^{2}$ value of 0.99764 .

The P.C. term was a pressure correction factor, the T.C. term was a temperature correction factor, and the T.E. was the thermal effect correction. The correction for the thermal effect was applied in a manner, which would benefit the devices accuracy. The following was a product specification sheet on the device used. 


\section{Product Specifications}

\section{Operating Specifications}

\begin{tabular}{|c|c|}
\hline Gases & Air, nitrogen and other non-combustible, non-corrosive gases \\
\hline Mass Flow Rates & $\begin{array}{l}0 \text { to } 200 \mathrm{sfpm} \text { ( } 0 \text { to } 1 \mathrm{nmps} \text { ) minimum, } 0 \text { to } 20,000 \mathrm{sfpm} \text { ( } 0 \text { to } 100 \mathrm{nmps} \text { ) } \\
\text { maximum for air and nitrogen (maximum full scale varies with gas) }\end{array}$ \\
\hline Dual Calibration & $\begin{array}{l}\text { User-selectable dual ranges or two different gases (the user full scale for } \\
\text { Range } 2 \text { two cannot be less than } 10 \% \text { of the full scale for Range 1) }\end{array}$ \\
\hline Gas Pressure & 150 psig (10 barg) at $80^{\circ} \mathrm{C}\left(176^{\circ} \mathrm{F}\right)$ \\
\hline Pressure Drop & Negligible \\
\hline Gas \& Ambient Temperature & $\begin{array}{l}\text { Gas............................14. } 34^{\circ} \text { to } 176^{\circ} \mathrm{F}\left(-10^{\circ} \text { to } 80^{\circ} \mathrm{C}\right) \\
\text { Ambient................... }\left(0^{\circ} \text { to } 50^{\circ} \mathrm{C}\right)\end{array}$ \\
\hline Power Requirements & $\begin{array}{l}11 \text { to } 18 \text { VDC (regulated), } 625 \mathrm{~mA} \text { maximum } \\
18 \text { to } 30 \text { VDC (regulated), } 625 \mathrm{~mA} \text { maximum }\end{array}$ \\
\hline Output Signal & $\begin{array}{l}\text { Linear 0-5 VDC (0-10 VDC optional) proportional to point mass flow rate or } \\
\text { velocity, } 1000 \text { Ohms minimum load resistance, and linear } 4-20 \mathrm{~mA} \text { proportional to } \\
\text { point mass flow rate or velocity, } 700 \text { Ohms maximum resistance (power supply } \\
\text { dependent), optically isolated (isolation is an input-to-output isolation of } 1500 \text { VAC } \\
\text { for } 1 \text { minute) }\end{array}$ \\
\hline Alarms & $\begin{array}{l}\text { User-adjustable low, high or window alarms } \\
\text { Deadband adjustable with Smart Interface }{ }^{\mathrm{TM}} \text { software } \\
\text { Relay rating................ Maximum } 42 \text { VAC or } 42 \text { VDC, } 140 \mathrm{~mA}, 27 \text { Ohm maxi- } \\
\text { mum on-resistance, optically isolated (isolation is an input-to-output isolation } \\
\text { of } 1500 \text { VAC for } 1 \text { minute) }\end{array}$ \\
\hline Display & $\begin{array}{l}\text { Alphanumeric } 2 \times 12 \text { digit backlit LCD } \\
\text { Adjustable variables via on-board membrane buttons or with Smart Interface } \\
\text { software } \\
\text { Adjustable variables.............. Full scale adjustment (50 to 100\%) } \\
\text { Time delay response }(0.1 \text { to } 7.2 \text { seconds) } \\
\text { Correction factor setting }(0.5 \text { to } 5) \\
\text { Zero and span adjustments }\end{array}$ \\
\hline Performance Spec & ifications \\
\hline Accuracy & $\pm 1 \%$ of full scale $+0.5 \%$ RDG \\
\hline Repeatability & $\pm 0.24 \%$ of full scale \\
\hline Temperature Coefficient & $\begin{array}{l} \pm 0.02 \% \text { of reading per }{ }^{\circ} \mathrm{F} \text { within } \pm 50^{\circ} \mathrm{F} \text { of customer specified conditions } \\
\pm 0.03 \% \text { of reading per }{ }^{\circ} \mathrm{F} \text { within } \pm 50^{\circ} \mathrm{F} \text { to } 100^{\circ} \mathrm{F} \text { of customer specified conditions } \\
\pm 0.04 \% \text { of reading per }{ }^{\circ} \mathrm{C} \text { within } \pm 25^{\circ} \mathrm{C} \text { of customer specified conditions } \\
\pm 0.06 \% \text { of reading per }{ }^{\circ} \mathrm{C} \text { within } \pm 25^{\circ} \mathrm{C} \text { to } 50^{\circ} \mathrm{C} \text { of customer specified conditions }\end{array}$ \\
\hline Pressure Coefficient & $0.02 \%$ per psi \\
\hline Response Time & 250 milliseconds to $63 \%$ of final velocity value \\
\hline \multicolumn{2}{|c|}{ Physical Specifications } \\
\hline Wetted Materials & Probe: 304SS, epoxy, ceramic, Viton \\
\hline Enclosure & NEMA 4X (IP65) powder-coated cast aluminum enclosure \\
\hline Mounting (optional) & 3/8-inch tube compression fitting with $1 / 2$-inch male NPT \\
\hline Certifications & CE approved \\
\hline
\end{tabular}

Figure 33 Product Specification Sheet for the Hot Film Anometer

The following is a calibration sheet for the hot film anemometer based on the original

full-scale range of $1500 \mathrm{scfm}$. 


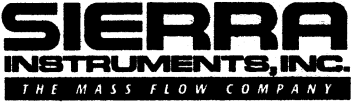

5 Harris COUR'; BULLING; L MONTEREY, CA 93940 USA 800-866-0200 831-373-0200 FAX 831-373-4402

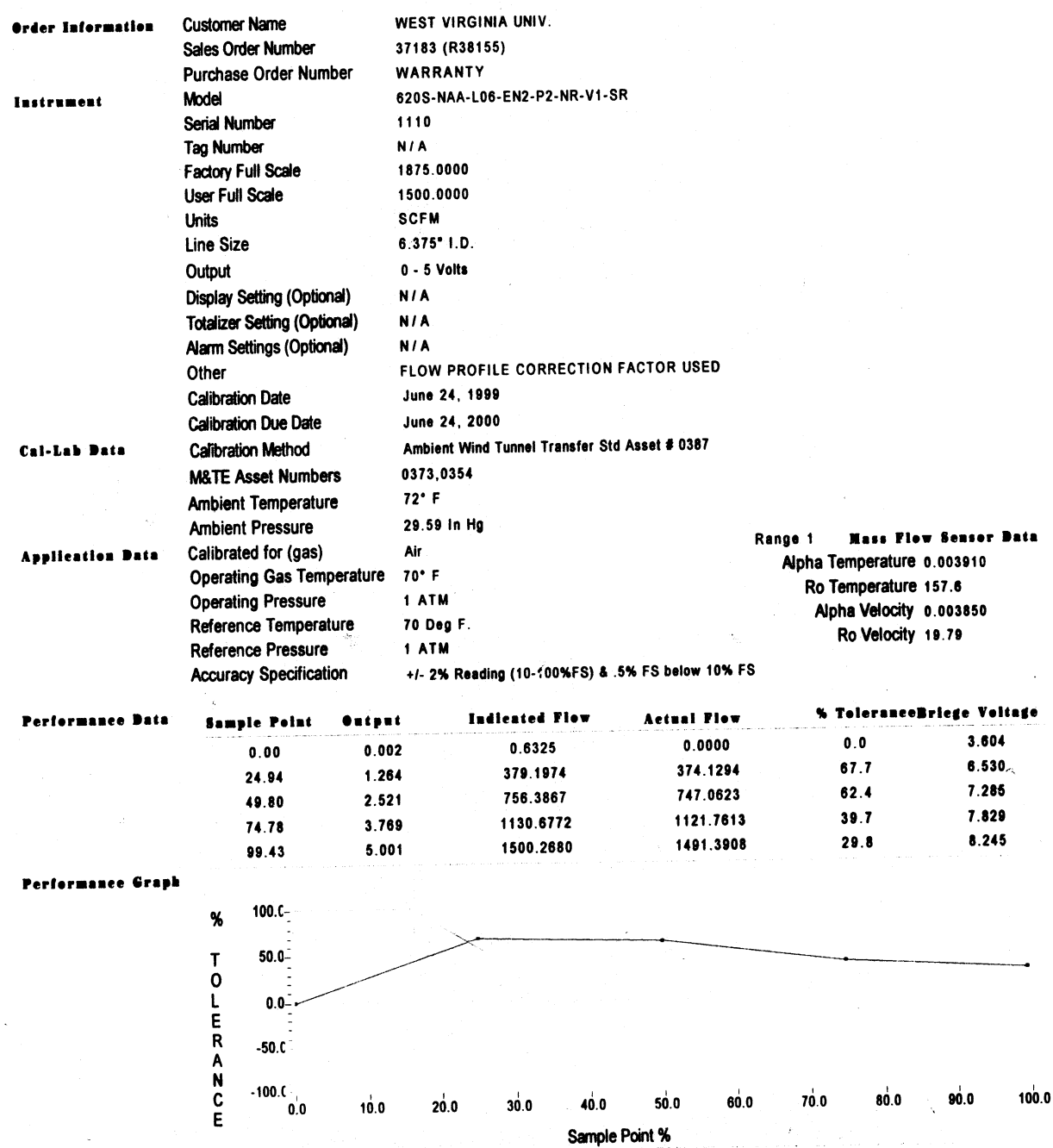

\section{CALIBRATION CERTIFICATE}

Print Date and Time

Thursday, June 24, 1999 5:47 PM
Figure 34 Calibration Sheet for the Hot Film Anemometer 


\section{Appendix V Pitot Static Tube}

The Pitot static tube like the Annubar and Accutube operates on the Bernoulli principle. The equation used to determine the flowrate was:

Flow in Cubic Feet per Minute $=$ Duct Area in Square Feet $*$ Air Velocity in ft. per min. The equation was to determine the velocity was:

Air Velocity $=1096.2 *\left(\mathrm{P}_{\mathrm{v}} / \mathrm{D}\right)^{.5}$

where $\mathrm{P}_{\mathrm{v}}$ was the velocity pressure in inches of water and $\mathrm{D}$ was the density in pounds per cubic foot. The following equation was used to determine the density of the air. Air Density $=1.325 * \mathrm{P}_{\mathrm{B}} / \mathrm{T}$

where $\mathrm{P}_{\mathrm{B}}$ was the absolute pressure in inches of mercury and $\mathrm{T}$ was the absolute temperature in degrees Rankine. 


\section{Appendix VI Venturi}

The venturi, like other head type flowmeters, uses Bernoulli's principle for evaluating flowrates. The basic equation used by the venturi was:

$$
m=0.52502\left(\frac{\mathrm{CY} \mathrm{d^{2 }} \mathrm{F}_{\mathrm{a}}}{\sqrt{1-\beta^{4}}}\right) \sqrt{\rho_{1}\left(\mathrm{p}_{1}-\mathrm{p}_{2}\right)}
$$

where $\mathrm{m}$ was the mass flowrate in pounds per second, $\mathrm{C}$ was the discharge coefficient, $\mathrm{Y}$ was the expansion factor, $\mathrm{d}$ was the throat diameter in inches, $\mathrm{F}_{\mathrm{a}}$ was the thermal correction factor, $\beta$ was the beta term, $\rho$ was the density of the fluid in pounds per cubic foot, and $\mathrm{p}_{1}-\mathrm{p}_{2}$ was the differential pressure created by the venturi itself in psia.

The discharge coefficient was found by using the following equation.

$\mathrm{C}=0.9975-0.00653 *\left(10^{6} / \mathrm{RD}\right)^{\mathrm{a}}$

where RD was the Reynolds number and a was a Reynolds number dependent

coefficient. For Reynolds numbers below $10^{6}$ a was $1 / 2$ and the Reynolds number above $10^{6}$ a was $1 / 5$.

The expansion factor was found by using the following equation.

$$
\mathrm{Y}=\left[\mathrm{r}^{2 / \gamma}\left(\frac{\gamma}{\gamma-1}\right)\left(\frac{1-\frac{\gamma-1}{\gamma}-\gamma}{1-\gamma}\right)\left(\frac{1-\beta^{4}}{1-\beta^{4} \mathrm{r}^{2 / \gamma}}\right)\right]^{1 / 2}
$$

where $r$ was the ratio between $p_{1}$ and $p_{2}, \gamma$ was the gas isentropic exponent, and $\beta$ was the beta ratio.

The $\mathrm{F}_{\mathrm{a}}$ term in the flow equation is found by using the following equation.

$$
\mathrm{F}_{\mathrm{a}}=1+2 * \mathrm{a}_{\mathrm{pe}} *\left(\mathrm{~T}_{\mathrm{F}}-68\right)
$$


where $\mathrm{a}_{\mathrm{pe}}$ was the coefficient of thermal expansion and $\mathrm{T}_{\mathrm{F}}$ was the fluid temperature in degrees Fahrenheit.

The beta term, $\beta$, was the throat diameter divided by the inlet diameter.

The last equation used was for converting from mass flowrate to volumetric flowrate.

The equation simply divides the mass flowrate equation by $\rho$. 


\section{Appendix VII Original Vortex Shedder}

The vortex shedder was the only device tested that reported the results in acfm. The range of the original vortex shedder was $450 \mathrm{acfm}$. This was true for a specific

temperature and pressure. The calibration sheet for the original vortex shedder can be seen on the next page.

Based upon this calibration sheet an equation was developed that related flowrate and the Voltage output of the device. The equation that was developed was:

Vortex Shedder Flowrate $=88.164 *$ Voltage Output +1.7041

This equation reports acfm so to convert to scfm a pressure and temperature correction factor had to be applied. 


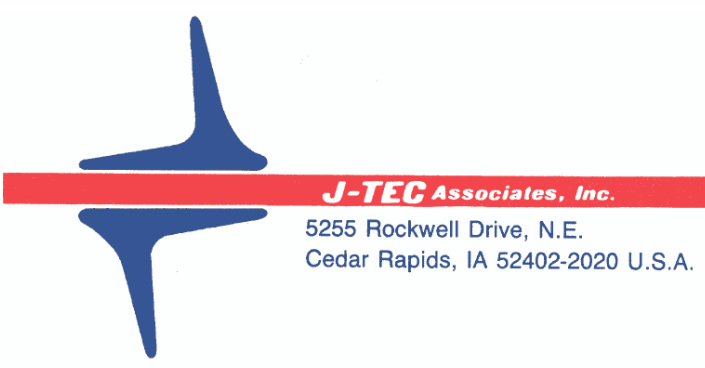

CUSTOMER DATA SHEET

CUSTOMER: WEST VIRGINIA UNI. MODEL: VE503

PART NUMBER: DAA0383-0003

Cal Temp F: 81.37

DATA
POINT
1.000
2.000
3.000
4.000
5.000
6.000
7.000
8.000
9.000
10.000
11.000
12.000
13.000
14.000
15.000

FLOW

ACFM

10.050

16.155

40.185

60.341

81.028

120.477

189.832

202.764

241.285

285.324

322.686

357.288

390.844

436.100

450.000

\section{4}

CALIBRATED BY:

L 00
SALES ORDER NO.: 5261

SERIAL NO.: O015EM

FULL SCALE: 450 ACFM

Cal Press PSIA: 14.23

SLOPE ACTUAL

HZ/FLOW VOLTAGE

$6.574 \quad 0.114$

$6.977 \quad 0.186$

$6.770 \quad 0.432$

$6.763 \quad 0.646$

$6.667 \quad 0.856$

$6.678 \quad 1.300$

$6.716 \quad 2.127$

$6.671 \quad 2.265$

$6.701 \quad 2.736$

6.6143 .220

$6.577 \quad 3.640$

6.5494 .020

$6.533 \quad 4.420$

$6.453 \quad 4.880$

$6.418 \quad 5.010$

This unit has been calibrated using standards and test equipment traceable to the National Institute of Standards and Technology. Meets MIL-STD-45662A.

Phone (319) 393-5200 FAX (319) 393-5211 e-mail: j-tec@j-tecassociates.com URL: http://www.j-tecassociates.com

Figure 35 Calibration Sheet for the VE 503 Vortex Shedder 


\section{Appendix VIII New Vortex Shedder Design}

The new vortex shedder design had no calibration sheet to develop an equation so it was calibrated against the LFE. The resulting equation was:

New Vortex Shedder Design Flowrate $=187.71 *$ Voltage Output -10.326

This equation was for acfm so a pressure correction and temperature correction factor had to be applied. The resulting equation had an $\mathrm{R}^{2}$ value of 0.9995 . 


\section{Appendix IX Differential Pressure Transducer Viatran 274}

The differential pressure transducer used for test in this thesis was a Viatran 274. The specification sheet for the transducer follows.

\section{4/374 Specifications}

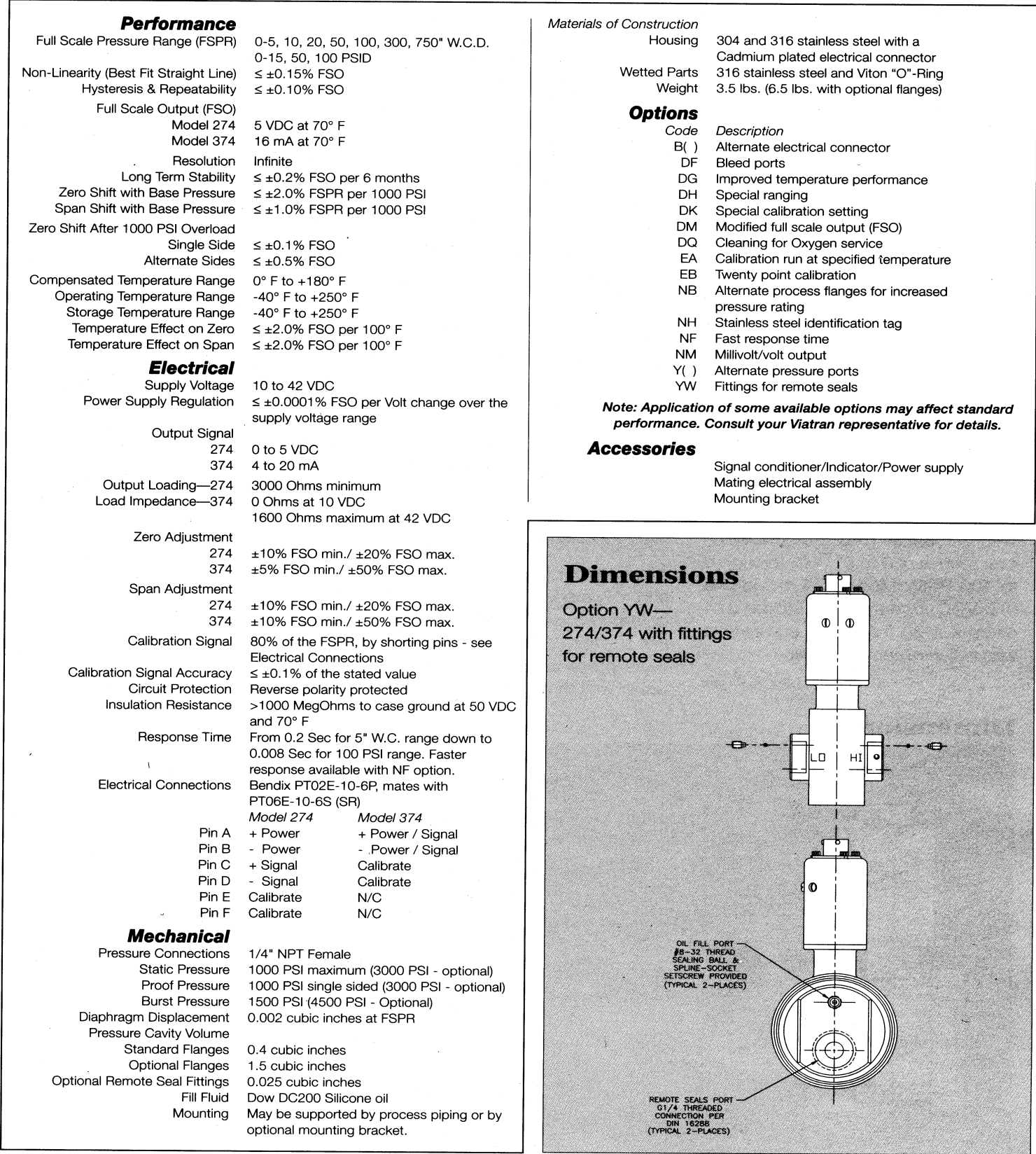

This information is accurate to the best of the manufacturer's knowledge, however, we reserve the right to change product specifications at any time. Please contact your sales representative for specific order inquiries.

Bulletin \#112-Printed on Recycled \& Recyclable Paper with Soybean Inks

$98 \mathrm{~PB} 112-374 \cdot 5150 \cdot 10.95 \bullet 10 \mathrm{M}$

Figure 36 Product Specification Sheet for the Viatran 274 Pressure Transducer 


\section{Appendix X Absolute Pressure Transducer Omega PX176}

The absolute pressure transducer used in the testing for this thesis was a Omega PX176.

A specification sheet for the pressure transducer follows.

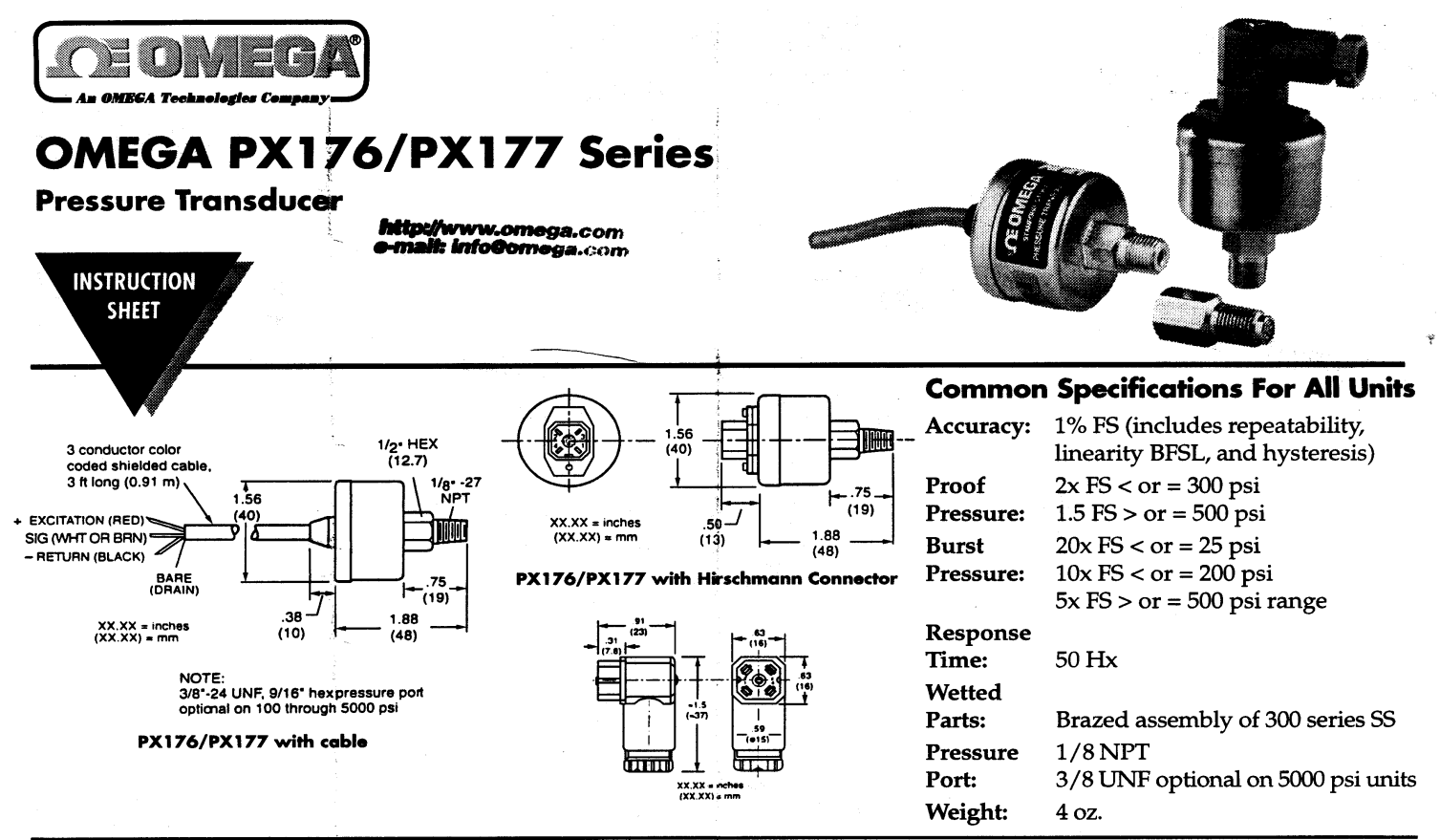

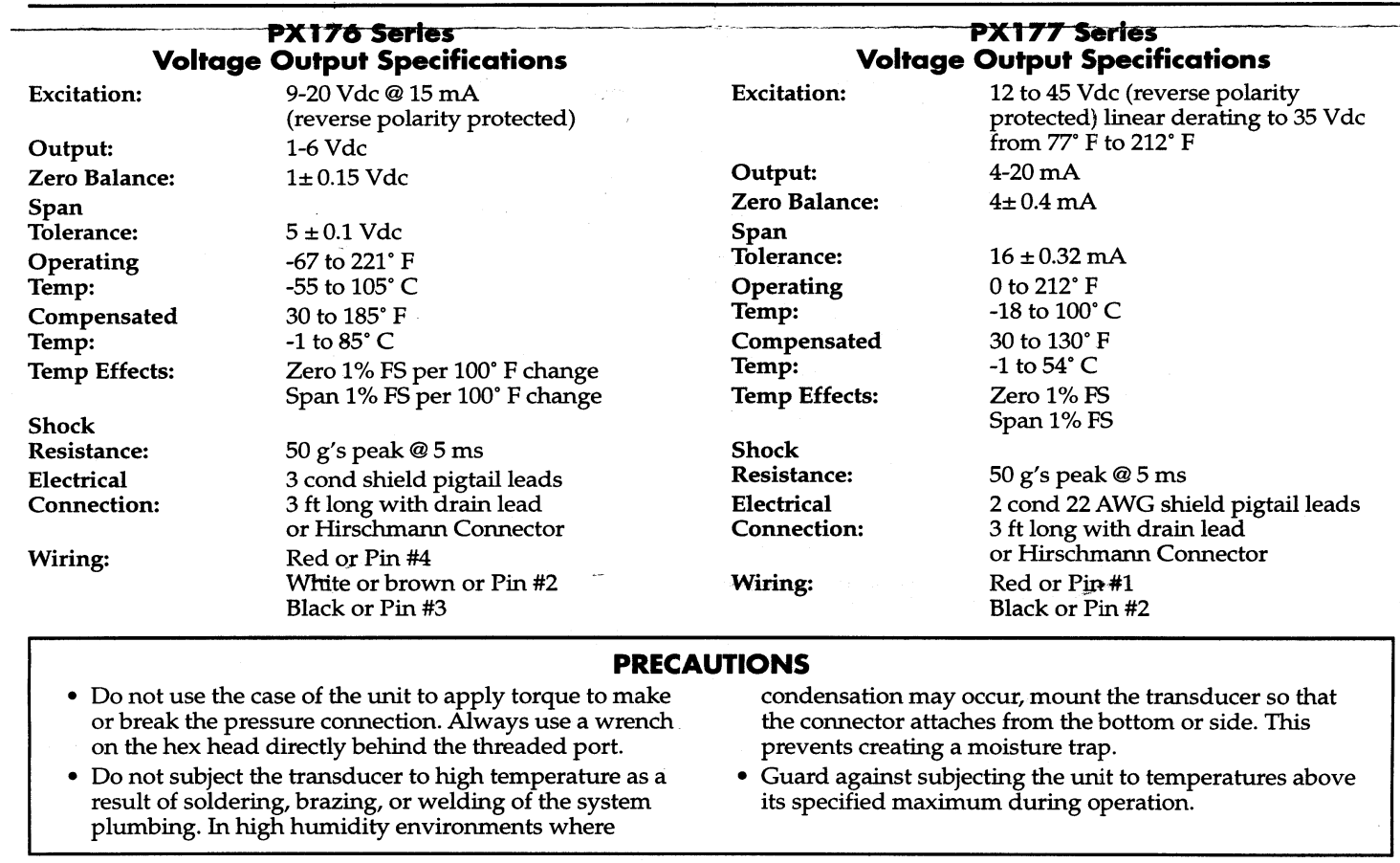

Figure 37 Omega PX 176 Absolute Pressure Transducer 